UNIVERSIDADE DE SÃO PAULO

FACULDADE DE ECONOMIA, ADMINISTRAÇÃO E CONTABILIDADE DEPARTAMENTO DE CONTABILIDADE E ATUÁRIA PROGRAMA DE PÓS-GRADUAÇÃO EM CIÊNCIAS CONTÁBEIS

O MERCADO DE AÇÕES NO BRASIL E O CICLO DE ABERTURAS DE CAPITAL NO PERÍODO 2004/2007: UM ESTUDO EXPLORATÓRIO-DESCRITIVO

José Machado Barbosa Neto

Orientador: Prof. Dr. Iran Siqueira Lima

SÃO PAULO 
Profa. Dra. Suely Vilela

Reitora da Universidade de São Paulo

Prof. Dr. Carlos Roberto Azzoni

Diretor da Faculdade de Economia, Administração e Contabilidade

Prof. Dr. Fábio Frezatti

Chefe do Departamento de Contabilidade e Atuária

Prof. Dr. Gilberto de Andrade Martins

Coordenador do Programa de Pós-Graduação em Ciências Contábeis 
O MERCADO DE AÇÕES NO BRASIL E O CICLO DE ABERTURAS DE CAPITAL NO PERÍODO 2004/2007: UM ESTUDO EXPLORATÓRIO-DESCRITIVO

\author{
Dissertação apresentada ao Departamento de \\ Contabilidade e Atuária da Faculdade de \\ Economia, Administração e Contabilidade da \\ Universidade de São Paulo como requisito para \\ a obtenção do título de Mestre em Ciências \\ Contábeis.
}

Orientador: Prof. Dr. Iran Siqueira Lima 
Dissertação defendida e aprovada no Departamento de Contabilidade e Atuária da Faculdade de Economia, Administração e Contabilidade da Universidade de São Paulo - Programa de Pós-Graduação em Ciências Contábeis, pela seguinte banca examinadora:

\section{FICHA CATALOGRÁFICA}

Elaborada pela Seção de Processamento Técnico do SBD/FEA/USP

\section{Barbosa Neto, José Machado}

O mercado de ações no Brasil e o ciclo de aberturas de capital no período 2004/2007: um estudo exploratório-descritivo / José Machado Barbosa Neto. -- São Paulo, 2008.

98 p.

Dissertação (Mestrado) - Universidade de São Paulo, 2009 Bibliografia.

1. Mercado de capitais 2. Ações 3. Capital (Economia) I. Universidade de São Paulo. Faculdade de Economia, Administração e Contabilidade II. Título. 
À minha mãe, pela presença de sempre, e aos meus filhos, pela razão de tudo. 


\section{Agradecimentos}

Em um percurso de quase três anos, são muitas as pessoas a quem devo agradecimentos. Pessoas que, direta ou indiretamente, algumas mesmo sem sabê-lo, ajudaram na concretização deste trabalho.

Inicialmente, quero agradecer àqueles que são os pilares da minha vida: minha mãe, $D$. Cida, pelo exemplo e força de sempre, e meus filhos, Isabele e Rodrigo, pela alegria, companheirismo e amor, e por tornarem minha existência mais completa.

À minha família, meus irmãos Rosa Paula (Cuca), Rubens (Bui) e Juliane (Jú), meu pai Rubens (in memorian), meu sobrinho Aristides (Netinho), minha tia Neyde (minha segunda mãe) e meu cunhado Luis Paulo (Lula). Mesmo à distância, a presença de todos é constante e fundamental.

Ainda na família, agradeço minha sobrinha Tatiana (Tati), que tem que agüentar o vigiar constante do tio.

Na esfera acadêmica, agradeço meu orientador, Prof. Dr. Iran Siqueira Lima, pelo exemplo de conduta e pelo apoio constante ao longo desse período. Seu suporte foi fundamental para a conclusão deste trabalho.

Agradeço também aos demais professores da FEA, com os quais tive a oportunidade e o privilégio de conviver. Cada um, à sua maneira, deixou um tipo de ensinamento.

Aos colegas de curso, com os quais compartilhei as dificuldades dessa etapa de vida. Menção especial ao Daniel e ao Mizu.

Aos funcionários da USP, nas suas diversas áreas, em especial à Cristina e ao Rodolfo, pelo apoio constante.

Alguns amigos que, nas horas de necessidade, estão sempre presentes, também merecem agradecimentos: Acrisio Leite, Estevão Alexandre, Luciana Takahashi, Zilda Mendes e Dorothy. A eles agradeço o apoio em momentos de grande dificuldade.

Agradeço também à Neiva, com quem compartilhei bons momentos, pelo apoio nessa travessia.

E, por fim, ao Criador, por todas as bênçãos com as quais me privilegiou. Espero poder retribuir à vida tudo o que me foi dado. 
"Pois muitos outros queremos um Brasil para os que hoje não recebem os meios de uma vida humanamente justa. Essa história de futuro tem 500 anos de Brasil. E nem por um só dos seus invocadores foi mais do que uma fuga às suas responsabilidades.” Jânio de Freitas 


\section{RESUMO}

O Sistema Financeiro de um país tem como uma de suas funções principais a de permitir a eficiência alocativa de recursos da sociedade, ou seja, viabilizar a transferência de recursos entre agentes superavitários e agentes deficitários, de maneira que os benefícios sejam adequadamente distribuídos, incentivando tanto a poupança quanto o investimento produtivo. O Mercado de Capitais, por sua vez, como um dos segmentos do sistema financeiro, atua na intermediação financeira de médio e longo prazo, disponibilizando recursos para investimentos com prazos de maturação mais longos, assumindo um relevante papel no desenvolvimento econômico. No Brasil, o mercado de capitais se especializou, historicamente, no repasse de recursos de dívida (debt). No entanto, nos últimos 4 anos, especificamente a partir de 2004, um segmento do mercado de capitais aflorou novamente: o de recursos de capital (equity). De fato, o volume de aberturas de capital via emissão pública de ações (initial public offer - IPO) cresceu mais de 600\% entre 2004 e 2007, saltando de um volume de R\$ 9,2 bilhões naquele ano para cerca de R\$ 67,3 bilhões em 2007. Para que se torne uma alternativa de financiamento permanente às empresas brasileiras, objetivo historicamente sempre perseguido pelas autoridades econômicas, é fundamental que os benefícios decorrentes do funcionamento desse mercado estejam sendo adequadamente distribuídos entre tomadores e doadores de recursos. Nessa lógica, o presente estudo possui dois objetivos específicos: (i) traçar um quadro geral do processo de abertura de capital via oferta pública de ações ocorrido no período 2004/2007 e (ii) verificar se os benefícios de tal processo estão sendo adequadamente distribuídos entre vendedores e compradores desses papéis. Para tanto, numa abordagem exploratório-descritiva, o trabalho foi estruturado em duas linhas: (i) análise comparada do atual ciclo de emissão de ações com os ciclos anteriores de abertura de capital, e (ii) análise dos retornos gerados por essas ações após sua emissão, a curto e longo prazo, analisando seus efeitos e conseqüências para vendedores e compradores, bem como para a sociedade em geral. Pela análise comparada com os ciclos anteriores, verificou-se a repetição do mesmo conjunto de características, com destaque para os indícios de especulação financeira. Na análise dos retornos dessas ações, verificou-se a ocorrência do underpricing no primeiro dia, enquanto que, no médio e longo prazo, observou-se a ocorrência de overpricing. Já quando comparadas com o retorno do Ibovespa, essas ações apresentaram retornos inferiores, enquanto o esperado seria um retorno superior, em função do risco mais elevado das novas ações. Em termos de retornos nominais, essas novas ações apresentaram retornos positivos enquanto o mercado estava em um ciclo de alta (20.05.08, pico de Ibovespa), e forte retorno negativo quando o mercado mudou para um período de queda (data-base 31.10.08). Por fim, foram apurados, mediante consulta aos prospectos de emissão, os valores patrimoniais das novas ações antes da emissão, identificando-se um conjunto de preços bem inferiores aos respectivos preços de lançamento. Tal realidade indica que as empresas e sócios que fizeram a venda desses papéis via oferta pública inicial obtiveram preços bastante elevados, que dificilmente obteriam em negociações privadas de ativos. Nessa lógica, a questão do underpricing perde consistência, cuja perda seria compensada pelo ganho com a abertura de capital. Esse conjunto de análises aponta que o atual ciclo vem trazendo ótimos retornos para os vendedores (empresas e sócios), mas retornos negativos aos compradores (investidores), com o que não estaria sendo benéfico para a sociedade como um todo. 


\begin{abstract}
The Financial System of a country has as one of its main features that of allowing the efficient allocation of resources of the society, that is, promote the transfer of resources between superavitary and deficitary agents, so that the benefits can be suitably distributed, fostering both savings and the productive investment. The Capital Market, on its side, as one of the segments of the financial system, acts in the financial intermediation of medium and long term, making resources available for investments with longer maturity terms, taking over a relevant role in the economic development. In Brazil, the capital markets historically specialized in the transfer of debt resources (debt). However, during the last 4 years, specifically as of 2004, a segment of the capital market has once again come up: that of capital resources (equity). Actually, the volume of the capital openings through public issue of shares (initial public offer - IPO) grew more than 600\% between 2004 and 2007, jumping from a volume of $\mathrm{R} \$ 9.2$ billion during such year to around $\mathrm{R} \$ 67.3$ billion in 2007. In order to remain a permanent finance alternative for the Brazilian companies, the object which has been historically pursued by the economic authorities, it is essential that the benefits originated from the operation of such market are suitably distributed among receivers and donors of resources. Within this logic, the present study has two specific purposes: (i) trace a general picture of the capital opening process by public offer of shares occurred during the period 2004/2007 and (ii) check whether the benefits of such process are being suitably distributed among sellers and buyers of such papers. For such purpose, in a descriptiveexploratory view, the work was structured in two lines: (i) comparative analysis of the current cycle of issue of shares with the previous cycles of capital opening, and (ii) analysis of returns generated by such shares after their issue, at short and long term, analyzing their effects and consequences for sellers and buyers, as well as for the general society. From the compared analysis with the previous cycles, we found the repetition of the same set of characteristics, with emphasis for the indications of financial speculation. From the analysis of the returns of such shares, we found the occurrence of underpricing on the first day, whilst at the medium and long range, overpricing was determined. When compared with the Ibovespa return, such shares showed inferior returns, whilst the expected would be a higher return, as a consequence of the higher risk of the new shares. In terms of nominal returns, such new shares showed positive returns whilst the market was in a height cycle (05.20.08, Ibovespa peak), and strong negative return when the market changed to a drop period (base date 10.31.08). Finally, there were determined, by means of consultation of the issue prospectus, the book values of the new shares prior to issue, identifying a set of prices quite lower than the corresponding launching prices. Such reality indicates that the companies and partners performing the sale of such papers through initial public offer obtained quite high prices, which would seldom be obtained in private negotiations of assets. Under such logic, the issue of underpricing looses consistency, which loss would be offset by the gains due to the open capital. This set of analysis points out that the current cycle has been producing excellent returns to the sellers (companies and partners) but negative returns to the buyers (investors), reason why it would not be beneficial to the society as a whole.
\end{abstract}




\section{SUMÁRIO}

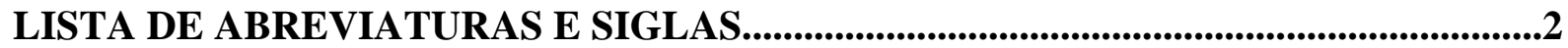

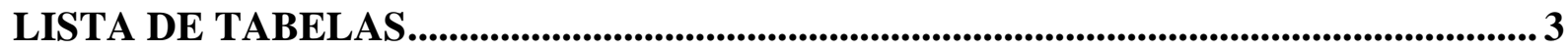

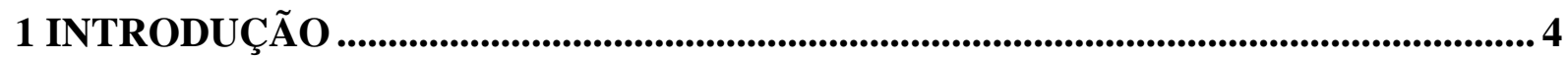

1.1 Apresentação ............................................................................................................................. 4

1.2 Contextualização da Pesquisa.........................................................................6 6

1.3 Formulação da Situação-Problema .......................................................................6 6

1.4 Objetivos da Pesquisa: Geral e Específico ........................................................... 7

1.5 Justificativa e Relevância da Pesquisa ...................................................................................... 8

2 FUNDAMENTAÇÃO TEÓRICA ............................................................................... 10

$2.1 \mathrm{O}$ mercado de capitais e sua importância na economia............................................... 10

2.2 Mercado de ações e abertura de capital.............................................................. 13

2.2.1 As normas brasileiras para emissões de ações e sua precificação..................... 13

2.3 Precificação de ações e valuation .............................................................................................. 15

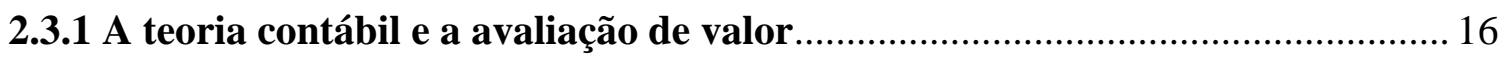

2.3.2 A informação contábil e o mercado de capitais................................................... 18

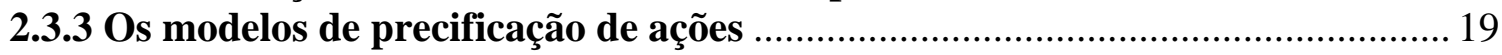

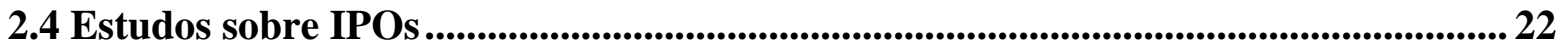

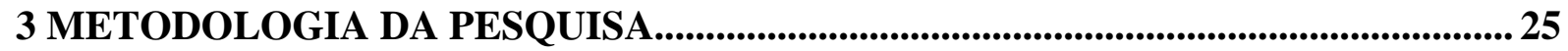

4 OS CICLOS ANTERIORES DE ABERTURAS DE CAPITAL NO BRASIL .............. 30

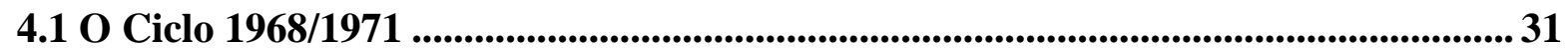

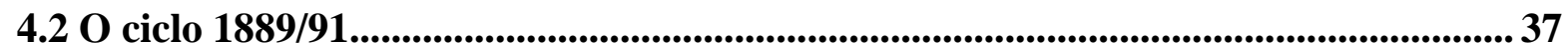

5 O CICLO DE ABERTURAS DE CAPITAL NO PERÍODO 2004/2007 - ANÁLISE

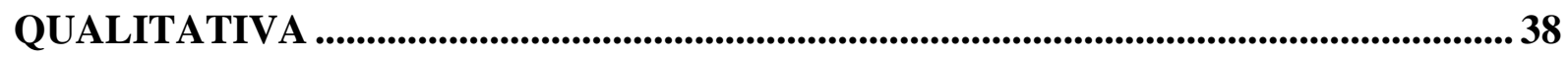

6 O CICLO DE ABERTURAS DE CAPITAL NO PERÍODO 2004/2007 - ANÁLISE

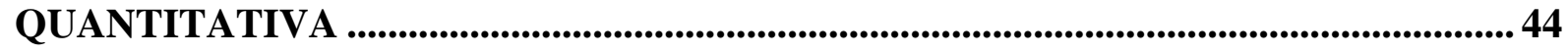

6.1 Comportamento dos retornos ............................................................................................... 44

6.2 Retorno Nominal das Ações ...................................................................................... 48

6.3 Valor de Emissão e Valor Patrimonial..................................................................... 52

7 CONCLUSÕES FINAIS E CONSIDERAÇÕES ..........................................................60

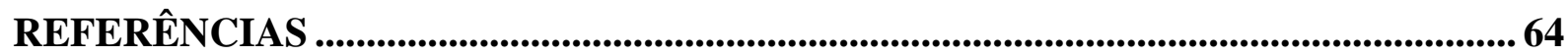




\section{LISTA DE ABREVIATURAS E SIGLAS}

Bacen: Banco Central do Brasil

Bovespa: Bolsa de Valores de São Paulo

BNDES: Banco Nacional de Desenvolvimento Econômico e Social

CAPM: Capital Asset Pricing Model

CMN: Conselho Monetário Nacional

CVM: Comissão de Valores Mobiliários

FCD: Fluxo de Caixa Descontado

FGTS: Fundo de Garantia por Tempo de Serviço

Ibovespa: Índice da Bolsa de Valores de São Paulo

IPO: Initial Public Offer

NM: Novo Mercado

N1: Nível 1 de Governança Corporativa

N2: Nível 2 de Governança Corporativa

P: Preço

PE/VC: Private Equity e Venture Capital

PL: Patrimônio Líquido

P/L: Índice Preço/Lucro

VP: Valor Patrimonial 


\section{LISTA DE TABELAS}

Tabela 1 - Emissões de Ações no Brasil - Período 2004/2007

Tabela 2 - Empresas que fizeram abertura de capital no período 2004/2007

Tabela 3 - Empresas de capital aberto listadas na Bovespa - 1970/2008. 30

Tabela 4 - Brasil: taxas de crescimento do PIB e da Indústria - 1968-77 33

Tabela 5 - Taxas de variação no valor das emissões de ações e debêntures (Taxas Anuais de Variação*)

Tabela 6 - Valor das Transações de Ações nas Bolsas de Valores (Taxas Anuais de Variação*)

Tabela 7 - Empresas emissoras e volumes de emissão - 2004/2007 38

Tabela 8 - Empresas emissoras - Segmento de Mercado, Classificação Setorial, Nr. de Investidores e Participação de Estrangeiros (\%).

Tabela 9 - Emissões por segmento de mercado da Bovespa

Tabela 10 - Retorno dos IPOs em diferentes prazos - Base 100 na data de início da série ..... 45

Tabela 11 - Retorno dos IPOs em diferentes prazos - Estatísticas descritivas.......................... 47

Tabela 12 - Retorno nominal dos IPOs - Base 100 na data de início da série ........................ 49

Tabela 13 - Retorno nominal dos IPOs - Estatísticas descritivas............................................ 52

Tabela 14 - Ganho no valor patrimonial para sócios anteriores............................................ 53

Tabela 15 - Geração de Valor para os sócios anteriores ....................................................... 55

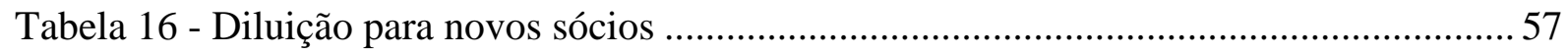




\section{INTRODUÇÃO}

\subsection{Apresentação}

Dentro da economia de um país, o Sistema Financeiro possui funções fundamentais para o perfeito funcionamento da economia. Dentre suas várias funções, existem duas básicas, quais sejam:

(i) permitir a circulação de recursos entre os detentores de capital (poupadores) e os tomadores (tomadores) de recursos;

(ii) permitir a alocação ótima de recursos, ou seja, que os capitais excedentes da sociedade sejam empregados da forma mais racional possível, tanto para poupadores quanto para tomadores.

O Mercado de Capitais constitui uma das vertentes do Sistema Financeiro, sendo responsável pela alocação de recursos de investimentos de médio e longo prazo. Nessa lógica, um mercado de capitais desenvolvido pode assumir um papel fundamental no desenvolvimento econômico do país.

O Mercado de Ações, por sua vez, representa um segmento do mercado de capitais, permitindo que as empresas (tomadores) captem recursos junto aos investidores (poupadores) na forma de participação de capital. Esses recursos, de longo prazo, permitem que as empresas cresçam, gerando emprego e renda, contribuindo dessa forma para o crescimento e desenvolvimento do país. Essa captação ocorre através do mecanismo denominado "Oferta Pública Inicial”1.

O mercado de IPO’s no Brasil nunca desempenhou um papel importante como alternativa de captação para as empresas brasileiras. No entanto, nos últimos anos, principalmente a partir

\footnotetext{
${ }^{1}$ Em ingles, esse mecanismo é denominado Initial Public Offer, geralmente representado pela sigla IPO. Essa sigla será, doravante, adotada neste trabalho, por ser o termo normalmente utilizado nos estudos acadêmicos.
} 
de 2004, esse quadro mudou radicalmente, em função de um forte incremento verificado nas captações de recursos via emissão de ações, conforme detalhado abaixo (Tabela 1):

Tabela 1 - Emissões de Ações no Brasil - Período 2004/2007

\begin{tabular}{|c|r|r|r|}
\hline \multirow{2}{*}{ Ano } & \multicolumn{2}{|c|}{ Emissões } & \multicolumn{1}{c|}{ Total } \\
\cline { 2 - 3 } & Primárias & \multicolumn{1}{|c|}{ Secundárias } & \\
\hline 2004 & $4.522 .552 .764,89$ & $4.682 .650 .177,38$ & $9.205 .202 .942,27$ \\
\hline 2005 & $4.559 .643 .361,71$ & $6.581 .611 .678,44$ & $11.141 .255 .040,15$ \\
\hline 2006 & $14.212 .632 .881,23$ & $12.771 .278 .339,25$ & $26.983 .911 .220,48$ \\
\hline 2007 & $33.200 .705 .420,02$ & $34.122 .238 .111,60$ & $67.322 .943 .531,62$ \\
\hline
\end{tabular}

De fato, a partir de maio/2004, com a emissão de ações da empresa Natura, observou-se um movimento crescente de abertura de capital via emissão de ações por parte de várias empresas. Assim, no período de quatro anos, o volume de emissões de ações cresceu cerca de $600 \%$, crescimento bastante expressivo, com mais de 100 empresas abrindo o capital no período. Ou seja, percebe-se que as empresas, necessitadas de recursos de longo prazo, passaram a contar com essa alternativa de obtenção de recursos e de financiamento.

Pelo lado dos poupadores, esse crescimento também foi observado. Como veremos adiante, diferentes poupadores passaram a investir recursos nesse mercado: investidores institucionais (nacionais e internacionais), empresas, bancos e pessoas físicas. No caso deste último, o crescimento foi expressivo, ajudado pela popularização das ferramentas de investimento via internet (denominadas home-broker).

Em função desse crescimento, vários artigos e entrevistas com especialistas vêm discutindo o tema na imprensa nacional. No entanto, no meio acadêmico, esse discussão vem tomando corpo mais recentemente. Isso decorre do fato de que o processo é relativamente novo (cientificamente falando), ou seja, possui apenas quatro anos, com o que os estudos encontram algumas limitantes. Ademais, é um processo que está ocorrendo (está em plena marcha), o que gera mais uma limitante para o seu completo entendimento.

No entanto, apesar dessas limitantes, esse processo já permite identificar algumas características importantes. Ademais, por ser uma alternativa de captação de recursos muito importante para as empresas, com reflexos diretos no crescimento do país, é fundamental que seja melhor estudado e compreendido. 


\subsection{Contextualização da Pesquisa}

Considerando-se os comentários anteriores, a presente pesquisa tem como contexto geral o Mercado de Capitais brasileiro. Mais objetivamente, teremos, como contexto específico, o mercado de ações brasileiro e o processo de abertura de capital via emissão pública de ações, o chamado mercado de IPO.

Esse mercado será estudado dentro de um período determinado, compreendido entre os anos de 2004 e 2007. As ações aqui estudadas serão aquelas emitidas pelas empresas que abriram seu capital no período em questão, descritas no capítulo 3, que discute a metodologia adotada no presente estudo.

Para o estudo das ações emitidas nesse período, consideraremos dois conjuntos de informação:

(i) a evolução de seus preços em períodos específicos de tempo, detalhados no respectivo capítulo;

(ii) dados específicos sobre seus valores patrimoniais .

Em relação ao item (i) retro, os dados foram obtidos da base de dados da Economática. Já em relação ao item (ii), as informações foram obtidas mediante consulta as prospectos de emissão divulgados pelas empresas quando da abertura de capital, os quais foram obtidos no endereço eletrônico da Comissão de Valores Mobiliários - CVM.

\subsection{Formulação da Situação-Problema}

Segundo Kerkinger (1980, p. 34), “...um problema é uma questão que mostra uma situação necessitada de discussão, investigação, decisão ou solução”.

Nesse sentido, e dado o contexto descrito anteriormente, o problema geral de pesquisa do presente estudo pode ser assim formulado: 
O ciclo (movimento) de aberturas de capital, iniciado em 2004, está trazendo benefícios reais à economia brasileira, na forma de um mercado de ações que permita uma captação saudável às empresas e uma alternativa de alocação de recursos atraente aos investidores, ou se esgotará como mais um movimento especulativo, tal qual os ciclos anteriores?

\subsection{Objetivos da Pesquisa: Geral e Específico}

Objetivo Geral:

Verificar se as aberturas de capital efetuadas via emissão pública de ações, ocorridas no Brasil no período compreendido entre os anos 2004 e 2007, estão trazendo benefícios reais à sociedade brasileira, na forma de retornos positivos aos dois agentes econômicos principais envolvidos nesse processo, vendedores e compradores dessas ações. O período em questão foi denominado “ciclo 2004/2007”

Objetivos Específicos:

1 Traçar um quadro geral das aberturas de capital via emissão pública de ações ocorridas no Brasil no período compreendido entre os anos 2004 e 2007, analisando e descrevendo seus principais componentes, por meio de uma análise descritiva e exploratória, pois, segundo Gil, estas são as formas de pesquisa mais utilizadas por pesquisadores sociais preocupados com a atuação prática.

2 Efetivar uma análise comparada desse ciclo com os ciclos anteriores de emissões de ações no Brasil, particularmente como ciclo verificado entre os anos de 1968 e 1971 (denominado “ciclo 1968/71”);

3 Observar o comportamento dos preços dessas novas emissões ao longo do tempo, com base nos retornos gerados por essas ações em datas específicas, discutindo-os à luz dos conceitos de underpricing (no primeiro dia) e overpricing (médio e longo prazo), encontrados na literatura e estudos sobre abertura de capital; 
4 Com base nos resultados apurados no item anterior, verificar se esse processo está gerando benefícios econômicos para os dois lados principais de um IPO: vendedor e comprador do papel (da ação) no momento da emissão. Somente nessa condição o processo de abertura de capital será benéfico à sociedade.

\subsection{Justificativa e Relevância da Pesquisa}

Segundo Martins (2000, p. 24), no aspecto metodológico, “[...] um tema profícuo para a pesquisa científica deve atender, simultaneamente, a três quesitos:”

\begin{tabular}{|l|l|}
\hline Viabilidade & $\begin{array}{l}\text { "[...] a questão da viabilidade do tema escolhido está relacionada às } \\
\text { evidências empíricas que permitem observações, testes e validações dos } \\
\text { possíveis achados da investigação, bem como às condições de prazo, } \\
\text { custos e potencialidade do pesquisador.” }\end{array}$ \\
\hline Importância & $\begin{array}{l}\text { "[...] o tema é importante quando, de alguma forma, está relacionado a uma } \\
\text { questão que polariza, ou afeta, um segmento substancial da sociedade. } \\
\text { Ou, ainda, está direcionado a uma questão teórica que merece atenção: isto } \\
\text { é, melhor definição, maior precisão etc.” }\end{array}$ \\
\hline Originalidade & $\begin{array}{l}\text { "[...] um tema é original quando há indicadores de que seus resultados irão } \\
\text { causar alguma surpresa. Isto é, se há possibilidades de encontrar novos } \\
\text { resultados ainda não disseminados no ambiente científico-profissional. O } \\
\text { original, em síntese, é a leitura do aluno-autor sobre o tema pesquisado. É } \\
\text { evidenciado pelo valor da reconstrução racional e lógica do tema } \\
\text { escolhido.” }\end{array}$ \\
\hline
\end{tabular}

Fonte: Adaptado de Martins (2000, p. 24)

Nesse aspecto, entendemos que o presente estudo atende aos três requisitos. É viável, por tratar de um momento histórico específico, onde as informações são de fácil acesso. É importante em função de envolver valores expressivos para a economia como um todo, sendo de fundamental importância o fortalecimento do mercado de capitais para o país. É original em função da abordagem aqui adotada, pois busca analisar a questão do underpricing sob um enfoque não observado em estudos anteriores.

Ademais, temos que considerar que o ressurgimento das aberturas de capital e emissão de ações, ocorrido a partir de maio de 2004 com a emissão da Natura, representou uma profunda mudança no mercado de capitais no Brasil, particularmente para o mercado de ações. 
Alem de reabrir essa alternativa de financiamento às empresas, esse mercado vem atraindo a atenção de um volume expressivo de novos investidores, nacionais e estrangeiros. No caso dos investidores nacionais, particularmente das pessoas físicas, percebe-se a mudança da cultura de investimentos no país, com o investimento em ações passando a fazer parte de seu leque de alternativas para aplicação de suas poupanças.

Considerando-se esse conjunto de fatores, o ideal é que essa retomada das emissões primárias seja perene, duradoura, representando uma alternativa permanente de financiamento às empresas e uma alternativa de investimento de longo prazo aos investidores nacionais e estrangeiros. Tal realidade só ocorrerá se os benefícios desse processo estiverem ocorrendo tanto para vendedores quanto para compradores, o que precisa ser verificado. Esse é um dos objetivos do presente estudo. 


\section{FUNDAMENTAÇÃO TEÓRICA}

Este capítulo visa apresentar e discutir todo o arcabouço teórico que dá suporte aos temas aqui discutidos. Seu objetivo é repassar a teoria de finanças relativa aos pontos aqui analisados, proporcionando o suporte teórico para discussão e eventuais conclusões.

Nesse sentido, foi estruturado da seguinte maneira. No tópico 2.1, discutiremos o sistema financeiro nacional e a importância de um mercado de capitais forte e dinâmico para as empresas, a economia e a sociedade em geral. No item seguinte, 2.2, discutiremos o processo de abertura de capital, detalhando esse processo em linhas gerais e a legislação específica sobre o tema, emanada pelas autoridades reguladoras no Brasil. Posteriormente, em 2.3, discutiremos o processo de precificação de ações, inicialmente de maneira geral para, em seguida, discorrer sobre a precificação de ações objeto de ofertas públicas iniciais. Por fim, no tópico 2.4, apresentaremos alguns estudos sobre IPO’s e sua precificação.

É de se destacar que, neste enfoque, a abordagem do tema vai do geral ao particular, ou seja, inicia discutindo a questão de maneira abrangente e, de forma gradativa, vai particularizando a discussão. Tal enfoque está em linha com a forma como é abordado o tema nesta dissertação, descrita tanto no capítulo 1 (Introdução) quanto no capítulo 3 (Metodologia).

\subsection{O mercado de capitais e sua importância na economia}

A evolução histórica das sociedades fez com que elas se tornassem, gradativamente, cada vez mais complexas. No aspecto econômico, uma das características básicas dessa complexidade é “[...] a crescente distância que separa o início da produção e o consumo final dos bens” (CASTRO E LESSA, pág. 25).

Para estudar, entender e explicar essa complexidade no aspecto econômico, os compêndios de Economia dividem o Sistema Econômico em duas vertentes: o chamado "lado real”, que compreende a produção de bens e serviços, e o "lado monetário", com discussões sobre a moeda e suas funções na economia. 
Esse "lado monetário" dos sistemas econômicos atuais funciona através do chamado Sistema Financeiro (SF). Apesar de sua complexidade no mundo moderno, o sistema financeiro tem suas origens ligada à mais básica das funções da moeda: funcionar como o denominador comum das trocas. À medida que os países foram evoluindo, foram surgindo as moedas nacionais. Nesse processo, alguns agentes econômicos passaram a acumular moedas, fazendo com que, através do processo histórico, surgissem os bancos, especificamente para efetivar a guarda desse dinheiro. Com o passar do tempo, os bancos foram percebendo que, na maior parte do tempo, esse dinheiro permanecia em seu poder, o que significava, em outras palavras, que os bancos não precisavam manter um volume de disponibilidade de moeda igual ao volume dos depósitos existentes. Mais especificamente, perceberam que bastava manter uma pequena parcela de dinheiro em caixa, para fazer frente aos saques, podendo assim emprestar parte dos recursos captados.

Nesse quadro, a atividade bancária foi evoluindo gradativamente, em um longo processo histórico, ao mesmo tempo em que os sistemas financeiros foram se tornando cada vez mais complexos. Essa história, aqui resumida em poucas linhas, tomou vários séculos, desembocando na complexa economia atual.

Segundo Assaf Neto (2008, p. 16), o Sistema Financeiro:

[...] é constituído por instituições financeiras, de natureza pública e privada, que viabilizam as transferências de recursos de agentes superavitários - com capacidade de poupança - para os agentes deficitários - que demandam recursos para consumo e investimentos.

Ou seja, compete ao sistema financeiro permitir a circulação da "liquidez” da economia.

Os agentes superavitários são capazes de gerar recursos em volumes superiores às suas necessidades, sendo denominados também "poupadores” ou “doadores” de recursos. Por outro lado, os agentes deficitários seriam aqueles cuja demanda de recursos é superior à sua capacidade de geração, sendo também denominados “tomadores" de recursos. Vale mencionar que, na prática, os agentes econômicos podem assumir e intercambiar seus papéis, de poupadores ou de tomadores de recursos, a qualquer momento.

$\mathrm{Na}$ interação entre esses dois tipos de agentes econômicos, encontramos situações diametralmente opostas. Os poupadores visam alocar seus recursos excedentes à melhor taxa 
possível, buscando o máximo de retorno. Já os tomadores de recursos buscam tomar recursos à menor taxa possível, a fim de minimizar seus custos. Desse conflito, surge um outro, e talvez mais importante, papel desempenhado pelo sistema financeiro: permitir a alocação ótima de recursos, benéficas às duas partes, poupadores e tomadores.

Esse conceito de alocação ótima não pode ser visualizado apenas no aspecto microeconômico, ou seja, pela ótica de cada investidor. À medida que cada investidor conseguir efetivar uma alocação ótima de seus recursos, o conjunto da economia também estaria fazendo uma alocação ótima de seus recursos. Ou seja, numa visão macroeconômica, também teríamos uma alocação ótima.

Por outro lado, poderia ser discutível essa generalização da visão micro para a visão macro, ou seja, poderíamos nos precipitar em afirmar que, pelo fato dos investidores efetivarem alocações ótimas, sob seus pontos de vista, a economia, como um todo, estaria realizando alocações ótimas. Um exemplo seria uma alta de juros, por parte do governo, nos títulos de sua emissão. No momento em que eleva os juros, o governo propicia uma alocação melhor de recursos para os investidores detentores de capital, fazendo com que os mesmos possam optar por comprar mais títulos do governo, obtendo um retorno superior, o que poderia significar uma alocação ótima do ponto de vista individual. Todavia, pelo fato de atrair recursos que poderiam estar investidos na atividade produtiva, a sociedade, como um todo, poderia não estar fazendo uma alocação ótima de seus recursos nesse momento.

No entanto, aqui poderíamos argumentar que, no momento que o governo aumenta os juros da economia, o faz com um propósito específico (geralmente o de combater a inflação). Nesse momento, ele estaria buscando aquilo que entende como o melhor para a economia, já que, pelo seu ponto de vista (do governo), seria mais conveniente a alocação de recursos na atividade rentista (mercado financeiro) e não na atividade produtiva. Ou seja, ao aumentar os juros, estaria havendo uma alocação ótima sob o ponto de vista da autoridade econômica.

Como se vê, o tema permite vários pontos de vista, e larga discussão, como que o poderíamos prejudicar o andamento do presente trabalho.

Em conseqüência, a visão de alocação ótima deste estudo, sob o ponto de vista de cada uma das partes, doador e tomador de recursos, será feita sob os seguintes ângulos: 
(i) Vendedores: será ótima se permitir que, pela emissão pública de ações, obtiver preços superiores aos que obteria através de negociações privadas de seus ativos;

(ii) Compradores: se estiver gerando retornos positivos ao longo do tempo, sob diferentes enfoques.

\subsection{Mercado de ações e abertura de capital}

A discussão na teoria de Finanças sobre abertura de capital via emissão pública de ações e suas motivações é bastante longa.

A Abertura de Capital de qualquer empresa ocorre através do processo de "Oferta Pública Inicial” (IPO - Initial Public Offer).

\subsubsection{As normas brasileiras para emissões de ações e sua precificação}

As emissões de ações no Brasil são disciplinadas pela Lei das Sociedades por Ações (Lei $n^{\circ}$ 6.404, de 15.12.1976 - LSAs) e também por instrução da CVM (Instrução 400/03, de 29.12.2003).

A LSAs é mais abrangente, sendo o instrumento legal que disciplina toda a vida das sociedades por ações. Em seu capítulo XIV, particularmente nos artigos 170 a 172, trata do aumento do capital social mediante subscrição de ações. No tocante ao preço de emissão de ações, diz, em seu art. 170:

\footnotetext{
“§ $1^{\circ} \mathrm{O}$ preço de emissão deverá ser fixado, sem diluição injustificada da participação dos antigos acionistas, ainda que tenham direito de preferência para subscrevê-las, tendo em vista, alternativa ou conjuntamente:

I - a perspectiva de rentabilidade da companhia;

II - o valor do patrimônio líquido da ação; ...”
}

Já a Instrução CMV 400 trata especificamente sobre as ofertas públicas de distribuição de valores mobiliários, tanto no mercado primário quanto no secundário. 
No parágrafo $1^{\circ}$ do art. 23, diz essa instrução:

O ofertante poderá estabelecer que o preço e, tratando-se de valores mobiliários representativos de dívida, também a taxa de juros, sejam determinados no dia da apuração do resultado da coleta de intenções de investimento, desde que sejam indicados os critérios objetivos que presidem à sua fixação no Prospecto Preliminar e no aviso a que se refere o art. 53.

Um pouco mais adiante, em seu artigo 32, essa Instrução determina que será obrigatória a apresentação de “estudo de viabilidade econômico-financeira da emissora” quando, entre outros fatores:

$[\ldots]$

III. a fixação do preço da oferta baseie-se, de modo preponderante, nas perspectivas de rentabilidade futura da emissora;

IV. houver emissão de valores mobiliários em montante superior ao patrimônio líquido da emissora, considerando o balanço referente ao último exercício social, e os recursos captados visarem à expansão ou diversificação das atividades ou investimento em controladas ou coligadas; $[\ldots]$

Ainda no mesmo documento, em seu art. 39, quando determina os dados e informações a serem incluídos no Prospecto da emissão, encontramos:

$\S 1^{\circ}$ Caso sejam incluídas as previsões relativas à evolução da atividade e dos resultados da emissora, bem como à evolução dos preços dos valores mobiliários que são objeto da oferta, deverão:

a. ser claras e objetivas; e

b. apoiar-se em opinião de auditor independente sobre os pressupostos, os critérios utilizados e a sua consistência e coerência com as previsões.

$\S 2^{\circ} \mathrm{A} C V M$ poderá exigir do ofertante e da emissora, inclusive com vistas à inclusão no Prospecto, as informações adicionais que julgar adequadas, além de advertências e considerações que entender cabíveis para a análise e compreensão do Prospecto pelos investidores.

Ainda no documento da CVM, o mesmo fala sobre "consulta sobre a viabilidade da oferta”. Para tanto, em seu art. 43, determina:

É permitida a consulta a potenciais investidores pelo ofertante e pela instituição líder da distribuição para apurar a viabilidade ou o interesse de uma eventual oferta pública de distribuição, devendo esta consulta não exceder de 20 investidores e ter critérios razoáveis para o controle da confidencialidade e do sigilo, caso já tenha havido a contratação prévia de instituição intermediária pelo ofertante. 
Vale acrescentar que, ainda nesse mesmo artigo, em parágrafos posteriores, determina que deverá ser mantida lista detalhada com informações sobre as pessoas consultadas, a data e hora em que foram consultadas e suas respectivas respostas, devendo essa lista ser apresentada à CVM junto aos demais documentos do pedido de registro da emissão naquele órgão.

Um pouco mais adiante, encontramos o artigo que trata da "COLETA DE INTENÇÕES DE INVESTIMENTO”. Nos prospectos de emissão, esse tema aparece denominado como “processo de bookbuilding”, termo pelo qual esse processo é conhecido no mercado. Diz o texto da CVM:

Art. 44 - É permitida a coleta de intenções de investimento, com ou sem o recebimento de reservas, a partir da divulgação de Prospecto Preliminar e do protocolo do pedido de registro de distribuição na CVM.

Parágrafo único. A intenção de realizar a coleta de intenções de investimento deverá ser comunicada à CVM juntamente com o pedido de registro de distribuição realizado nos termos do art. $7^{\circ}$.

\subsection{Precificação de ações e valuation}

A precificação de ativos, processo também conhecido como “valuation”, é um tema chave na ciência econômica, com discussões particulares na Teoria de Finanças.

Nas últimas décadas, inúmeros modelos de precificação foram criados, todos buscando sempre um único objetivo: a melhor forma de se determinar o preço correto de negociação de um ativo.

No caso do mercado de ações, essa discussão assume aspectos particulares. Isso se deve à dinâmica do mercado de ações, onde esses ativos, transacionados em bolsas de valores, passam a sofrer influências de uma série de outras fatores, que vão muito além da simples realidade das empresas.

No prefácio de seu livro, DAMODARAN (2002, p. XVII) apresenta a seguinte reflexão:

Será que as regras antigas ainda valem? Será que precisamos de novas medidas de avaliação, ou será que as antigas são flexíveis o bastante para lidarem com as empresas que constituem a nova 
economia? Será possível avaliar uma empresa que não tenha lucros ou histórico e que não seja comparável a quaisquer outras?

Quando tratamos de empresas em processo de abertura de capital, geralmente nos deparamos com questionamentos similares. Na referida obra, o autor levanta essas reflexões em relação às empresas de tecnologia (classificando-as como pertencentes à “nova economia), em função de características particulares, quais sejam:

i. expansão em função do investimento em pesquisa e por aquisições;

ii. baixos investimentos em ativos fixos (construção de instalações e compra de equipamentos);

iii. taxas elevadas (e, em alguns casos, astronômicas) de crescimento das receitas, simultaneamente à ocorrência de poucos lucros;

iv. "seus ativos são, muitas vezes, patentes, tecnologia e empregados habilidosos" (DAMODARAN, op. cit., p. XVIII)

\subsubsection{A teoria contábil e a avaliação de valor}

A avaliação de valor pode ser definida como o processo prévio a todo investimento, onde se procura determinar o preço adequado do ativo, considerando sua perspectiva de retorno, tempo e risco. Possui vários sinônimos, como valoração, precificação e valuation. Doravante, esses termos serão usados indistintamente.

Quando um investidor está comprando ações, seja em uma emissão primária ou secundária, ele está comprando, na prática, uma parte da empresa. Mais especificamente, cada ação comprada representa a parcela mínima do patrimônio da empresa. Ou seja, nesse processo, estamos falando do “patrimônio líquido”. Devemos então caracterizar melhor esse termo.

Segundo Iudícibus (2004), existem três definições centrais para o termo. O primeiro, fundamentado na "teoria do proprietário", define patrimônio líquido como a diferença entre ativo e passivo. É a abordagem mais antiga, onde o proprietário é o centro da atenção da contabilidade. Os dividendos representariam retiradas de capital, e os lucros acumulados são parte da propriedade. Segundo esse autor, essa teoria se aplicaria melhor às organizações mais simples, como as firmas individuais, do que às sociedades por ações, apesar da teoria do proprietário ainda influenciar os autores que tratam dessas últimas. 
Uma segunda definição, baseada na “teoria da entidade”, afirma que as atividades da entidade devem ser tratadas de maneira distinta em relação às atividades e interesses dos proprietários detentores de parcelas do capital. Ganhos e lucros são tratados como pertencentes à entidade, até que ocorra a transferência dessa riqueza, no todo ou em parte, para os participantes individuais por intermédio de uma declaração de dividendos.

A terceira definição é baseada na "teoria do fundo", onde são abandonadas as relações pessoais, que sustenta a teoria do proprietário, bem como a personalização da empresa como entidade, como ocorre na teoria da entidade. Nessa terceira definição, segundo Iudícibus (2004):

[...] o capital investido representa uma restrição financeira ou legal para o uso dos ativos, isto é, o capital investido precisa ser mantido intacto, a não ser que uma autorização específica tenha sido obtida para uma liquidação completa ou mesmo parcial.

Existem algumas definições diferentes, mas que, na prática, seriam uma variante de uma das três teorias acima.

É fácil prever que diferentes teorias e definições de PL poderiam originar diferentes métodos de avaliação de valor.

Segundo Povoa (2004):

[...] o objetivo mais importante do avaliador é, através da aplicação de uma teoria específica ou algumas combinadas, atingir não necessariamente um só valor, mas uma região de preço para o ativo. É necessário nunca perder de vista que, em qualquer análise que esteja sendo realizada, existem duas dimensões que jamais podem se ignoradas: o potencial de retorno, seja de lucros ou de fluxo de caixa, e o risco embutido nessa projeção".

Martins, em texto que fala sobre avaliação de empresas, afirma:

A grande confusão parece, pelo menos em parte, devido à não percepção de que todos os modelos até hoje surgidos nada mais são do que visões temporalmente diferentes do mesmo objeto: o patrimônio; e mais, são todos eles, numa perspectiva ainda mais simples, visões temporais de um único elemento patrimonial: o caixa.

Damodaran (1997) lembra que grande parte dos investidores tem utilizado a relação entre o preço e o valor contábil em algumas estratégias de investimento. Segundo esse autor, “[...] 
alguns têm utilizado baixos valores de índices preço / valor contábil como um filtro para selecionar ações subvalorizadas”.

Mais adiante, informa:

Vários estudos estabeleceram a relação entre os índices P/VP e os retornos adicionais. Rosenberg, Reid e Lanstein (1985) descobriram que os retornos médios das ações norte-americanas relacionavam-se positivamente com as razões entre o valor contábil e de mercado. Entre 1973 e 1984, a estratégia de se selecionar ações com altos índices valor contábil / preço (baixos índices preço / valor contábil) rendeu um retorno adicional de 36 pontos básicos por mês. Fama e French (1992), ao examinarem o perfil de retornos esperados de ações entre 1963 e 1990, estabeleceram que a relação positiva entre o índice valor contábil / preço e os retornos médios tanto em testes univariantes quanto em multivariantes, é ainda mais forte que o efeito do porte da empresa para justificar os retornos. Quando classificaram empresas em 12 carteiras com base nos índices valor contábil / preço, as empresas da classe de menor valor contábil / preço (maiores P/VP) obtiveram um retorno médio mensal de $0,30 \%$, ao passo que as empresa da classe de mais alto valor contábil / preço (menores P/VP) obtiveram um retorno médio mensal de 1,83\% no período 1963-1990.

Segundo Lopes (2002):

[...] a relação do patrimônio da empresa com seu preço de mercado também tem sido estudada pelos pesquisadores em contabilidade. A diferença entre o valor de livro da empresa e o seu preço de mercado é conhecida como erro de mensuração (measurement error) e deveria ser igual a zero no longo prazo se não houvesse diferenças entre a mensuração contábil e os preços de mercado.

\subsubsection{A informação contábil e o mercado de capitais}

A relação entre informação contábil e mercado de capitais vem sendo largamente estudada nos últimos anos pela teoria contábil, mais especificamente pela Teoria Contábil Positiva.

Até o advento dessa nova corrente de pesquisa contábil, predominava a tradição normativa. Com base nessa abordagem, a pesquisa contábil realizada até então, segundo Lopes e Martins (2005):

[...] preocupava-se principalmente com a avaliação de práticas contábeis de acordo com padrões teóricos daquilo que se considerava como ideal. O "ideal” normalmente era baseado em conceitos econômicos de lucro e riqueza. 
Mais adiante, mencionam que a abordagem normativa pode ser visualizada na observação de recomendações contábeis originadas pelos órgãos reguladores e teóricos da contabilidade.

A Teoria Positiva surgiu no final dos anos 60, onde a ênfase da contabilidade começou a migrar da tradição econômica e normativa para uma perspectiva baseada na informação, que ficou conhecida como “informational approach”. Nessa abordagem, a ciência contábil deixa de ser prescritiva, passando a ter um caráter explicativo e preditivo. Como exemplo, caso uma pesquisa nessa linha tivesse como tema a realidade contábil brasileira, ela não buscaria julgar a qualidade da contabilidade brasileira, mas buscaria entender com o mercado trabalha com essa informação.

Segundo Iudícibus e Lopes, pesquisas com abordagem positiva tem sido raras no Brasil. No entanto, destacam o trabalho de Lopes (2001), onde foi investigado o papel das informações contábeis para explicar o comportamento dos preços dos títulos negociados na Bolsa de Valores de São Paulo (Bovespa). Essa análise foi realizada dentro de três áreas gerais: (i) comparação entre o modelo de avaliação baseado em variáveis contábeis e o modelo de avaliação baseado em dividendos futuros; (ii) poder explicativo das variáveis contábeis correntes para explicar preços correntes; (iii) relação entre o reconhecimento do resultado econômico pelo contábil e a assimetria nesse processo.

Segundo Lopes (2002), os resultados demonstraram que os números contábeis são significativamente relevantes para a explicação dos preços. Mais adiante, informa que os resultados da pesquisa “[...] demonstram que grande parte da relevância dos números contábeis se deve ao valor do patrimônio líquido e não aos lucros”.

Diante do discutido, fica evidente que a informação contábil, particularmente o patrimônio líquido, possui informação relevante. A pergunta que se apresenta é como as novas emissões tem ignorado totalmente o conteúdo informacional dos dados contábeis? Como ações são emitidas a preços tão elevados e superiores ao seu valor patrimonial e aos resultados passados da empresa?

\subsubsection{Os modelos de precificação de ações}




\subsubsection{O Modelo de Indicadores de Mercado}

\subsubsection{1. - Índice Preço/Lucro (P/L)}

Segundo Assaf Neto (2000), “[...] o índice preço/lucro constitui-se em um dos quocientes mais tradicionais do processo de análise de ações, sendo bastante utilizado pelos investidores”.

É calculado pela seguinte fórmula:

$$
\mathrm{P} / \mathrm{L}=\frac{\text { Preço de Mercado da Ação }}{\text { Lucro por Ação (LPA) }}
$$

Sua larga utilização deve-se, em grande parte, ao fato de ser um índice de fácil entendimento e apuração. Esse índice indica o número de anos que serão necessários para o investidor recuperar o capital investido.

Para um investimento ideal, com retorno anual de 12\%, esse índice teria o valor de 8,33 (1 / 0,12). Qualquer investimento com índice $\mathrm{P} / \mathrm{L}$ inferior a 8,33 estaria proporcionando um retorno superior a $12 \%$, enquanto um investimento com indicador superior estaria proporcionando um rendimento inferior ao ideal. Alguns investidores chegam a calcular esse índice com base no rendimento proporcionado pela taxa referencial paga pelo governo em seus títulos (taxa SELIC). Neste caso, considerando um rendimento anual de 15\%, o índice P/L máximo seria 6,67, sendo que qualquer investimento com índice preço/lucro superior a esse seria descartado, por proporcionar menor rentabilidade e tomar mais tempo para retorno do capital investido.

\subsubsection{2. - Índice Preço/Valor Patrimonial (P/VP)}

Outro índice bastante utilizado, esse índice aponta quantas vezes o valor de mercado da ação supera seu valor patrimonial (ou valor em livros).

Seu cálculo se dá pela seguinte fórmula:

$$
\mathrm{P} / \mathrm{VP}=\frac{\text { Preço de Mercado da Ação }}{\text { Valor Patrimonial da Ação (VP) }}
$$




\subsection{Considerações e críticas a esses índices}

Existem várias críticas à utilização de índices e indicadores na análise de ações. Uma primeira crítica é que esses indicadores possuem natureza estática, ou seja, não incorporam variações futuras, que ocorrem de maneira contínua nas empresas e em seus números. Outra crítica é que esses índices são calculados com base em números contábeis, sujeitos a toda sorte de manipulações.

Em que pese a validade dessas e de outras críticas, esses indicadores nos dão alguma informação sobre as ações e seus preços, sendo bastante utilizados e servindo para várias conclusões, dependendo do método de investimento de cada aplicador.

\subsubsection{O modelo de Fluxo de Caixa Descontado (FCD)}

Como já mencionado, o processo de análise de valor (doravante AV) é fundamental em finanças. Para alguns, seria nesse momento que as finanças se tornariam uma ciência.

A utilização de indicadores de mercado, como feita no item anterior, serve como um importante referencial. No entanto, todo investimento, para ser considerado de boa qualidade, deve ser precedido por um processo de AV, com base nas modernas técnicas das finanças.

A técnica mais conhecida, e largamente utilizada, é a do Fluxo de Caixa Descontado, que discutiremos adiante.

Conforme Damodaran (1997), “[...] esta abordagem tem sua fundamentação na regra de 'valor presente', onde o valor de qualquer ativo é o valor presente dos fluxos de caixa futuros dele esperados”.

Apesar de aparentemente simples, as dificuldades aparecem logo no início do processo. A primeira delas advém do fato de trabalharmos com fluxos futuros, que não podem ser determinados, mas apenas estimados. E é nessa estimação que surgem as grandes variações. Como estimar a taxa de crescimento da empresa e de seus fluxos, qual referencial ou método utilizar? 
Em consequência do nível de crescimento estimado, Damodaran (1997), cita diferentes modelos para o "fluxo de caixa livre”, para crescimento estável, para crescimento em dois estágios (acelerado no período inicial e estável após este período), e também para crescimento em três estágios (alto, transição e estável). Qualquer um poderia ser aplicado às novas emissões, dependendo das particularidades de cada empresa emissora.

Outra questão: qual fluxo futuro devemos trazer a valor presente, o fluxo de caixa livre para acionista, o fluxo de caixa livre para a empresa ou o fluxo de dividendos.

Adicionalmente, temos mais um item fundamental: a taxa de desconto a ser utilizada, cuja estimação é fundamental.

Não é nossa intenção aqui discorrer largamente sobre esse método, pois existem vários livros especializados sobre o tema. Apenas levantamos suas particularidades pois, dadas as várias questões que se apresentam na sua utilização, no momento de sua aplicação podem surgir muitas variações nos preços das valorações realizadas.

Vale citar que, segundo, Copeland, Koller e Murrin (1996), o FCD proporciona um quadro mais sofisticado e confiável do valor de uma empresa que a abordagem contábil (baseada em índices e indicadores).

\subsection{Estudos sobre IPOs}

O processo de abertura de capital é amplamente estudado em finanças, em vários aspectos. No entanto, a quantidade de estudos desse tipo nos Estados Unidos e Europa é bastante superior ao volume dessas pesquisas no Brasil. Essa realidade se deve, basicamente, ao fato de os mercados de ofertas públicas naqueles países serem extremamente maduros, funcionando como uma efetiva fonte de alocação e tomada de recursos a investidores e empresas, enquanto que, no Brasil, apesar do expressivo crescimento de aberturas de capital no período 2004/2007, ainda não temos um mercado de ofertas públicas plenamente amadurecido.

Outros dois fatores que dificultam os estudos da espécie no Brasil são: 
- desde o fim do ciclo de aberturas de capital de 1970, até o início do presente ciclo, o volume de aberturas de capital no Brasil foi bastante tímido, propiciando um volume de casos muito pequeno;

- o período de maior volume, iniciado em 2004, ainda é, relativamente, muito recente, dado o tempo demandado para se verificar as ocorrências propostas nos estudos. Ademais, esse processo ainda está ocorrendo, não se encerrou, dificultando o distanciamento e análise dos pesquisadores.

\subsubsection{Estudos Internacionais}

Leal (1991, p. 119) realizou uma revisão das teorias explicativas dos retornos anormais nas aberturas de capital, definindo como retorno anormal a elevada valorização de novas ações nos primeiros dias de negociação, mesmo quando ajustado pelo retorno do mercado em tal período. Dividindo o trabalho em três etapas, discutiu inicialmente as hipóteses mais populares (tradicionais), encontradas nos primeiros trabalhos sobre o tema, para depois, nas etapas seguintes, analisar o fenômeno pelo enfoque da assimetria de informação e pela hipótese da bolha especulativa. Entre as hipóteses tradicionais, teríamos as seguintes hipóteses: a colocação mais fácil de papéis mais baratos, a colocação mais rápida também em função do baixo preço, possibilidade dos agentes colocadores recebem suas comissões em ações (ganhando com a valorização da ação) e, por fim, pelo fato do baixo preço permitir que os investidores tenham mais boa vontade com emissões subseqüentes da empresa. Sob o enfoque da assimetria informacional, discutiu três hipóteses: assimetria informacional entre a empresa emissora e o mercado (mediada pelo agente colocador), a assimetria informacional entre os investidores (informados e não informados) e, como terceira hipótese, a associação entre o prestígio do agente colocador e o resultado da emissão. Na terceira etapa do trabalho, revisa as teorias que associam os retornos iniciais anormais a bolhas especulativas, onde os preços dos negócios iniciais não refletiriam os fundamentos, por estarem inflados. Ademais, os excessos nos retornos iniciais seriam seguidos por retornos negativos excessivos em prazos mais longos, o que comprovaria a existência e estouro da bolha especulativa inicial. Importante mencionar novamente que o estudo em questão é todo teórico, ou seja, apresenta uma rápida revisão da literatura sobre o tema, sem discutir qualquer exemplo empírico.

Em outro estudo, Leal (2001, p. 132) discutiu três razões que, segundo ele, inibiriam as aberturas de capital por emissões de ações no Brasil. O primeiro motivo seria o elevado custo 
do capital próprio, tanto pelo enfoque do "prêmio de risco adicionado ao custo da dívida da empresa”, quanto pelo CAPM - Capital Asset Pricing Model. Ou seja, o elevado custo dos novos recursos, decorrentes da abertura de capital, seria um forte inibidor ao processo. O segundo motivo seria a falta de proteção ao acionista minoritário, dado o fato do Brasil não oferecer proteção legal ao pequeno acionista (aqui, temos que considerar que, decorridos sete anos da data do artigo, e mesmo com a evolução do processo de governança corporativa no país, essa discussão ainda é pertinente, apesar de alguma evolução legal). Já o terceiro motivo inibidor das aberturas de capital no Brasil seriam os custos indiretos de emissão, ou seja, o fato de que os elevados retornos iniciais das emissões públicas faria com que as empresas emissoras deixassem muito “dinheiro sobre a mesa” (pelo fato de que essa valorização inicial seria absorvida pelos comprados da ação e não pela empresa emissora). Essa elevada diferença entre o preço de emissão e o preço de mercado nos primeiros dias seria frustrante para a empresa emissora, funcionando como um inibidor.

Charchat (2001, p. 141) analisa aquilo que ele denomina a triste história das aberturas de capital no Brasil: o comportamento de longo prazo das empresas que abriram seu capital no ano de 1986, durante o Plano Cruzado. Especificamente durante a primeira metade daquele ano, ocorreu um volume recorde de emissões de ações, dado o sucesso do referido plano econômico e a elevada valorização do mercado de ações no período. Nesse sentido, o autor analisou o comportamento de longo prazo dos papéis de 24 empresas que emitiram ações naquele ano. Sem querer simplificar o estudo, que apresenta várias informações, o autor concluiu que haviam evidências empíricas de que as empresas se aproveitaram do momento de euforia por parte dos investidores, abrindo seu capital valendo-se de uma "janela de oportunidade” causada por essa euforia. A performance de longo prazo dos papéis foi bastante ruim, gerando fortes prejuízos aos investidores. Vale destacar que, passados 10 anos, apenas 8 (oito) sobreviveram. Ainda dentro das 24 empresas analisadas, 9 (38\%) pediram concordata e 10 (42\%) foram alienadas ou sofreram alteração do grupo controlador. 


\section{METODOLOGIA DA PESQUISA}

Um homem nada faria se, para principiar a fazer as coisas, esperasse até fazê-las com tal perfeição que ninguém lhes acharia defeito.

Cardeal Newman

Existem vários conceitos e definições para a palavra “método”. Lakatos e Marconi (2006, p. 44) chegam a citar 9 definições do termo, de diferentes autores. Entre as várias definições ali citadas, tomaremos a seguinte:

"Método é a forma de proceder ao longo de um caminho. Na ciência os métodos constituem os instrumentos básicos que ordenam de início o pensamento em sistemas, traçam de modo ordenado a forma de proceder do cientista ao longo de um percurso para alcançar um objetivo” (Trujillho, 1974:24)

Na discussão do mesmo tema, encontramos a seguinte definição em Gil (2000, p. 31):

Etimologicamente, método significa caminho para se chegar a um fim. Assim, método científico pode ser entendido como "o caminho para se chegar à verdade em ciência" ou como "o conjunto de procedimentos que ordem o pensamento e esclarecem acerca dos meios adequados para se chegar ao conhecimento.

Operacionalmente, utilizaremos essas duas definições como guia. Nessa lógica, podemos dizer que a metodologia compreende a adoção da abordagem metodológica mais adequada para o estudo, considerando-se o problema de pesquisa e os objetivos do trabalho, previamente definidos em etapa anterior.

Em relação à abordagem metodológica, encontramos em Marconi e Lakatos (1999, p. 32) a seguinte orientação:

A seleção do instrumental metodológico está, portanto, diretamente relacionada com o problema a ser estudado: a escolha dependerá dos vários fatores relacionados com a pesquisa, ou seja, a natureza dos fenômenos, o objeto da pesquisa, os recursos financeiros, a equipe humana e outros elementos que possam surgir no campo da investigação.

A abordagem metodológica, por sua vez, está relacionada à forma como as pesquisas podem ser classificadas. Tal qual a definição da palavra metodologia, encontramos também várias formas de classificação das pesquisas científicas. No entanto, de maneira geral, elas são 
classificadas em três grandes grupos: exploratórias, descritivas e explicativas. Em Gil (2002, p.41, encontramos as seguintes considerações:

(i) Pesquisas exploratórias

Estas pesquisas têm como objetivo proporcionar maior familiaridade com o problema, com vistas a torná-lo mais explícito ou a constituir hipóteses. Pode-se dizer que estas pesquisas têm como objetivo principal o aprimoramento de idéias ou a descoberta de intuições. Seu planejamento é, portanto, bastante flexível, de modo que possibilite a consideração dos mais variados aspectos relativos ao fato estudado. Na maioria dos casos, essas pesquisas envolvem: (a) levantamento bibliográfico; (b) entrevistas com pessoas que tiveram experiências práticas com o problema pesquisado; e (c) análise de exemplos que “estimulem a compreensão” [...]

(ii) Pesquisas descritivas

As pesquisas descritivas têm como objetivo primordial a descrição das características de determinada população ou fenômeno ou, então, o estabelecimento de relações entre variáveis. São inúmeros os estudos que podem ser classificados sob este título e uma de suas características mais significativas está na utilização de técnicas padronizadas de coleta de dados, tais como o questionário e a observação sistemática.

(iii) Pesquisas explicativas

Estas pesquisas têm como preocupação central identificar os fatores que determinam ou que contribuem para a ocorrência dos fenômenos. Esse é o tipo de pesquisa que mais aprofunda o conhecimento da realidade, porque explica a razão, o porquê das coisas. Por isso mesmo, é o tipo mais complexo e delicado, já que o risco de cometer erros aumenta consideravelmente.

Com base no exposto, podemos dizer que a presente pesquisa pode ser classificada como exploratório-descritiva. Seu caráter exploratório deve-se ao fato de que buscaremos aprofundar o conhecimento sobre o tema (ciclo de aberturas de capital no período 2004/2007), a fim de adquirir maior familiaridade com o tema. Isso nos permitirá também que, ao final, possamos levantar hipóteses sobre o tema, indicativas para futuros estudos, uma das características das pesquisas exploratórias.

Por outro lado, o caráter descritivo da presente pesquisa decorre da abordagem quantitativa que faremos do tema, buscando descrever o comportamento dos preços das novas ações emitidas no período em questão e seus efeitos em termos de geração de riqueza. Essa análise terá um foco apenas descritivo, sem que busquemos estabelecer relações entre quaisquer das variáveis analisadas. Vale ressaltar que essas variáveis não receberão um tratamento estatístico aprofundado, mas apenas o levantamento de suas estatísticas descritivas.

\subsection{Dados}


Conforme já detalhado, no presente trabalho serão estudadas as ações das empresas que fizeram abertura de seu capital no período compreendido entre os anos de 2004/2007. Dessa forma, as ações a serem estudadas são aquelas discriminadas na tabela abaixo (Tabela 2):

Tabela 2 - Empresas que fizeram abertura de capital no período 2004/2007

\begin{tabular}{|c|c|c|c|}
\hline & Empresa & Código na Bolsa & Data do Início da Série \\
\hline 1 & Natura & NATU3 & $25 / 05 / 04$ \\
\hline 2 & Gol & GOLL4 & 23/06/04 \\
\hline 3 & CPFL Energia & CPFE3 & 28/09/04 \\
\hline 4 & Grendene & GRND3 & $28 / 10 / 04$ \\
\hline 5 & Dasa & DASA3 & $18 / 11 / 04$ \\
\hline 6 & Porto Seguro & PSSA3 & 19/11/04 \\
\hline 7 & Renar & RNAR3 & $25 / 02 / 05$ \\
\hline 8 & B2W Varejo - ex-Submarino & SUBA3+BTOW3 & $29 / 03 / 05$ \\
\hline 9 & Localiza & RENT3 & 20/05/05 \\
\hline 10 & Energias BR & ENBR3 & $12 / 07 / 05$ \\
\hline 11 & OHL Brasil & OHLB3 & $14 / 07 / 05$ \\
\hline 12 & TAM S/A & TAMM3 & 09/08/05 \\
\hline 13 & Nossa Caixa & BNCA3 & $27 / 10 / 05$ \\
\hline 14 & Cosan & CSAN3 & $17 / 11 / 05$ \\
\hline 15 & Uol & UOLL4 & $15 / 12 / 05$ \\
\hline 16 & Copasa & CSMG3 & 07/02/06 \\
\hline 17 & Vivax & VVAX11 & 07/02/06 \\
\hline 18 & Gafisa & GFSA3 & $16 / 02 / 06$ \\
\hline 19 & Company & CPNY3 & 01/03/06 \\
\hline 20 & Totvs & TOTS3 & 08/03/06 \\
\hline 21 & Equatorial & EQTL11+EQTL3 & $31 / 03 / 06$ \\
\hline 22 & Abnote & ABNB3 & 26/04/06 \\
\hline 23 & BrasilAgro & AGRO3 & 28/04/06 \\
\hline 24 & CSU CardSystem & CARD3 & 28/04/06 \\
\hline 25 & Lupatech & LUPA3 & $12 / 05 / 06$ \\
\hline 26 & GP Invest & GPIV11 & $31 / 05 / 06$ \\
\hline 27 & Datasul & DSUL3 & 01/06/06 \\
\hline 28 & MMX Miner & MMXM3 & $21 / 07 / 06$ \\
\hline 29 & Abyara & ABYA3 & 26/07/06 \\
\hline 30 & Medial Saude & MEDI3 & $21 / 09 / 06$ \\
\hline 31 & Klabinsegall & KSSA3 & 06/10/06 \\
\hline 32 & Santos BRP & STBR11+STBP11 & $12 / 10 / 06$ \\
\hline 33 & M. Diasbranco & MDIA3 & $17 / 10 / 06$ \\
\hline 34 & Brascan Res & BISA3 & 20/10/06 \\
\hline 35 & Profarma & PFRM3 & $25 / 10 / 06$ \\
\hline 36 & Terna Part & TRNA11 & 26/10/06 \\
\hline 37 & Ecodiesel & ECOD3 & 21/11/06 \\
\hline 38 & Odontoprev & ODPV3 & $30 / 11 / 06$ \\
\hline 39 & Positivo Inf & POSI3 & $08 / 12 / 06$ \\
\hline 40 & Lopes Brasil & LPSB3 & $15 / 12 / 06$ \\
\hline 41 & Dufrybras & DUFB11 & 19/12/06 \\
\hline 42 & PDG Realt & PDGR3 & 25/01/07 \\
\hline 43 & CC Des Imob & CCIM3 & $30 / 01 / 07$ \\
\hline 44 & Rodobensimob & RDNI3 & $30 / 01 / 07$ \\
\hline
\end{tabular}




\begin{tabular}{|c|c|c|c|}
\hline 45 & Tecnisa & TCSA3 & $31 / 01 / 07$ \\
\hline 46 & Iguatemi & IGTA3 & $06 / 02 / 07$ \\
\hline 47 & GVT Holding & GVTT3 & $15 / 02 / 07$ \\
\hline 48 & Anhanguera & AEDU11 & 09/03/07 \\
\hline 49 & JBS & JBSS3 & 28/03/07 \\
\hline 50 & Even & EVEN3 & $30 / 03 / 07$ \\
\hline 51 & Pine & PINE4 & 30/03/07 \\
\hline 52 & BR Malls Par & BRML3 & $04 / 04 / 07$ \\
\hline 53 & Fer Heringer & FHER3 & $11 / 04 / 07$ \\
\hline 54 & JHSF Part & JHSF3 & $11 / 04 / 07$ \\
\hline 55 & Metalfrio & FRIO3 & $12 / 04 / 07$ \\
\hline 56 & Bematech & BEMA3 & $18 / 04 / 07$ \\
\hline 57 & CR2 & CRDE3 & $20 / 04 / 07$ \\
\hline 58 & Agra Incorp & AGIN3 & $25 / 04 / 07$ \\
\hline 59 & Cremer & CREM3 & $27 / 04 / 07$ \\
\hline 60 & Wilson Sons & WSON11 & $27 / 04 / 07$ \\
\hline 61 & Sofisa & SFSA4 & $30 / 04 / 07$ \\
\hline 62 & Tarpon & TARP11 & $30 / 05 / 07$ \\
\hline 63 & Inpar S/A & INPR3 & 05/06/07 \\
\hline 64 & Parana & PRBC4 & $13 / 06 / 07$ \\
\hline 65 & SLC Agricola & SLCE3 & $14 / 06 / 07$ \\
\hline 66 & Log-In & LOGN3 & $20 / 06 / 07$ \\
\hline 67 & Eztec & EZTC3 & $21 / 06 / 07$ \\
\hline 68 & Cruzeiro Sul & CZRS4 & $25 / 06 / 07$ \\
\hline 69 & Daycoval & DAYC4 & $28 / 06 / 07$ \\
\hline 70 & Marfrig & MRFG3 & $28 / 06 / 07$ \\
\hline 71 & Tegma & TGMA3 & $02 / 07 / 07$ \\
\hline 72 & Indusval & IDVL4 & $11 / 07 / 07$ \\
\hline 73 & Redecard & RDCD3 & $12 / 07 / 07$ \\
\hline 74 & Invest Tur & IVTT3 & $13 / 07 / 07$ \\
\hline 75 & Banco Patagonia & BPAT11 & 19/07/07 \\
\hline 76 & Minerva & BEEF3 & $19 / 07 / 07$ \\
\hline 77 & Guarani & ACGU3 & $20 / 07 / 07$ \\
\hline 78 & Kroton & KROT11 & 20/07/07 \\
\hline 79 & MRV & MRVE3 & $20 / 07 / 07$ \\
\hline 80 & Triunfo Part & TPIS3 & $20 / 07 / 07$ \\
\hline 81 & Abc Brasil & ABCB4 & $24 / 07 / 07$ \\
\hline 82 & Multiplan & MULT3 & $26 / 07 / 07$ \\
\hline 83 & Providencia & PRVI3 & $26 / 07 / 07$ \\
\hline 84 & Springs & SGPS3 & $26 / 07 / 07$ \\
\hline 85 & Estacio & ESTC11+ESTC3 & $27 / 07 / 07$ \\
\hline 86 & Generalshop & GSHP3 & $27 / 07 / 07$ \\
\hline 87 & Cosan Ltd & CZLT11 & $16 / 08 / 07$ \\
\hline 88 & Satipel & SATI3 & 20/09/07 \\
\hline 89 & Sul America & SULA11 & $04 / 10 / 07$ \\
\hline 90 & Bicbanco & BICB4 & $11 / 10 / 07$ \\
\hline 91 & Tenda & TEND3 & $11 / 10 / 07$ \\
\hline 92 & Trisul & TRIS3 & $11 / 10 / 07$ \\
\hline 93 & Seb & SEBB11 & 17/10/07 \\
\hline 94 & Marisa & MARI3 & 19/10/07 \\
\hline 95 & Agrenco & AGEN11 & $24 / 10 / 07$ \\
\hline 96 & Bovespa Holding & BOVH3 & $25 / 10 / 07$ \\
\hline
\end{tabular}




\begin{tabular}{|r|l|c|c|}
97 & Amil & AMIL3 & $26 / 10 / 07$ \\
\hline 98 & Br Brokers & BBRK3 & $26 / 10 / 07$ \\
\hline 99 & Helbor & HBOR3 & $26 / 10 / 07$ \\
\hline 100 & Laep & MILK11 & $30 / 10 / 07$ \\
\hline 101 & Panamericano & BPNM4 & $16 / 11 / 07$ \\
\hline 102 & BM\&F & BMEF3 & $29 / 11 / 07$ \\
\hline 103 & MPX Energia & MPXE3 & $13 / 12 / 07$ \\
\hline 104 & Tempo Part & TEMP3 & $17 / 12 / 07$ \\
\hline
\end{tabular}

Fonte: CVM, Economática, Bovespa

Compreende um total de 104 ações, sendo que os dados foram obtidos de diferentes fontes, a saber: endereços eletrônicos da CVM (http://www.cvm.gov.br) e da Bovespa (http://www.bovespa.com.br), e do sistema de informações Economática. 


\section{OS CICLOS ANTERIORES DE ABERTURAS DE CAPITAL NO BRASIL}

Na tabela ... abaixo, encontramos o número de empresas listadas na Bovespa em cada um dos anos compreendidos no período 1970/2008. Num longo período de quase 40 anos, um ano em particular se destaca: 1971, quando o crescimento de empresas listadas cresceu expressivos 68,5\%. Como veremos a seguir, o período de 1968/71 apresentou um forte crescimento do mercado de ações, com um grande número de empresas abrindo seu capital via emissão de ações.

Outro período importante para o mercado de ações foi o ano de 1889, exatamente o primeiro ano da República, onde, em função de um forte apoio governamental, um número expressivo de empresas efetivaram a abertura de capital.

Esses dois períodos serão aqui analisados, a fim de identificar suas características principais. Veremos que, apesar de um longo intervalo entre esses dois momentos, as características foram bastante similares, principalmente o movimento de especulação financeira. Posteriormente, esses ciclos serão comparados com o atual ciclo, a fim de determinar possíveis riscos ao ciclo atual.

Tabela 3 - Empresas de capital aberto listadas na Bovespa - 1970/2008

\begin{tabular}{|r|r|r|r|r|r|r|r|}
\hline Ano & $\begin{array}{c}\text { Número de } \\
\text { Empresas }\end{array}$ & $\begin{array}{c}\text { Variação no } \\
\text { número de } \\
\text { Empresas }\end{array}$ & Variação \\
percentual & Ano & $\begin{array}{c}\text { Número } \\
\text { de } \\
\text { Empresas }\end{array}$ & $\begin{array}{c}\text { Variação } \\
\text { no } \\
\text { número } \\
\text { de } \\
\text { Empresas }\end{array}$ & $\begin{array}{c}\text { Variação } \\
\text { percentual }\end{array}$ \\
\hline 1970 & 200 & - & - \\
\hline 1971 & 337 & 137 & $68,5 \%$ \\
\hline 1972 & 381 & 44 & $13,1 \%$ \\
\hline 1973 & 395 & 14 & $3,7 \%$ \\
\hline 1974 & 398 & 3 & $0,8 \%$ \\
\hline 1975 & 362 & -36 & $-9,0 \%$ \\
\hline 1976 & 387 & 25 & $6,9 \%$ \\
\hline 1977 & 452 & 65 & $16,8 \%$ \\
\hline 1978 & 399 & -53 & $-11,7 \%$ \\
\hline 1979 & 404 & 5 & $1,3 \%$ \\
\hline 1980 & 426 & 22 & $5,4 \%$ \\
\hline 1981 & 488 & 62 & $14,6 \%$ \\
\hline 1982 & 493 & 5 & $1,0 \%$ \\
\hline 1983 & 506 & 13 & $2,6 \%$ \\
\hline 1984 & 522 & 16 & $3,2 \%$ \\
\hline 1985 & 541 & 19 & $3,6 \%$ \\
\hline 1986 & 592 & 51 & $9,4 \%$ \\
\hline
\end{tabular}




\begin{tabular}{|l|r|r|r|}
1987 & 590 & -2 & $-0,3 \%$ \\
\hline 1988 & 589 & -1 & $-0,2 \%$ \\
\hline 1989 & 592 & 3 & $0,5 \%$ \\
\hline
\end{tabular}

Fonte: Bovespa (1970-1999) e

CVM

\begin{tabular}{|c|c|c|c|}
2007 & 366 & 27 & $8,0 \%$ \\
\hline 2008 & 400 & 34 & $9,3 \%$ \\
\hline 2009 & - & - & - \\
\hline
\end{tabular}

\subsection{O Ciclo 1968/1971}

Durante a década de 60 do século passado (doravante denominado “anos 60”), o Brasil vivenciou um período político extremamente conturbado, em decorrência de uma série de fatos e acontecimentos. Por não estarem relacionados ao escopo deste trabalho, serão apenas citados, já que estão na origem das mudanças econômicas ocorridas naquele período. Tais fatos foram: fim do governo de Juscelino Kubitscheck, eleição de Jânio Quadros, sua renúncia com apenas 7 meses de governo, dificuldades para assunção do governo pelo vice-presidente à época, João Goulart, instalação do parlamentarismo, fim do parlamentarismo por plebiscito nacional e assunção de João Goulart. O período do governo Goulart (1962-1964) foi também bastante conturbado, política e economicamente, sendo encerrado através de um golpe militar.

O governo militar assumiu o país em abril de 1964, dando início a uma série de reformas econômicas. Considerando o período 1964/1972, podemos destacar dois conjuntos de medidas: (i) aquelas decorrentes do diagnóstico econômico inicial do governo militar, consubstanciadas no Plano de Ação Econômica do Governo (PAEG,), no período de 1964/1967, e (ii) aquelas adotas pelo ministro do planejamento Delfim Neto, a partir de 1967.

Nesse conjunto de medidas econômicas, um dos objetivos do governo militar era construir um novo padrão de financiamento da economia. Nesse sentido, afirma Rodrigues (2002, p. 14):

[...] o Governo empenhou-se na montagem de um novo padrão de financiamento do crescimento econômico. Os problemas cruciais identificados no Plano eram o baixo volume da poupança privada, a inexistência de mecanismos de financiamento de longo prazo (exceto os governamentais, através do Banco Nacional de Desenvolvimento Econômico - BNDE) e um mercado de capitais incipiente. Tendo em vista a superação desses problemas, empreendeu-se uma ampla reordenação do Sistema Financeiro Nacional bem como incentivou-se a entrada de capital estrangeiro, tanto sob a forma de empréstimo quanto de investimento direto, para complementar a poupança nacional. 
Na mesma lógica, Lago (1990, p. 259) afirma:

A partir de 1964, e também de 1967-1973, o governo buscou atingir o duplo objetivo de: (i) conter as necessidades de financiamento do setor público e (ii) assegurar uma oferta de crédito adequada ao setor privado.

Em julho de 1964, foi promulgada a Lei ${ }^{0}$ 4.357, através da qual eram criadas as Obrigações Reajustáveis do Tesouro Nacional (ORTNs), além da concessão de uma série de incentivos fiscais à aplicação em ativos financeiros.

Logo em seguida, através da Lei $\mathrm{n}^{\circ} 4.380$, de agosto do mesmo ano, foi constituído o Sistema Financeiro de Habitação (SFH), através da criação do Banco Nacional da Habitação (BNH). A fim de criar mecanismos de financiamento dos programas habitacionais, criou mecanismos de poupança voluntária (letras imobiliárias e hipotecárias e a caderneta de poupança) e compulsória (Fundo de Garantia por Tempo de Serviço - FGTS).

Em 31 de dezembro de 1964, através da Lei 4.595, o governo deu início à Reforma Bancária, através da qual reformulou todo o SFN. Nessa lei, foram criados o Conselho Monetário Nacional (CMN) - responsável pela política monetária e financeira -, e o Banco Central (BACEN).

Posteriormente, em 16 de julho de 1965, foi publicada a Lei 4.728, denominada Lei do Mercado de Capitais. Segundo Rodrigues (op. cit., p. 17):

Através desse diploma legal o Governo pretendia resolver os problemas afetos ao financiamento de investimentos privados a médio e longo prazos bem como estimular o mercado de ações, que deveria se constituir num importante instrumento de capitalização das empresas privadas nacionais criando, dessa forma, as condições para o desenvolvimento das modernas S/A.

Nesse contexto, foi criado um novo tipo de instituição financeira: os Bancos Privados de Investimento (BIs). A criação dos bancos de investimento tinha como objetivo criar uma fonte de financiamento para investimentos privados de médio e longo prazo, além de fomentar a captação de recursos pelas empresas através da abertura de seu capital social.

Posteriormente, seriam criados os “Fundos 157”. Segundo Lago (op. cit., p. 263): 
Esse mecanismo iria canalizar volumosos recursos para as bolsas de valores e seria reforçado pela retomada do crescimento econômico, pelo aumento de lucratividade das empresas, por aprimoramentos no tratamento contábil dos resultados das empresas, e por uma tributação favorável dos dividendos.

Uma maior demanda do público e dos fundos de ações diante de uma oferta limitada de títulos levou a um forte aumento de preços, "culminando com um boom especulativo seguido de um traumático processo de reajuste em 1971”.

Como resultado do conjunto de medidas econômicas do período, observou-se, a partir de 1968, uma vigorosa retomada do crescimento econômico, cujo auge ocorreu no início dos anos 70. Esse período de crescimento, entre 1968 e 1973, ficou conhecido como "Milagre Brasileiro”, cujos números estão apresentados a seguir (Tabela 4):

Tabela 4 - Brasil: taxas de crescimento do PIB e da Indústria - 1968-77

(percentagem em relação ao ano anterior)

\begin{tabular}{|ccc|}
\hline Ano & PIB & Indústria \\
\hline 1968 & 9,8 & 13,3 \\
1969 & 9,5 & 12,1 \\
1970 & 10,4 & 11,9 \\
1971 & 11,3 & 11,8 \\
1972 & 11,9 & 14,2 \\
1973 & 14,0 & 17,0 \\
1974 & 8,2 & 8,5 \\
1975 & 5,2 & 6,2 \\
1976 & 10,3 & 10,7 \\
1977 & 4,9 & 3,9 \\
\hline
\end{tabular}

Fonte: Gremaud et al (1997, p. 184).

Adaptado.

No bojo desse crescimento econômico, e fruto do conjunto de medidas institucionais e de incentivos adotadas pelo governo, o mercado de capitais passou a vivenciar um forte crescimento no volume de emissões de ações e debêntures, conforme demonstra a Tabela 5:

Tabela 5 - Taxas de variação no valor das emissões de ações e debêntures (Taxas Anuais de Variação*)

\begin{tabular}{|r|r|r|r|r|r|}
\hline Ano & \multicolumn{1}{c|}{$\begin{array}{c}\text { Oferta } \\
\text { Comum }\end{array}$} & DL-157 & \multicolumn{1}{c|}{$\begin{array}{c}\text { Incentivos } \\
\text { Fiscais }\end{array}$} & Total & $\begin{array}{r}\text { Número } \\
\text { Total de } \\
\text { Registros }\end{array}$ \\
\hline 1968 & $1.136,20$ & 57,40 & $1.571,40$ & 384,50 & 143 \\
\hline 1969 & $-64,00$ & 103,50 & 53,00 & 26,40 & 150 \\
\hline 1970 & 43,50 & $-68,80$ & $2.120,00$ & $-5,50$ & 137 \\
\hline 1971 & 457,30 & 50,00 & 401,60 & 349,50 & 307 \\
\hline 1972 & $-82,60$ & $-92,60$ & $-74,20$ & $-83,50$ & 111 \\
\hline 1973 & $-4,40$ & nd & 76,80 & 21,00 & 128 \\
\hline 1974 & $-16,20$ & nd & $-40,60$ & $-31,10$ & \\
\hline
\end{tabular}




\begin{tabular}{|r|r|r|r|r|r|} 
& & & & & 78 \\
\hline 1975 & $-47,00$ & nd & $-42,90$ & $-42,00$ & 59 \\
\hline 1976 & 152,70 & nd & 44,10 & 110,00 & 74 \\
\hline 1977 & 36,70 & nd & $-69,00$ & $-20,10$ & 74 \\
\hline
\end{tabular}

Fonte: Rodrigues (2002, p. 128)

(*) em termos reais, a preços de 1970

Ao mesmo tempo que cresciam as emissões, elevavam-se também os volumes transacionados, conforme detalhado abaixo (Tabela 6):

Tabela 6 - Valor das Transações de Ações nas Bolsas de Valores (Taxas Anuais de Variação*)

\begin{tabular}{|cc|}
\hline Ano & $\%$ \\
\hline 1968 & 24,60 \\
1969 & 389,70 \\
1970 & 54,60 \\
1971 & 365,50 \\
1972 & 39,80 \\
1973 & $-13,90$ \\
1974 & $-40,90$ \\
1975 & 53,80 \\
1976 & $-25,50$ \\
1977 & $-5,90$ \\
\hline
\end{tabular}

Fonte: Rodrigues (2002, p. 129)

(*) em termos reais, a preços de 1970

O crescimento do volume de emissões e nos valores transacionados foi acompanhado por um forte movimento especulativo. Nesse sentido, Tavares (1974, p. 232), em ensaio preparado para o seminário denominado "Mercado de Capitais e Desenvolvimento Econômico", realizado pelo IBMEC (Instituto Brasileiro de Mercado de Capitais) em setembro de 1971, afirmou:

A partir de fins de 1968, ao acelerado desenvolvimento financeiro ligado à multiplicação das relações de débito dentro do setor urbano da economia veio juntar-se a euforia especulativa das ações em bolsa, trazendo para o centro das atenções o problema do mercado de capitais.

Resultados do processo. Segundo Lago (op. cit., p. 263):

A partir de fins de 1971 e até o final da década, o mercado de ações deixou de exercer a mesma atração sobre os investidores do que a observada antes da “crise” de 1971, e portanto falhou a tentativa de torná-lo um instrumento duradouro de capitalização das empresas. 
Análise desse ciclo:

O ciclo de aberturas de capital ocorrido no início dos anos 70 está compreendido dentro de um processo mais amplo, qual seja, a tentativa dos governos militares, a partir do ano de 1964, de montar um sistema privado de financiamento da economia. Nas palavras de Pereira (1998, p. 130):

No Brasil, a partir de 1964, todas as tentativas foram feitas no sentido de se montar um sistema privado de financiamento da acumulação, mas afinal esse financiamento acabou sendo fundamentalmente público.

A base inicial para isso foi a criação da correção monetária, a fim de incentivar os rentistas a aplicar seu dinheiro a juros. Novamente segundo Pereira (1998, p. 130):

\begin{abstract}
A partir dessa inovação básica, tentaram-se outras medidas que visavam desenvolver um sistema de financiamento da acumulação. Tentou-se desenvolver as bolsas de valores e o mercado de ações. A compra de novas ações seria uma forma por excelência de financiamento privado da acumulação. Criaram-se incentivos aos investimentos em ações. Mas, na verdade, as bolsas são muito mais instituições que garantem a liquidez dos títulos (além de procurarem legitimar ideologicamente o sistema capitalista por meio da idéia de "democratização" da propriedade) do que meios de financiar a acumulação. As esperanças nas ações e nas bolsas de valores terminaram com a grande especulação de 1971.
\end{abstract}

Importante mencionar que o processo de incentivo ao crescimento do mercado de capitais, e especificamente ao mercado de ações, como já mencionado, fazia parte de um conjunto de medidas econômicas, que incluía, entre outras, a criação dos bancos de investimento, o incentivo à fusão de bancos e à formação de conglomerados financeiros, como também a criação de uma série de fundos de poupança forçada - PIS, PASEP, FGTS etc.

Na análise desse processo, Pereira (1998, p. 131) comenta:

O fracasso da instalação de um sistema privado de financiamento da acumulação não se deveu, entretanto, apenas à falta de capital disponível por parte dos rentistas. Esta é uma causa básica, estrutural. A grande maioria dos capitalistas no Brasil ainda são ativos empresários. Mas há uma segunda razão: a especulação atingiu graus elevadíssimos no mercado financeiro brasileiro. Grandes lucros foram realizados nesse mercado às custas de lucros e investimentos no setor privado.

Também analisando esse processo, especificamente o mercado de ações, Rodrigues (2002, p. 89) afirma: 
O mercado de ações, reestruturado para se constituir num eficiente instrumento à capitalização das empresas e à formação das modernas S/A, após um curto período de euforia mergulhou num forte estado de apatia do qual nem mesmo todo o aparato de incentivos conseguiu reanimá-lo.

Mais adiante, Pereira destaca os efeitos positivos desse processo, tendo em vista o crescimento no volume das operações de crédito e o relativo amadurecimento do mercado financeiro no período. No entanto, ressalva (p. 132):

\begin{abstract}
"Esse aprofundamento financeiro permitiu, sem dúvida, uma melhor captação de poupanças privadas. Mas seus limites são muito claros, já que o Estado continua a ser o grande agente financiador da acumulação privada. Por outro lado, foi muito alto o custo para o país desse desenvolvimento financeiro marcado por especulação desenfreada e pelo aventureirismo, sempre bancados pelo Estado. Este, para salvar o mercado, garantia o pagamento dos créditos aos aplicadores individuais, ou seja, aos rentistas, quando as empresas financeiras se tornavam insolventes, incapazes de pagar seus compromissos.”.
\end{abstract}

Por fim, conclui com um comentário que resume o processo naquele período:

\begin{abstract}
Apesar de seus defeitos, especialmente do seu excessivo custo e de seu caráter especulativo, não há dúvida de que se constituiu um mercado financeiro poderoso. E que esse mercado, desde que devidamente controlado, poderá ser um instrumento importante para o desenvolvimento brasileiro. Para isto, entretanto, será essencial que se torne compatível com taxas de juros reais consideravelmente mais baixas do que aquelas que vêm sendo praticadas na economia brasileira.
\end{abstract}

Esse comentário, pertinente para o ciclo dos anos 70, servirá também para analisarmos, mais adiante, o ciclo de aberturas de capital iniciado em 2004.

Uma outra característica desse ciclo, e que também será discutida adiante, é que o governo, à época, incentivou o mercado de capitais imbuído de um propósito louvável, qual seja: o de permitir que o mercado de capitais se tornasse uma alternativa de financiamento de longo prazo à economia. Para isso, adotou uma série de medidas, que, de qualquer maneira, permitiram um crescimento do mercado de ações. No entanto, ao longo do tempo, surgiu uma outra característica desse processo: a dificuldade, ou mesmo a impossibilidade, do governo de administrar e coibir a especulação financeira, que foi a grande causadora do fim desse processo. Seja numa visão mais romântica, onde o criatura se volta contra seu criador, ou seja numa visão dialética (e mais científica), onde a tese dá origem à sua antítese, ao não controlar a especulação financeira, criam-se as condições para o fim do processo. 


\subsection{0 ciclo 1889/91}

Logo após a proclamação da República, o novo governo implanta uma série de medidas econômicas, a fim de estimular a economia.

Dentre esse conjunto de medidas, criaram-se vários incentivos à abertura de novas empresas.

Esse processo fez aflorar uma forte especulação financeira.

Conforme Prado Junior (1970, p. 220):

Começam a surgir em grande número novas empresas de toda ordem e finalidade. Eram bancos, firmas comerciais, companhias industriais, de estradas de ferro, toda sorte de negócios possíveis e impossíveis. Entre a data da proclamação da República e o fim da aventura (1891) incorporar-seão no Rio de Janeiro sociedades com capital global de 3.000 .000 de contos; ao iniciar-se a especulação, isto é, em novembro de 1889, o capital de todas as sociedades existentes no país apenas ultrapassava 800.000 contos. Quintuplicara-se quase este capital em pouco mais de dois anos!

Mais adiante, Prado Junior continua sua análise (1970, p. 220):

Naturalmente, a quase totalidade das novas empresas era fantástica e não tinha existência senão no papel. Organizavam-se apenas com o fito de emitir ações e despejá-las no mercado de títulos, onde passavam rapidamente de mão em mão em valorizações sucessivas. Chegaram a faltar nomes apropriados para designar novas sociedades, e inventaram-se as mais extravagantes denominações. Ao lado de projetos irrealizáveis, como estradas de ferro transcontinentais, grandes empresas de navegação, colonização de territórios os mais afastados, e inacessíveis do país, surgem negócios de todo disparatados. Ninguém se lembrava nunca de indagar da exeqüibilidade de uma empresa, das perspectivas de negócio. Tudo era apenas pretexto para incorporação de sociedades, emissão de títulos e especulação. 


\section{O CICLO DE ABERTURAS DE CAPITAL NO PERÍODO 2004/2007 - ANÁLISE QUALITATIVA}

\subsection{Antecedentes}

Tal qual o ciclo de aberturas de capital analisado no capítulo anterior, o ciclo 2004/2007 também ocorreu após uma série de mudanças ocorridas nos anos precedentes.

Durante as décadas de 80 e 90, não se verificou a ocorrência de períodos mais longos de aberturas de capital. O que se viu foram momentos pontuais vividos pelo mercado, em um ou outro ano, mas sem qualquer consolidação. Esses pequenos momentos ocorreram em anos específicos, em função de fatos econômicos.

Tabela 7 - Empresas emissoras e volumes de emissão - 2004/2007

\begin{tabular}{|c|c|c|c|c|}
\hline $\begin{array}{l}\text { NOME DE } \\
\text { PREGÃ̃O }\end{array}$ & $\begin{array}{l}\text { INÍCIO DE } \\
\text { NEGOCIAÇÃO }\end{array}$ & $\begin{array}{c}\text { VOLUME PRIMÁRIA } \\
\text { (R\$) }\end{array}$ & $\begin{array}{l}\text { VOLUME SECUNDÁRIA } \\
\text { (R\$) }\end{array}$ & VOLUME TOTAL (R\$) \\
\hline NATURA & $26 / 05 / 04$ & - & 768.120 .637 & 768.120 .637 \\
\hline GOL & $24 / 06 / 04$ & 498.187.500 & 379.951 .000 & 878.138 .500 \\
\hline CPFL ENERGIA & 29/09/04 & 684.649 .515 & 136.312 .659 & 820.962.174 \\
\hline GRENDENE & $29 / 10 / 04$ & - & 616.900 .000 & 616.900 .000 \\
\hline DASA & $19 / 11 / 04$ & 126.136 .300 & 311.247 .720 & 437.384 .020 \\
\hline PORTO SEGURO & $22 / 11 / 04$ & 129.022 .800 & 248.311.894 & 377.334.694 \\
\hline RENAR & $28 / 02 / 05$ & 16.000 .000 & - & 16.000 .000 \\
\hline SUBMARINO & $30 / 03 / 05$ & 135.125 .000 & 337.812 .500 & 472.937.500 \\
\hline LOCALIZA & $23 / 05 / 05$ & - & 264.802 .738 & 264.802 .738 \\
\hline TAM S/A & $14 / 06 / 05$ & 383.942 .160 & 164.546 .640 & 548.488 .800 \\
\hline ENERGIAS BR & $13 / 07 / 05$ & 1.170.132.696 & 14.570 .028 & 1.184 .702 .724 \\
\hline OHL BRASIL & $15 / 07 / 05$ & 135.000 .000 & 360.999 .990 & 495.999 .990 \\
\hline NOSSA CAIXA & $28 / 10 / 05$ & - & 953.955 .994 & 953.955 .994 \\
\hline COSAN & $18 / 11 / 05$ & 885.767 .328 & - & 885.767 .328 \\
\hline UOL & $16 / 12 / 05$ & 322.972 .416 & 301.708 .170 & 624.680 .586 \\
\hline COPASA & $08 / 02 / 06$ & 813.461.524 & - & 813.461.524 \\
\hline VIVAX & 08/02/06 & 58.800 .000 & 470.400 .000 & 529.200 .000 \\
\hline GAFISA & $17 / 02 / 06$ & 494.394 .000 & 432.594 .750 & 926.988 .750 \\
\hline COMPANY & $02 / 03 / 06$ & 208.000 .000 & 73.600 .000 & 281.600 .000 \\
\hline TOTVS & 09/03/06 & 344.800 .000 & 115.200 .000 & 460.000 .000 \\
\hline EQUATORIAL & $03 / 04 / 06$ & 185.600 .000 & 354.670 .000 & 540.270 .000 \\
\hline ABNOTE & $27 / 04 / 06$ & - & 480.434 .790 & 480.434 .790 \\
\hline CSU CARDSYST & $02 / 05 / 06$ & & & \\
\hline
\end{tabular}




\begin{tabular}{|c|c|c|c|c|}
\hline & & 100.288 .746 & 240.683.832 & 340.972 .578 \\
\hline BRASILAGRO & $02 / 05 / 06$ & 583.200 .000 & - & 583.200 .000 \\
\hline LUPATECH & $15 / 05 / 06$ & 155.048 .652 & 297.691.372 & 452.740 .024 \\
\hline GP INVEST 1 & $01 / 06 / 06$ & 705.980 .849 & - & 705.980 .849 \\
\hline DATASUL & $02 / 06 / 06$ & 150.697 .674 & 166.314 .834 & 317.012 .508 \\
\hline MMX MINER & $24 / 07 / 06$ & 1.118 .895 .570 & - & 1.118 .895 .570 \\
\hline ABYARA & 27/07/06 & 163.770 .250 & - & 163.770 .250 \\
\hline MEDIAL SAUDE & $22 / 09 / 06$ & 474.075 .000 & 268.212.328 & 742.287 .328 \\
\hline KLABINSEGALL & 09/10/06 & 360.573 .750 & 166.773 .750 & 527.347 .500 \\
\hline SANTOS BRAS & $13 / 10 / 06$ & 924.968.759 & 8.433.341 & 933.402 .100 \\
\hline M.DIASBRANCO & $18 / 10 / 06$ & - & 410.766 .300 & 410.766 .300 \\
\hline BRASCAN RES & $23 / 10 / 06$ & 940.000 .000 & 248.000 .000 & 1.188 .000 .000 \\
\hline PROFARMA & $26 / 10 / 06$ & 310.500 .000 & 90.562 .500 & 401.062 .500 \\
\hline TERNA PART & 27/10/06 & 371.360 .304 & 255.310.209 & 626.670 .513 \\
\hline ECODIESEL & $22 / 11 / 06$ & 378.932 .220 & - & 378.932 .220 \\
\hline ODONTOPREV & $01 / 12 / 06$ & 161.913 .052 & 360.118 .192 & 522.031 .244 \\
\hline POSITIVO INF & $11 / 12 / 06$ & 65.800 .000 & 538.312 .150 & 604.112 .150 \\
\hline LOPES BRASIL & $18 / 12 / 06$ & - & 474.720 .000 & 474.720 .000 \\
\hline DUFRYBRAS & 20/12/06 & - & 849.754 .937 & 849.754 .937 \\
\hline PDG REALT & $26 / 01 / 07$ & 432.263.062 & 216.131.538 & 648.394 .600 \\
\hline RODOBENSIMOB & $31 / 01 / 07$ & 448.500 .000 & - & 448.500 .000 \\
\hline CC DES IMOB & $31 / 01 / 07$ & 478.500 .000 & 43.499.986 & 521.999 .986 \\
\hline TECNISA & $01 / 02 / 07$ & 590.652 .257 & 200.650 .827 & 791.303.084 \\
\hline IGUATEMI & $07 / 02 / 07$ & 548.677 .440 & - & 548.677 .440 \\
\hline SAO MARTINHO & $12 / 02 / 07$ & 260.000 .000 & 163.680 .000 & 423.680 .000 \\
\hline GVT HOLDING & $16 / 02 / 07$ & 1.076 .400 .000 & - & 1.076 .400 .000 \\
\hline ANHANGUERA & $12 / 03 / 07$ & 426.825 .000 & 85.500 .000 & 512.325 .000 \\
\hline JBS & 29/03/07 & 1.216 .750 .400 & 400.000 .000 & 1.616 .750 .400 \\
\hline PINE & $02 / 04 / 07$ & 356.859 .900 & 160.328 .365 & 517.188 .265 \\
\hline EVEN & $02 / 04 / 07$ & 460.000 .000 & - & 460.000 .000 \\
\hline BR MALLS PAR & $05 / 04 / 07$ & 657.118 .665 & - & 657.118 .665 \\
\hline FER HERINGER & $12 / 04 / 07$ & 203.163.056 & 146.414 .302 & 349.577 .358 \\
\hline JHSF PART & $12 / 04 / 07$ & 432.400 .000 & - & 432.400 .000 \\
\hline METALFRIO & $13 / 04 / 07$ & 302.280 .500 & 150.670 .000 & 452.950 .500 \\
\hline BEMATECH & $19 / 04 / 07$ & 270.000 .030 & 136.630 .020 & 406.630 .050 \\
\hline CR2 & $23 / 04 / 07$ & 307.575 .000 & - & 307.575 .000 \\
\hline AGRA INCORP & $26 / 04 / 07$ & 752.348 .515 & 33.688 .985 & 786.037 .500 \\
\hline CREMER & $30 / 04 / 07$ & 210.000 .000 & 341.631 .500 & 551.631 .500 \\
\hline WILSON SONS & $30 / 04 / 07$ & 261.470 .000 & 444.499 .000 & 705.969 .000 \\
\hline SOFISA & $02 / 05 / 07$ & 497.336.256 & 7.207.728 & 504.543 .984 \\
\hline TARPON & $31 / 05 / 07$ & 443.828 .000 & - & 443.828 .000 \\
\hline INPAR S/A & $06 / 06 / 07$ & 756.000 .000 & - & 756.000 .000 \\
\hline PARANA & $14 / 06 / 07$ & & & \\
\hline
\end{tabular}




\begin{tabular}{|c|c|c|c|c|}
\hline & & 529.200 .000 & - & 529.200 .000 \\
\hline SLC AGRICOLA & $15 / 06 / 07$ & 308.000 .000 & 182.043 .750 & 490.043 .750 \\
\hline LOG-IN & $21 / 06 / 07$ & 443.333.318 & 404.913.337 & 848.246 .654 \\
\hline EZTEC & $22 / 06 / 07$ & 542.145 .813 & - & 542.145 .813 \\
\hline CRUZEIRO SUL & $26 / 06 / 07$ & 439.695 .785 & 133.820 .459 & 573.516.244 \\
\hline DAYCOVAL & 29/06/07 & 936.406 .104 & 156.067 .684 & 1.092 .473 .788 \\
\hline MARFRIG & $29 / 06 / 07$ & 654.065 .548 & 366.444 .452 & 1.020 .510 .000 \\
\hline TEGMA & $03 / 07 / 07$ & 290.228 .506 & 313.751 .494 & 603.980 .000 \\
\hline INDUSVAL & $12 / 07 / 07$ & 227.500.018 & 25.060 .753 & 252.560 .770 \\
\hline REDECARD & $13 / 07 / 07$ & 419.999 .985 & 4.222.694.700 & 4.642.694.685 \\
\hline INVEST TUR & $16 / 07 / 07$ & 945.000 .000 & - & 945.000 .000 \\
\hline MINERVA & 20/07/07 & 370.000 .000 & 74.000 .000 & 444.000 .000 \\
\hline PATAGONIA ${ }^{1}$ & $20 / 07 / 07$ & 7.619 .850 & 68.336 .750 & 75.956 .600 \\
\hline MRV & $23 / 07 / 07$ & 1.071.155.202 & 122.244 .798 & 1.193 .400 .000 \\
\hline KROTON & $23 / 07 / 07$ & 395.695 .287 & 83.078 .463 & 478.773 .750 \\
\hline GUARANI & $23 / 07 / 07$ & 665.758 .062 & - & 665.758 .062 \\
\hline TRIUNFO PART & $23 / 07 / 07$ & 304.438 .720 & 208.561.281 & 513.000 .000 \\
\hline ABC BRASIL & $25 / 07 / 07$ & 599.400 .000 & 9.450 .000 & 608.850 .000 \\
\hline SPRINGS & 27/07/07 & 446.500 .000 & 209.000 .000 & 655.500 .000 \\
\hline PROVIDENCIA & $27 / 07 / 07$ & 468.750 .000 & - & 468.750 .000 \\
\hline MULTIPLAN & $27 / 07 / 07$ & 688.327.725 & 236.200 .650 & 924.528.375 \\
\hline GENERALSHOPP & $30 / 07 / 07$ & 286.728 .400 & - & 286.728 .400 \\
\hline ESTACIO PART & $30 / 07 / 07$ & 268.164 .000 & 178.776 .000 & 446.940 .000 \\
\hline COSAN LTD $^{1}$ & $17 / 08 / 07$ & 275.016 .440 & - & 275.016 .440 \\
\hline SATIPEL & $21 / 09 / 07$ & 227.766 .344 & 184.774 .057 & 412.540 .401 \\
\hline SUL AMERICA & $05 / 10 / 07$ & 775.000 .000 & - & 775.000 .000 \\
\hline BICBANCO & $15 / 10 / 07$ & 492.915 .645 & 328.610 .430 & 821.526.075 \\
\hline TRISUL & $15 / 10 / 07$ & 330.281 .050 & - & 330.281 .050 \\
\hline TENDA & $15 / 10 / 07$ & 603.000 .000 & - & 603.000 .000 \\
\hline SEB & $18 / 10 / 07$ & 288.750 .000 & 123.750 .000 & 412.500 .000 \\
\hline MARISA & $22 / 10 / 07$ & 506.000 .000 & - & 506.000 .000 \\
\hline AGRENCO & $25 / 10 / 07$ & 666.187 .454 & - & 666.187.454 \\
\hline BOVESPA HLD & $26 / 10 / 07$ & - & 6.625.520.875 & 6.625.520.875 \\
\hline BR BROKERS & $29 / 10 / 07$ & 304.017 .100 & 395.087 .900 & 699.105 .000 \\
\hline AMIL & 29/10/07 & 994.700 .000 & 406.000 .000 & 1.400 .700 .000 \\
\hline HELBOR & 29/10/07 & 251.832.053 & - & 251.832 .053 \\
\hline LAEP & $31 / 10 / 07$ & 507.611 .108 & - & 507.611 .108 \\
\hline PANAMERICANO & 19/11/07 & 700.426 .000 & - & 700.426 .000 \\
\hline BMF & $30 / 11 / 07$ & - & 5.983.696.920 & 5.983 .696 .920 \\
\hline MPX ENERGIA & $14 / 12 / 07$ & 2.035.409.887 & - & 2.035.409.887 \\
\hline TEMPO PART & 19/12/07 & 393.750 .000 & 26.045 .600 & 419.795 .600 \\
\hline
\end{tabular}


Tabela 8 - Empresas emissoras - Segmento de Mercado, Classificação Setorial, Nr. de Investidores e

Participação de Estrangeiros (\%).

\begin{tabular}{|c|c|c|c|c|}
\hline NOME DE PREGÃO & $\begin{array}{l}\text { LISTAGEM NA } \\
\text { OFERTA }\end{array}$ & $\begin{array}{l}\text { CLASSIFICAÇÃO SETORIAL BOVESPA } \\
\text { (SEGMENTO) }\end{array}$ & $\begin{array}{c}\mathbf{N}^{\circ} \text { DE } \\
\text { INVESTIDORES }\end{array}$ & $\begin{array}{l}\text { PARTICIPAÇÃO } \\
\text { ESTRANGEIROS }^{2}\end{array}$ \\
\hline NATURA & NM & Prod. de Uso Pessoal & 5.460 & $67 \%$ \\
\hline GOL & N2 & Transporte Aéreo & 12.380 & $75 \%$ \\
\hline CPFL ENERGIA & NM & Energia Elétrica & 3.271 & $69 \%$ \\
\hline GRENDENE & NM & Calçados & 8.998 & $64 \%$ \\
\hline DASA & NM & Serv. Méd. Hospit., Análises e Diagnósticos & 3.482 & $68 \%$ \\
\hline PORTO SEGURO & NM & Seguradoras & 6.499 & $71 \%$ \\
\hline RENAR & NM & Alimentos Diversos & 1.781 & $5 \%$ \\
\hline SUBMARINO & NM & Produtos Diversos & 4.368 & $65 \%$ \\
\hline LOCALIZA & NM & Aluguel de Carros & 958 & $87 \%$ \\
\hline TAM S/A & N2 & Transporte Aéreo & 1.647 & $74 \%$ \\
\hline ENERGIAS BR & NM & Energia Elétrica & 1.473 & $26 \%$ \\
\hline OHL BRASIL & NM & Exploração de Rodovias & 1.367 & $70 \%$ \\
\hline NOSSA CAIXA & NM & Bancos & 8.983 & $71 \%$ \\
\hline COSAN & NM & Alimentos Diversos & 10.359 & $72 \%$ \\
\hline UOL & N2 & Programas e Serviços & 14.346 & $71 \%$ \\
\hline COPASA & NM & Água e Saneamento & 17.214 & $74 \%$ \\
\hline VIVAX & N2 & Televisão Por Assinatura & 9.017 & $69 \%$ \\
\hline GAFISA & NM & Construção Civil & 15.560 & $72 \%$ \\
\hline COMPANY & NM & Construção Civil & 13.701 & $64 \%$ \\
\hline TOTVS & NM & Programas e Serviços & 17.600 & $69 \%$ \\
\hline EQUATORIAL & N2 & Energia Elétrica & 7.886 & $77 \%$ \\
\hline ABNOTE & NM & Serviços Diversos & 16.861 & $70 \%$ \\
\hline CSU CARDSYST & NM & Serviços Diversos & 15.585 & $72 \%$ \\
\hline BRASILAGRO & NM & Exploração de Imóveis & 39 & $82 \%$ \\
\hline LUPATECH & NM & Motores, Compressores e Outros & 12.203 & $73 \%$ \\
\hline GP INVEST $^{1}$ & BDR & Holdings Diversificadas & 2.524 & $76 \%$ \\
\hline DATASUL & NM & Programas e Serviços & 5.973 & $72 \%$ \\
\hline MMX MINER & NM & Minerais Metálicos & 110 & $76 \%$ \\
\hline ABYARA & NM & Construção Civil & 37 & $83 \%$ \\
\hline MEDIAL SAUDE & NM & Serv. Méd. Hospit., Análises e Diagnósticos & 3.596 & $76 \%$ \\
\hline KLABINSEGALL & NM & Construção Civil & 5.131 & $65 \%$ \\
\hline SANTOS BRAS & N2 & Serviços de Apoio e Armazenagem & 4.873 & $77 \%$ \\
\hline M.DIASBRANCO & NM & Alimentos Diversos & 3.737 & $71 \%$ \\
\hline BRASCAN RES & NM & Construção Civil & 4.735 & $87 \%$ \\
\hline PROFARMA & NM & Medicamentos & 4.995 & $70 \%$ \\
\hline TERNA PART & N2 & Energia Elétrica & 7.326 & $65 \%$ \\
\hline ECODIESEL & NM & Exploração e/ou Refino & 9.841 & $59 \%$ \\
\hline ODONTOPREV & NM & Serv. Méd. Hospit., Análises e Diagnósticos & 9.772 & $63 \%$ \\
\hline
\end{tabular}




\begin{tabular}{|c|c|c|c|c|}
\hline POSITIVO INF & NM & Computadores e Equipamentos & 19.543 & $64 \%$ \\
\hline LOPES BRASIL & NM & Intermediação Imobiliária & 10.438 & $71 \%$ \\
\hline DUFRYBRAS & $\mathrm{BDR}$ & Produtos Diversos & 10.805 & $69 \%$ \\
\hline PDG REALT & NM & Construção Civil & 12.422 & $84 \%$ \\
\hline RODOBENSIMOB & NM & Construção Civil & 14.782 & $67 \%$ \\
\hline CC DES IMOB & NM & Construção Civil & 23.552 & $48 \%$ \\
\hline TECNISA & NM & Construção Civil & 18.216 & $59 \%$ \\
\hline IGUATEMI & NM & Exploração de Imóveis & 18.100 & $72 \%$ \\
\hline SAO MARTINHO & NM & Alimentos Diversos & 25.864 & $53 \%$ \\
\hline GVT HOLDING & NM & Telefonia Fixa & 15.645 & $76 \%$ \\
\hline ANHANGUERA & N2 & Serviços Educacionais & 14.651 & $76 \%$ \\
\hline JBS & NM & Carnes e Derivados & 23.690 & $74 \%$ \\
\hline PINE & N1 & Bancos & 20.668 & $78 \%$ \\
\hline EVEN & NM & Construção Civil & 11.634 & $53 \%$ \\
\hline BR MALLS PAR & NM & Exploração de Imóveis & 14.518 & $68 \%$ \\
\hline FER HERINGER & NM & Fertilizantes e Defensivos & 9.770 & $65 \%$ \\
\hline JHSF PART & NM & Construção Civil & 4.749 & $89 \%$ \\
\hline METALFRIO & NM & Equipamentos Elétricos & 9.970 & $57 \%$ \\
\hline BEMATECH & NM & Computadores e Equipamentos & 9.331 & $70 \%$ \\
\hline CR2 & NM & Construção Civil & 2.926 & $0 \%$ \\
\hline AGRA INCORP & NM & Construção Civil & 5.651 & $67 \%$ \\
\hline CREMER & NM & Medicamentos e Outros Produtos & 9.717 & $76 \%$ \\
\hline WILSON SONS & BDR & Serviços de Apoio e Armazenagem & 12.393 & $74 \%$ \\
\hline SOFISA & N1 & Bancos & 7.521 & $76 \%$ \\
\hline TARPON & BDR & Holdings Diversificadas & 10.949 & $87 \%$ \\
\hline INPAR S/A & NM & Construção Civil & 10.114 & $70 \%$ \\
\hline PARANA & N1 & Bancos & 8.800 & $78 \%$ \\
\hline SLC AGRICOLA & NM & Alimentos Diversos & 10.166 & $70 \%$ \\
\hline LOG-IN & NM & Transporte Hidroviário & 28.172 & $75 \%$ \\
\hline EZTEC & NM & Construção Civil & 5.802 & $68 \%$ \\
\hline CRUZEIRO SUL & N1 & Bancos & 4.442 & $59 \%$ \\
\hline DAYCOVAL & $\mathrm{N} 1$ & Bancos & 8.014 & $70 \%$ \\
\hline MARFRIG & NM & Carnes e Derivados & 5.527 & $68 \%$ \\
\hline TEGMA & NM & Transporte Rodoviário & 7.147 & $59 \%$ \\
\hline INDUSVAL & N1 & Bancos & 348 & $88 \%$ \\
\hline REDECARD & NM & Serviços Financeiros Diversos & 31.297 & $72 \%$ \\
\hline INVEST TUR & NM & Exploração de Imóveis & 114 & $87 \%$ \\
\hline MINERVA & NM & Carnes e Derivados & 12.115 & $62 \%$ \\
\hline 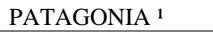 & BDR & Bancos & 2.917 & $97 \%$ \\
\hline MRV & NM & Construção Civil & 16.745 & $73 \%$ \\
\hline KROTON & N2 & Serviços Educacionais & 12.081 & $70 \%$ \\
\hline GUARANI & NM & Alimentos Diversos & 12.750 & $45 \%$ \\
\hline
\end{tabular}




\begin{tabular}{|c|c|c|c|c|}
\hline TRIUNFO PART & NM & Exploração de Rodovias & 7.427 & $75 \%$ \\
\hline ABC BRASIL & N2 & Bancos & 6.364 & $65 \%$ \\
\hline SPRINGS & NM & Fios e Tecidos & 7.592 & $37 \%$ \\
\hline PROVIDENCIA & NM & Materiais Diversos & 11.615 & $67 \%$ \\
\hline MULTIPLAN & N2 & Exploração de Imóveis & 25.531 & $64 \%$ \\
\hline GENERALSHOPP & NM & Exploração de Imóveis & 5.168 & $66 \%$ \\
\hline ESTACIO PART & N2 & Serviços Educacionais & 11.320 & $64 \%$ \\
\hline COSAN LTD ${ }^{1}$ & BDR & Alimentos Diversos & 1.819 & $93 \%$ \\
\hline SATIPEL & NM & Madeira & 7.211 & $69 \%$ \\
\hline SUL AMERICA & N2 & Seguradoras & 19.979 & $72 \%$ \\
\hline BICBANCO & N1 & Bancos & 6.257 & $85 \%$ \\
\hline TRISUL & $\mathrm{NM}$ & Construção Civil & 2.713 & $91 \%$ \\
\hline TENDA & NM & Construção Civil & 10.636 & $66 \%$ \\
\hline SEB & N2 & Serviços Educacionais & 3.875 & $80 \%$ \\
\hline MARISA & NM & Tecidos, Vestuário e Calçados & 13.733 & $64 \%$ \\
\hline AGRENCO & BDR & Alimentos & 908 & $88 \%$ \\
\hline BOVESPA HLD & NM & Serviços Financeiros Diversos & 67.914 & $78 \%$ \\
\hline BR BROKERS & NM & Intermediação Imobiliária & 130 & $98 \%$ \\
\hline AMIL & NM & Serv. Méd. Hospit., Análises e Diagnósticos & 4.675 & $80 \%$ \\
\hline HELBOR & NM & Construção Civil & 845 & $56 \%$ \\
\hline LAEP & BDR & Laticínios & 706 & $64 \%$ \\
\hline PANAMERICANO & N1 & Bancos & 21.792 & $67 \%$ \\
\hline BMF & NM & Serviços Financeiros Diversos & 260.946 & $77 \%$ \\
\hline MPX ENERGIA & NM & Energia Elétrica & 325 & $71 \%$ \\
\hline TEMPO PART & NM & Serv. Méd. Hospit., Análises e Diagnósticos & 3.938 & $84 \%$ \\
\hline
\end{tabular}

Fonte: Bovespa

${ }^{1}$ Dados referentes somente à ("Oferta Brasileira").

${ }^{2}$ Participação no volume antes da Recompra no Âmbito das Atividades de Estabilização.

Tabela 9 - Emissões por segmento de mercado da Bovespa

\begin{tabular}{|r|rr|r|rr|}
\hline NM & N2 & N1 & BDR \\
\hline & & 14 & & 8 & \\
\hline
\end{tabular}




\section{O CICLO DE ABERTURAS DE CAPITAL NO PERÍODO 2004/2007 - ANÁLISE QUANTITATIVA}

No capítulo anterior, buscamos conhecer, de maneira qualitativa, o atual ciclo de aberturas de capital. Buscou-se conhecer aspectos relevantes desse período, além de efetuarmos uma comparação histórica com o ciclo dos anos 70.

Neste capítulo, daremos continuidade à análise do ciclo atual, no entanto, com um enfoque mais quantitativo.

Nesse sentido, faremos uma análise das emissões selecionadas, apresentadas no capítulo 3, sob três diferentes enfoques:

(i) Retorno em relação ao índice Bovespa: verificaremos como se comportaram os preços dessas ações no período posterior ao IPO. Essa verificação ocorrerá tanto para o primeiro dia, quanto para períodos mais longos, conforme descrição e detalhamento adiante;

(ii) Retorno nominal das ações: analisaremos o retorno individual ... usar CAGR;

(iii) Valor de emissão X Valor Patrimonial: comparação do preço de abertura com os valores patrimoniais dessas ações, processo também detalhado adiante.

Os objetivos deste capítulo são basicamente dois, a saber:

(i) identificar o comportamento dos preços no curto e longo prazo, a fim de verificar se existe um comportamento padrão para os preços dessas ações;

(ii) considerando esse comportamento de preços, e comparando-o com os valores patrimoniais das ações, buscar identificar se essas novas emissões permitem uma alocação adequada tanto para vendedores quanto para compradores, ou se existem detalhes não observados ou ainda não devidamente caracterizados.

\subsection{Comportamento dos retornos}


Neste tópico, verificaremos como se comportaram os preços dessas ações após a abertura do capital.

Existe vasta literatura a respeito do comportamento dos preços das ações após o IPO. Esses estudos geralmente identificam ... citar estudos

Na tabela a seguir (Tabela 10), apresentamos os retornos das ações emitidas no período 2004/2007, em diferentes períodos:

Tabela 10 - Retorno dos IPOs em diferentes prazos - Base 100 na data de início da série

\begin{tabular}{|c|c|c|c|c|c|c|c|c|c|c|c|}
\hline Empresa & $\begin{array}{c}\text { Data do Início da } \\
\text { Série } \\
\end{array}$ & $1^{\circ} \mathrm{dia}$ & 30 dias & 90 dias & $\begin{array}{l}180 \\
\text { dias }\end{array}$ & 1 ano & $\begin{array}{l}540 \\
\text { dias }\end{array}$ & 2 anos & 3 anos & 20.05 .08 & 31.10 .08 \\
\hline Natura & $25 / 05 / 04$ & 114,34 & 117,65 & 116,00 & 133,09 & 156,19 & 160,99 & 178,07 & 142,38 & 82,91 & 155,96 \\
\hline Gol & $23 / 06 / 04$ & 106,03 & 92,65 & 102,54 & 134,27 & 114,53 & 154,40 & 176,02 & 96,06 & 30,18 & 21,09 \\
\hline CPFL Energia & $28 / 09 / 04$ & 100,15 & 96,79 & 90,40 & 94,02 & 110,03 & 123,88 & 119,16 & 100,19 & 94,20 & 157,35 \\
\hline Grendene & $28 / 10 / 04$ & 111,49 & 97,94 & 92,58 & 53,71 & 44,74 & 34,20 & 36,48 & 31,33 & 20,16 & 27,22 \\
\hline Dasa & $18 / 11 / 04$ & 120,54 & 109,15 & 138,46 & 145,45 & 159,09 & 164,05 & 142,40 & 67,93 & 70,68 & 81,91 \\
\hline Porto Seguro & $19 / 11 / 04$ & 104,62 & 93,93 & 128,69 & 110,67 & 117,45 & 149,01 & 180,28 & 162,33 & 113,08 & 129,53 \\
\hline Renar & $25 / 02 / 05$ & 102,28 & 86,50 & 72,58 & 46,68 & 32,67 & 32,61 & 31,66 & 58,68 & 101,82 & 97,11 \\
\hline $\begin{array}{l}\text { B2W Varejo - ex- } \\
\text { Submarino }\end{array}$ & $29 / 03 / 05$ & 97,63 & 83,24 & 83,87 & 107,24 & 167,01 & 139,90 & 209,30 & 137,62 & 130,76 & 103,21 \\
\hline Localiza & $20 / 05 / 05$ & 101,27 & 95,30 & 125,90 & 164,31 & 255,22 & 297,48 & 300,44 & 205,31 & 205,31 & 164,89 \\
\hline Energias BR & $12 / 07 / 05$ & 109,80 & 128,92 & 111,22 & 124,98 & 112,03 & 108,80 & 107,24 & 84,22 & 70,63 & 99,43 \\
\hline OHL Brasil & $14 / 07 / 05$ & 103,91 & 102,59 & 108,59 & 112,72 & 90,19 & 97,03 & 93,52 & 64,38 & 53,35 & 47,66 \\
\hline TAM S/A & $09 / 08 / 05$ & nd & nd & nd & nd & nd & nd & nd & nd & nd & nd \\
\hline Nossa Caixa & $27 / 10 / 05$ & 116,83 & 107,46 & 131,58 & 116,40 & 128,21 & 66,98 & 49,74 & 100,72 & 39,59 & 95,20 \\
\hline Cosan & 17/11/05 & 115,78 & 125,48 & 178,68 & 259,63 & 176,07 & 176,19 & 77,00 & 64,72 & 73,29 & 57,02 \\
\hline Uol & $15 / 12 / 05$ & 116,32 & 99,14 & 79,37 & 60,35 & 99,53 & 42,79 & 34,61 & $32,40 *$ & 21,09 & 32,71 \\
\hline Copasa & $07 / 02 / 06$ & 104,80 & 100,19 & 79,30 & 78,33 & 98,86 & 88,99 & 66,35 & & 68,38 & 61,92 \\
\hline Vivax & $07 / 02 / 06$ & 110,80 & 108,47 & 116,38 & 127,47 & 151,95 & nd & nd & & nd & nd \\
\hline Gafisa & $16 / 02 / 06$ & 128,90 & 127,36 & 119,35 & 140,67 & 150,95 & 108,43 & 97,67 & & 97,70 & 85,50 \\
\hline Company & $01 / 03 / 06$ & 118,91 & 114,20 & 84,33 & 92,88 & 129,92 & 153,60 & 115,83 & & 87,20 & 79,36 \\
\hline Totvs & $08 / 03 / 06$ & 109,11 & 109,86 & 115,09 & 127,47 & 142,09 & 130,13 & 100,91 & & 97,02 & 120,71 \\
\hline Equatorial & $31 / 03 / 06$ & 114,65 & 100,51 & 107,18 & 114,53 & 106,85 & 89,74 & 79,29 & & 71,21 & 100,99 \\
\hline Abnote & $26 / 04 / 06$ & 107,64 & 95,32 & 94,61 & 107,67 & 94,48 & 74,14 & 62,12 & & 58,31 & 73,86 \\
\hline BrasilAgro & $28 / 04 / 06$ & 108,25 & 126,37 & nd & 97,50 & 106,50 & 75,10 & 67,98 & & 71,37 & 102,64 \\
\hline CSU CardSystem & $28 / 04 / 06$ & 95,67 & 98,68 & 72,34 & 74,12 & 52,61 & 26,23 & 15,71 & & 16,17 & 12,82 \\
\hline Lupatech & $12 / 05 / 06$ & 108,49 & 119,84 & 126,16 & 122,54 & 147,54 & 151,39 & 151,06 & & 154,66 & 91,07 \\
\hline GP Invest & $31 / 05 / 06$ & 96,86 & 100,66 & 111,80 & 114,40 & 150,78 & 130,19 & 106,95 & & 104,38 & 86,73 \\
\hline Datasul & $01 / 06 / 06$ & 92,86 & 105,06 & 84,83 & 97,94 & 95,04 & 68,83 & 63,31 & & 60,76 & nd \\
\hline MMX Miner & $21 / 07 / 06$ & 97,91 & 97,32 & 90,20 & 101,33 & 157,77 & 257,97 & 229,43 & & 261,91 & 86,40 \\
\hline Abyara & $26 / 07 / 06$ & 99,21 & 103,05 & 118,40 & 138,43 & 255,30 & 123,79 & 103,07 & & 103,70 & 18,44 \\
\hline Medial Saude & $21 / 09 / 06$ & 102,88 & 95,58 & 89,62 & 92,31 & 63,99 & 49,98 & 38,86 & & 43,06 & 29,20 \\
\hline Klabinsegall & $06 / 10 / 06$ & 98,79 & 93,15 & 108,97 & 93,81 & 76,21 & 36,04 & 15,94 & & 41,29 & 19,25 \\
\hline Santos BRP & $12 / 10 / 06$ & 106,15 & 99,43 & 104,39 & 90,09 & 67,00 & 72,02 & 50,06 & & 65,86 & 45,08 \\
\hline M. Diasbranco & $17 / 10 / 06$ & 101,27 & 97,96 & 104,89 & 104,09 & 79,36 & 59,18 & 96,39 & & 64,54 & 82,69 \\
\hline Brascan Res & $20 / 10 / 06$ & 104,67 & 113,03 & 97,21 & 68,19 & 52,72 & 32,76 & 23,82 & & 33,04 & 20,56 \\
\hline
\end{tabular}




\begin{tabular}{|c|c|c|c|c|c|c|c|c|c|c|}
\hline Profarma & $25 / 10 / 06$ & 114,21 & 117,06 & 141,65 & 113,27 & 95,30 & 81,42 & 47,10 & 66,76 & 45,13 \\
\hline Terna Part & $26 / 10 / 06$ & 109,92 & 108,73 & 100,74 & 105,77 & 97,35 & 98,13 & 121,67 & 88,49 & 98,68 \\
\hline Ecodiesel & $21 / 11 / 06$ & 98,36 & 91,03 & 86,36 & 86,24 & 44,03 & 26,26 & 6,98 & 26,62 & 8,09 \\
\hline Odontoprev & $30 / 11 / 06$ & 117,37 & 115,16 & 140,74 & 149,02 & 120,06 & 91,32 & $110,06^{*}$ & 90,06 & 115,30 \\
\hline Positivo Inf & $08 / 12 / 06$ & 97,78 & 101,88 & 120,21 & 140,14 & 134,79 & 48,84 & $29,62^{*}$ & 45,21 & 30,39 \\
\hline Lopes Brasil & $15 / 12 / 06$ & 115,98 & 117,73 & 105,27 & 100,16 & 105,79 & 105,53 & $32,45 *$ & 100,88 & 48,94 \\
\hline Dufrybras & $19 / 12 / 06$ & 110,13 & 112,38 & 129,07 & 127,80 & 118,67 & 91,95 & $54,18 *$ & 87,04 & 58,73 \\
\hline PDG Realt & $25 / 01 / 07$ & 100,62 & 97,11 & 92,38 & 132,39 & 107,82 & 123,75 & & 113,41 & 97,46 \\
\hline CC Des Imob & $30 / 01 / 07$ & 96,55 & 82,35 & 69,21 & 84,09 & 49,40 & 39,52 & & 42,40 & 16,75 \\
\hline Rodobensimob & $30 / 01 / 07$ & 115,11 & 113,21 & 91,77 & 94,38 & 71,88 & 77,83 & & 72,99 & 42,78 \\
\hline Tecnisa & $31 / 01 / 07$ & 103,44 & 95,40 & 79,10 & 80,42 & 48,79 & 43,63 & & 40,96 & 26,48 \\
\hline Iguatemi & $06 / 02 / 07$ & 113,92 & 106,16 & 99,96 & 83,96 & 68,52 & 54,61 & & 52,47 & 43,12 \\
\hline GVT Holding & $15 / 02 / 07$ & 127,52 & 132,73 & 145,04 & 170,17 & 153,67 & 167,79 & & 134,11 & 161,11 \\
\hline Anhanguera & $09 / 03 / 07$ & 121,07 & 122,97 & 128,85 & 139,23 & 108,98 & 133,64 & & 101,39 & 105,23 \\
\hline JBS & $28 / 03 / 07$ & 85,82 & 90,36 & 80,10 & 75,31 & 61,08 & 55,85 & & 63,16 & 58,96 \\
\hline Even & $30 / 03 / 07$ & 96,96 & 108,61 & 125,95 & 114,22 & 66,61 & 32,32 & & 63,70 & 29,97 \\
\hline Pine & $30 / 03 / 07$ & 98,34 & 88,59 & 76,89 & 94,49 & 44,67 & 33,11 & & 47,07 & 32,82 \\
\hline BR Malls Par & $04 / 04 / 07$ & 105,12 & 94,46 & 141,87 & 120,22 & 78,02 & 74,32 & & 81,86 & 66,64 \\
\hline Fer Heringer & $11 / 04 / 07$ & 99,43 & 101,98 & 117,05 & 114,86 & 92,46 & 41,24 & & 84,51 & 34,87 \\
\hline JHSF Part & $11 / 04 / 07$ & 102,86 & 96,83 & 124,94 & 84,55 & 58,44 & 33,13 & & 64,28 & 31,67 \\
\hline Metalfrio & $12 / 04 / 07$ & 106,59 & 105,20 & 123,81 & 75,65 & 88,52 & 97,55 & & 76,45 & 57,35 \\
\hline Bematech & $18 / 04 / 07$ & 111,94 & 103,26 & 99,40 & 73,97 & 36,51 & 39,79 & & 36,88 & 34,67 \\
\hline CR2 & $20 / 04 / 07$ & 95,48 & 74,95 & 94,62 & 85,60 & 34,98 & 29,09 & & 45,42 & 29,57 \\
\hline Agra Incorp & $25 / 04 / 07$ & 107,79 & 132,05 & 169,89 & 127,02 & 67,69 & 20,23 & & 60,81 & 18,51 \\
\hline Cremer & $27 / 04 / 07$ & 100,56 & 108,73 & 115,77 & 87,05 & 63,44 & 72,38 & & 56,50 & 70,51 \\
\hline Wilson Sons & $27 / 04 / 07$ & 101,53 & 101,11 & 103,71 & 70,57 & 62,75 & 68,73 & & 61,63 & 54,87 \\
\hline Sofisa & $30 / 04 / 07$ & 110,50 & 108,66 & 112,14 & 96,63 & 50,66 & 36,79 & & 56,00 & 37,09 \\
\hline Tarpon & $30 / 05 / 07$ & 100,50 & 93,94 & 76,79 & 79,58 & 77,82 & $80,79 *$ & & 81,75 & 81,47 \\
\hline Inpar S/A & $05 / 06 / 07$ & 102,49 & 111,40 & 100,45 & 74,86 & 46,88 & & & 45,45 & 11,01 \\
\hline Parana & $13 / 06 / 07$ & 95,14 & 87,66 & 82,38 & 54,07 & 52,17 & & & 53,53 & 28,27 \\
\hline SLC Agricola & $14 / 06 / 07$ & 99,93 & 97,84 & 108,07 & 97,69 & 174,56 & & & 162,76 & 115,66 \\
\hline Log-In & $20 / 06 / 07$ & 113,49 & 99,34 & 84,95 & 74,95 & 78,16 & & & 59,26 & 46,77 \\
\hline Eztec & $21 / 06 / 07$ & 96,14 & 118,94 & 91,98 & 64,57 & 35,58 & & & 40,61 & 26,71 \\
\hline Cruzeiro Sul & $25 / 06 / 07$ & 96,53 & 99,61 & 85,11 & 65,51 & 39,07 & & & 46,61 & 48,97 \\
\hline Daycoval & $28 / 06 / 07$ & 101,60 & 103,52 & 94,03 & 85,99 & 59,48 & & & 66,82 & 45,35 \\
\hline Marfrig & $28 / 06 / 07$ & 107,22 & 119,77 & 100,08 & 76,92 & 101,69 & & & 90,95 & 90,81 \\
\hline Tegma & $02 / 07 / 07$ & 101,32 & 122,66 & 95,41 & 76,65 & 61,06 & & & 56,69 & 31,14 \\
\hline Indusval & $11 / 07 / 07$ & 99,81 & 106,08 & 111,62 & 103,88 & 74,20 & & & 74,27 & 43,59 \\
\hline Redecard & $12 / 07 / 07$ & 124,01 & 125,54 & 119,24 & 90,40 & 96,63 & & & 98,39 & 144,00 \\
\hline Invest Tur & $13 / 07 / 07$ & 105,49 & 115,43 & 85,05 & 70,91 & 77,52 & & & 62,73 & 62,66 \\
\hline Banco Patagonia & $19 / 07 / 07$ & 105,62 & 107,63 & 81,88 & 88,05 & 39,08 & & & 49,78 & 41,62 \\
\hline Minerva & $19 / 07 / 07$ & 105,02 & 113,29 & 94,16 & 52,33 & 48,21 & & & 44,57 & 16,82 \\
\hline Guarani & $20 / 07 / 07$ & 96,04 & 100,31 & 76,86 & 76,36 & 62,56 & & & 57,47 & 26,72 \\
\hline Kroton & $20 / 07 / 07$ & 112,12 & 113,74 & 94,33 & 61,47 & 73,66 & & & 66,09 & 31,63 \\
\hline MRV & $20 / 07 / 07$ & 118,01 & 139,19 & 124,44 & 116,41 & 125,71 & & & 111,62 & 68,36 \\
\hline Triunfo Part & $20 / 07 / 07$ & 98,98 & 92,16 & 74,37 & 62,04 & 50,40 & & & 51,40 & 29,21 \\
\hline Abc Brasil & $24 / 07 / 07$ & 93,99 & 93,03 & 98,99 & 73,96 & 66,04 & & & 59,95 & 47,80 \\
\hline Multiplan & $26 / 07 / 07$ & 97,76 & 99,25 & 85,49 & 68,46 & 66,33 & & & 60,11 & 61,91 \\
\hline
\end{tabular}




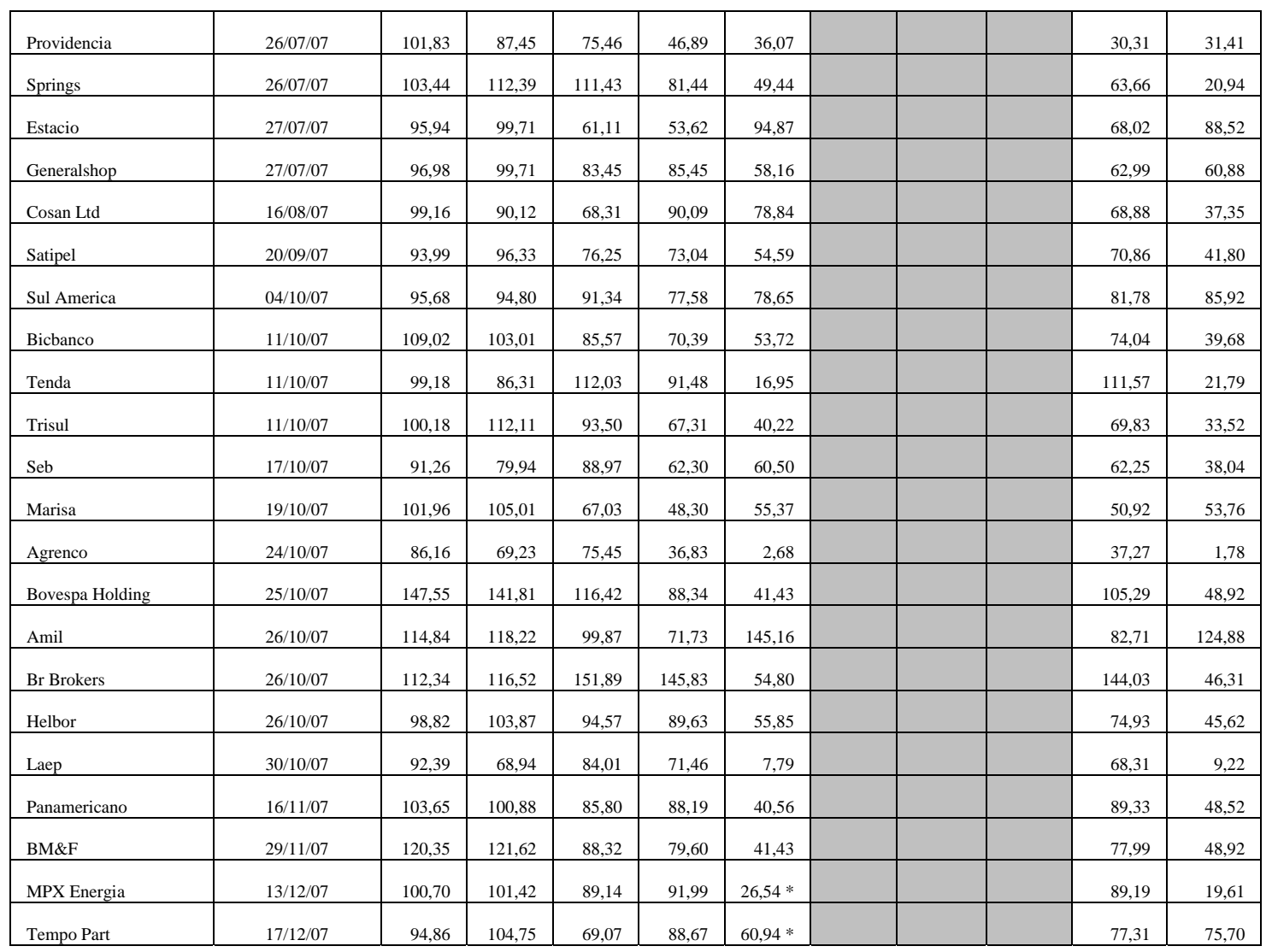

Fonte: Economática

* Utilizada cotação de 26.11 .08

nd = não disponível

Na tabela a seguir (Tabela 11), apresentamos as estatísticas descritivas dos retornos indicados na tabela anterior:

Tabela 11 - Retorno dos IPOs em diferentes prazos - Estatísticas descritivas

\begin{tabular}{|c|c|c|c|c|c|c|c|c|c|c|}
\hline & $1^{\circ}$ dia & 30 dias & 90 dias & 180 dias & 1 ano & 540 dias & 2 anos & 3 anos & 20.05 .08 & 31.10 .08 \\
\hline Maior & 147,55 & 141,81 & 178,68 & 259,63 & 255,30 & 297,48 & 300,44 & 205,31 & 261,91 & 164,89 \\
\hline Menor & 85,82 & 68,94 & 61,11 & 36,83 & 2,68 & 20,23 & 6,98 & 31,33 & 16,17 & 1,78 \\
\hline Desvio-padrão & 9,54 & 13,65 & 22,40 & 31,75 & 46,12 & 55,73 & 64,38 & 48,40 & 35,88 & 37,29 \\
\hline
\end{tabular}

De fato, a média dos retornos para o primeiro dia é positiva, com um retorno médio de 5,10\% acima da variação do Índice Bovespa. Ademais, observa-se que essa média de retorno vai gradativamente diminuindo, à medida que vai aumentando o prazo de observação dos preços. Até o prazo de 90 dias, a média dos retornos é positiva. No entanto, a partir do prazo de 180 dias, esses retornos passam a ficar inferiores ao retorno do Ibovespa. 
Já em relação ao desvio-padrão, ocorre o mesmo, ou seja, à medida que aumentamos o prazo das cotações, essa medida estatística também aumenta, e de maneira bastante expressiva. Se considerarmos que o Risco é, por definição, “a variabilidade do retorno”, podemos dizer que o risco dessas ações aumenta à medida que aumenta o tempo de distância em relação ao IPO, o que significa um aumento do risco de manutenção desses papéis em uma carteira de investimentos de maior prazo de maturação.

\subsection{Retorno Nominal das Ações}

Neste tópico, faremos uma análise dos retornos nominais das ações emitidas no período 2004/2007.

Partimos de uma base 100, ou seja, a todas as ações é atribuído um valor 100 na data de lançamento. A partir dessa data, esses valores são corrigidos de acordo com a variação observada na ação ao longo do tempo, com os devidos ajustes em função dos proventos, inclusive dividendos, que tenham sido distribuídos nesse período.

Esses valores foram calculados até duas datas específicas, a saber:

(i) 20.05.08: essa data corresponde ao ponto histórico mais alto do índice Bovespa - 73.516. Até essa data, o mercado de ações vinha subindo fortemente, impulsionado pelo fato do Brasil ter sido elevado a grau de investimento por uma importante agência internacional de classificação de risco;

(ii) 31.10.08: data escolhida aleatoriamente. Após atingir o pico em maio de 2008, o mercado de ações passou a cair vertiginosamente alguns meses depois, em função da crise no mercado imobiliário americano. Em 31.10.08, o índice Bovespa estava em ... .

A escolha dessas duas datas tem objetivos definidos e muito claros, detalhados a seguir:

(i) 20.05.08: como o mercado vinha subindo fortemente até essa data, esse fato deveria estar impulsionando a grande maioria das ações cotadas na Bovespa, 
inclusive os IPOs aqui estudados. Em conseqüência, o efeito do mercado (risco sistemático) estaria atuando positivamente sobre o preço do papel, sendo que qualquer comportamento negativo na ação decorreria apenas de fatores específicos do título (risco não sistemático, ou específico), identificados ou atribuídos pelo mercado de maneira específica;

(ii) 31.10.08: tal qual ocorrido no ciclo de aberturas de capital do período 1968/72, uma queda forte do mercado deixou patente a especulação que vinha ocorrendo sobre essas novas emissões. Numa correção do mercado, as fragilidades do papel são potencializadas em função do risco sistêmico, fazendo com que esses papéis tenham quedas acentuadas. O objetivo é verificar se tal fato vem ocorrendo também na queda atual. Ademais, estaríamos observando as emissões do atual ciclo em dois períodos distintos, um período de alta, até 20.05.08, e um período de baixa, até 31.10.08.

As informações, na forma descrita acima, foram obtidas do sistema Economática, sendo posteriormente estruturadas na tabela abaixo (Tabela 12):

Tabela 12 - Retorno nominal dos IPOs - Base 100 na data de início da série

\begin{tabular}{|c|c|c|c|c|c|c|c|}
\hline \multirow[t]{2}{*}{ Empresa } & \multirow[t]{2}{*}{ Código na Bolsa } & \multirow[t]{2}{*}{$\begin{array}{l}\text { Data do } \\
\text { Início da } \\
\text { Série }\end{array}$} & \multicolumn{2}{|c|}{$\begin{array}{l}\text { Cotação, em moeda } \\
\text { original 100, ajustada por } \\
\text { proventos }\end{array}$} & \multicolumn{3}{|c|}{ Valores em Reais } \\
\hline & & & 20.05 .08 & 31.10 .08 & $\begin{array}{l}\text { Valor Original da } \\
\text { Emissão } \\
\end{array}$ & Valor em 20.05.08 & Valor em 31.10.08 \\
\hline Natura & NATU3 & $25 / 05 / 04$ & 323,22 & 308,09 & $768.120 .636,50$ & $2.482 .703 .494,00$ & 2.366.527.716,01 \\
\hline Gol & GOLL4 & $23 / 06 / 04$ & 106,47 & 37,72 & $1.009 .859 .275,00$ & $1.075 .210 .488,32$ & $380.871 .389,02$ \\
\hline CPFL Energia & CPFE3 & $28 / 09 / 04$ & 298,12 & 252,35 & $940.556 .882,16$ & 2.803.964.767,95 & 2.373.531.584,08 \\
\hline Grendene & GRND3 & $28 / 10 / 04$ & 64,65 & 44,24 & $616.900 .000,00$ & $398.831 .723,79$ & $272.904 .225,78$ \\
\hline Dasa & DASA3 & $18 / 11 / 04$ & 215,24 & 126,40 & $437.384 .060,00$ & $941.404 .372,81$ & $552.860 .312,52$ \\
\hline Porto Seguro & PSSA3 & $19 / 11 / 04$ & 345,89 & 200,80 & 442.958.118,75 & 1.532.139.132,15 & $889.468 .879,97$ \\
\hline Renar & RNAR3 & $25 / 02 / 05$ & 263,34 & 127,28 & $16.000 .000,00$ & 42.134.062,93 & $20.364 .797,08$ \\
\hline B2W Varejo - ex-Submarino & SUBA3+BTOW3 & 29/03/05 & 371,99 & 148,80 & $543.878 .125,00$ & 2.023.166.462,18 & $809.266 .584,86$ \\
\hline Localiza & RENT3 & $20 / 05 / 05$ & 615,50 & 250,52 & $284.039 .937,50$ & 1.748.273.262,13 & $711.565 .603,02$ \\
\hline Energias BR & ENBR3 & $12 / 07 / 05$ & 203,33 & 145,06 & $1.184 .702 .724,00$ & $2.408 .835 .746,81$ & 1.718.498.672,99 \\
\hline OHL Brasil & OHLB3 & $14 / 07 / 05$ & 151,33 & 68,50 & 495.999.990,00 & $750.598 .673,93$ & $339.759 .627,01$ \\
\hline Tam & TAMM3 & $09 / 08 / 05$ & nd & nd & nd & nd & nd \\
\hline Nossa Caixa & BNCA3 & $27 / 10 / 05$ & 99,90 & 121,75 & 953.955.994,00 & 953.017.486,68 & 1.161.413.027,91 \\
\hline Cosan & CSAN3 & $17 / 11 / 05$ & 173,32 & 68,34 & $885.767 .328,00$ & $1.535 .241 .330,00$ & $605.332 .471,47$ \\
\hline Uol & UOLL4 & $15 / 12 / 05$ & 46,72 & 36,71 & $532.135 .314,00$ & $248.626 .371,70$ & $195.349 .292,05$ \\
\hline Copasa & CSMG3 & $07 / 02 / 06$ & 137,50 & 63,10 & 813.461.524,00 & 1.118.513.320,67 & 513.269.073,69 \\
\hline Vivax & VVAX11 & $07 / 02 / 06$ & nd & nd & nd & nd & nd \\
\hline Gafisa & GFSA3 & $16 / 02 / 06$ & 187,76 & 83,26 & $926.988 .750,00$ & $1.740 .471 .269,49$ & $771.856 .773,40$ \\
\hline Company & CPNY3 & $01 / 03 / 06$ & 163,64 & 75,47 & $281.600 .000,00$ & $460.810 .019,76$ & $212.512 .351,06$ \\
\hline
\end{tabular}




\begin{tabular}{|c|c|c|c|c|c|c|c|}
\hline Totvs & TOTS3 & 08/03/06 & 191,27 & 120,60 & $460.000 .000,00$ & $879.857 .204,47$ & $554.757 .423,82$ \\
\hline Equatorial & EQTL11+EQTL3 & $31 / 03 / 06$ & 137,94 & 99,15 & $540.000 .000,00$ & $744.875 .263,12$ & $535.392 .877,08$ \\
\hline Abnote & ABNB3 & $26 / 04 / 06$ & 106,09 & 68,10 & $552.500 .000,00$ & $586.133 .630,88$ & $376.246 .355,87$ \\
\hline BrasilAgro & AGRO3 & $28 / 04 / 06$ & 130,00 & 90,18 & $583.200 .000,00$ & $758.160 .000,00$ & $525.929 .760,00$ \\
\hline CSU CardSystem & CARD3 & $28 / 04 / 06$ & 29,44 & 11,83 & $392.118 .462,00$ & $115.457 .102,70$ & $46.400 .684,67$ \\
\hline Lupatech & LUPA3 & $12 / 05 / 06$ & 282,77 & 84,37 & $483.036 .224,00$ & $1.365 .871 .564,22$ & 407.558.450,61 \\
\hline GP Invest & GPIV11 & $31 / 05 / 06$ & 210,07 & 88,45 & $706.000 .000,00$ & 1.483.102.689,37 & $624.464 .290,26$ \\
\hline Datasul & DSUL3 & $01 / 06 / 06$ & 118,34 & nd & $364.564 .350,00$ & 431.422.753,25 & nd \\
\hline MMX Miner & MMXM3 & $21 / 07 / 06$ & 542,23 & 90,64 & 1.183.362.070,00 & $6.416 .581 .177,55$ & 1.072.646.974,56 \\
\hline Abyara & ABYA3 & $26 / 07 / 06$ & 208,34 & 18,77 & $188.312 .500,00$ & $392.328 .901,58$ & $35.355 .220,78$ \\
\hline Medial Saude & MEDI3 & $21 / 09 / 06$ & 90,89 & 31,23 & 742.287.328,00 & $674.681 .855,16$ & $231.813 .765,62$ \\
\hline Klabinsegall & KSSA3 & 06/10/06 & 80,02 & 18,91 & $557.175 .000,00$ & $445.832 .600,57$ & 105.344.411,95 \\
\hline Santos BRP & STBR11+STBP11 & $12 / 10 / 06$ & 126,34 & 43,83 & $933.000 .000,00$ & $1.178 .765 .685,30$ & 408.916.945,70 \\
\hline M. Diasbranco & MDIA3 & $17 / 10 / 06$ & 121,97 & 79,20 & 415.863.000,00 & $507.243 .016,90$ & $329.352 .179,32$ \\
\hline Brascan Res & BISA3 & 20/10/06 & 62,86 & 19,82 & $1.188 .000 .000,00$ & 746.733.150,85 & $235.449 .534,29$ \\
\hline Profarma & PFRM3 & $25 / 10 / 06$ & 123,92 & 42,50 & 401.062.500,00 & 496.996.650,00 & $170.450 .391,09$ \\
\hline Terna Part & TRNA11 & $26 / 10 / 06$ & 164,10 & 92,73 & $627.000 .000,00$ & $1.028 .890 .762,39$ & $581.444 .258,25$ \\
\hline Ecodiesel & ECOD3 & $21 / 11 / 06$ & 47,08 & 7,25 & $435.772 .056,00$ & $205.176 .009,70$ & $31.593 .474,06$ \\
\hline Odontoprev & ODPV3 & $30 / 11 / 06$ & 157,91 & 102,45 & $522.031 .188,00$ & $824.330 .155,88$ & $534.816 .277,58$ \\
\hline Positivo Inf & POSI3 & 08/12/06 & 77,34 & 26,34 & $644.781 .250,00$ & 498.677.300,45 & $169.849 .132,00$ \\
\hline Lopes Brasil & LPSB3 & $15 / 12 / 06$ & 170,12 & 41,82 & $474.720 .000,00$ & $807.588 .439,28$ & $198.547 .384,02$ \\
\hline Dufrybras & DUFB11 & $19 / 12 / 06$ & 146,80 & 50,20 & $850.000 .000,00$ & $1.247 .764 .530,52$ & $426.664 .517,63$ \\
\hline PDG Realt & PDGR3 & $25 / 01 / 07$ & 186,57 & 81,26 & $724.500 .000,00$ & $\begin{array}{r}1.351 .727 .554,19 \\
\end{array}$ & $588.706 .054,49$ \\
\hline CC Des Imob & CCIM3 & $30 / 01 / 07$ & 70,77 & 14,17 & $600.299 .985,50$ & $424.812 .070,08$ & $85.045 .385,12$ \\
\hline Rodobensimob & RDNI3 & $30 / 01 / 07$ & 121,83 & 36,19 & $448.500 .000,00$ & $546.407 .709,62$ & $162.294 .715,46$ \\
\hline Tecnisa & TCSA3 & $31 / 01 / 07$ & 67,46 & 22,10 & $909.998 .544,00$ & $613.857 .653,86$ & $201.091 .300,40$ \\
\hline Iguatemi & IGTA3 & 06/02/07 & 85,06 & 35,43 & $548.677 .440,00$ & $466.701 .989,97$ & $194.379 .758,99$ \\
\hline GVT Holding & GVTT3 & $15 / 02 / 07$ & 214,56 & 130,61 & $1.076 .400 .000,00$ & $2.309 .476 .000,05$ & 1.405.897.999,99 \\
\hline Anhanguera & AEDU11 & $09 / 03 / 07$ & 168,89 & 88,83 & $512.330 .000,00$ & $865.269 .587,25$ & $455.120 .417,77$ \\
\hline JBS & JBSS3 & 28/03/07 & 104,38 & 49,38 & $1.840 .000 .000,00$ & $1.920 .614 .254,62$ & $908.554 .048,64$ \\
\hline Even & EVEN3 & $30 / 03 / 07$ & 102,24 & 24,38 & $460.000 .000,00$ & $470.302 .870,88$ & $112.149 .146,14$ \\
\hline Pine & PINE4 & $30 / 03 / 07$ & 75,55 & 26,70 & $594.766 .500,00$ & $449.373 .195,01$ & $158.775 .374,79$ \\
\hline BR Malls Par & BRML3 & 04/04/07 & 129,27 & 53,33 & $696.070 .665,00$ & $899.787 .346,31$ & $371.237 .688,00$ \\
\hline Fer Heringer & FHER3 & $11 / 04 / 07$ & 132,37 & 27,68 & $349.577 .358,00$ & $462.720 .188,36$ & $96.750 .584,84$ \\
\hline JHSF Part & JHSF3 & $11 / 04 / 07$ & 100,67 & 25,14 & $432.400 .000,00$ & 435.293.251,75 & $108.687 .453,62$ \\
\hline Metalfrio & FRIO3 & $12 / 04 / 07$ & 118,71 & 45,13 & $452.950 .500,00$ & $537.715 .592,93$ & $204.422 .779,89$ \\
\hline Bematech & BEMA3 & $18 / 04 / 07$ & 55,67 & 26,51 & $406.630 .050,00$ & $226.357 .394,50$ & $107.814 .680,88$ \\
\hline CR2 & CRDE3 & $20 / 04 / 07$ & 67,58 & 22,30 & $353.711 .240,00$ & $239.027 .140,50$ & $78.864 .810,84$ \\
\hline Agra Incorp & AGIN3 & $25 / 04 / 07$ & 90,00 & 13,88 & $786.037 .500,00$ & 707.433.750,00 & $109.120 .500,00$ \\
\hline Cremer & CREM3 & $27 / 04 / 07$ & 84,37 & 53,36 & $584.034 .500,00$ & $492.747 .333,75$ & $311.631 .382,23$ \\
\hline Wilson Sons & WSON11 & $27 / 04 / 07$ & 92,03 & 41,52 & $706.000 .000,00$ & $649.761 .726,40$ & 293.148.313,77 \\
\hline Sofisa & SFSA4 & $30 / 04 / 07$ & 84,09 & 28,23 & $504.543 .984,00$ & $424.265 .431,19$ & $142.410 .774,11$ \\
\hline Tarpon & TARP11 & $30 / 05 / 07$ & 114,41 & 58,08 & $444.000 .000,00$ & $507.980 .941,77$ & $257.875 .200,00$ \\
\hline Inpar S/A & INPR3 & 05/06/07 & 62,86 & 7,71 & $756.000 .000,00$ & $475.200 .000,00$ & $58.320 .000,00$ \\
\hline Parana & PRBC4 & $13 / 06 / 07$ & 74,27 & 19,87 & $604.800 .000,00$ & $449.155 .838,44$ & $120.201 .827,39$ \\
\hline SLC Agricola & SLCE3 & $14 / 06 / 07$ & 222,77 & 80,23 & $490.043 .750,00$ & $1.091 .680 .149,65$ & $393.145 .262,89$ \\
\hline Log-In & LOGN3 & 20/06/07 & 80,63 & 32,25 & $848.246 .654,25$ & 683.918.476,99 & 273.567.390,79 \\
\hline Eztec & EZTC3 & $21 / 06 / 07$ & 54,63 & 18,21 & $542.145 .813,00$ & $296.167 .253,49$ & $98.722 .417,83$ \\
\hline Cruzeiro Sul & CZRS4 & $25 / 06 / 07$ & & & & & \\
\hline
\end{tabular}




\begin{tabular}{|c|c|c|c|c|c|c|c|}
\hline & & & 63,41 & 33,76 & $644.197 .794,00$ & $408.493 .304,01$ & $217.481 .074,62$ \\
\hline Daycoval & DAYC4 & $28 / 06 / 07$ & 90,73 & 31,21 & $1.092 .473 .788,00$ & $991.174 .899,32$ & $340.920 .039,81$ \\
\hline Marfrig & MRFG3 & $28 / 06 / 07$ & 123,48 & 62,48 & $1.020 .510 .000,00$ & $1.260 .142 .480,38$ & $637.662 .460,00$ \\
\hline Tegma & TGMA3 & $02 / 07 / 07$ & 75,27 & 20,95 & $603.980 .000,00$ & $454.605 .539,30$ & $126.539 .613,17$ \\
\hline Indusval & IDVL4 & $11 / 07 / 07$ & 96,89 & 28,82 & $260.000 .020,00$ & 251.913.169,99 & 74.925.319,61 \\
\hline Redecard & RDCD3 & $12 / 07 / 07$ & 125,55 & 93,12 & 4.642.694.685,00 & $5.828 .698 .040,95$ & 4.323.240.795,38 \\
\hline Invest Tur & IVTT3 & $13 / 07 / 07$ & 80,00 & 40,50 & $945.000 .000,00$ & $755.990 .550,00$ & $382.725 .000,00$ \\
\hline Banco Patagonia & BPAT11 & $19 / 07 / 07$ & 62,96 & 26,68 & $76.000 .000,00$ & $47.847 .517,57$ & $20.274 .371,85$ \\
\hline Minerva & BEEF3 & $19 / 07 / 07$ & 56,38 & 10,78 & $510.600 .000,00$ & 287.859.449,63 & $55.056 .613,18$ \\
\hline Guarani & ACGU3 & $20 / 07 / 07$ & 73,56 & 17,33 & $765.621 .760,50$ & 563.157.339,39 & $132.707 .771,82$ \\
\hline Kroton & KROT11 & $20 / 07 / 07$ & 84,59 & 20,51 & $479.000 .000,00$ & 405.184.871,80 & $98.256 .410,26$ \\
\hline MRV & MRVE3 & $20 / 07 / 07$ & 142,85 & 44,34 & $1.193 .400 .000,00$ & $1.704 .762 .497,44$ & $529.143 .555,20$ \\
\hline Triunfo Part & TPIS3 & $20 / 07 / 07$ & 65,79 & 18,95 & $589.950 .000,00$ & $388.125 .000,00$ & $111.780 .000,00$ \\
\hline Abc Brasil & ABCB4 & $24 / 07 / 07$ & 78,99 & 31,92 & $699.300 .000,00$ & $552.384 .522,85$ & 223.225.351,63 \\
\hline Multiplan & MULT3 & $26 / 07 / 07$ & 82,00 & 42,80 & $1.062 .008 .750,00$ & $870.847 .175,00$ & 454.539.745,00 \\
\hline Providencia & PRVI3 & $26 / 07 / 07$ & 41,35 & 21,71 & $609.375 .000,00$ & $251.988 .313,54$ & $132.304 .041,84$ \\
\hline Springs & SGPS3 & $26 / 07 / 07$ & 86,84 & 14,47 & $655.500 .000,00$ & $569.250 .000,00$ & $94.875 .000,00$ \\
\hline Estacio & ESTC11+ESTC3 & $27 / 07 / 07$ & 94,49 & 62,32 & $447.000 .000,00$ & 422.348.202,30 & 278.548.695,32 \\
\hline Generalshop & GSHP3 & $27 / 07 / 07$ & 87,50 & 42,86 & $313.950 .000,00$ & $274.706 .250,00$ & $134.550 .000,00$ \\
\hline Cosan Ltd & CZLT11 & $16 / 08 / 07$ & 105,46 & 28,98 & $275.000 .000,00$ & $290.023 .752,95$ & 79.691.211,40 \\
\hline Satipel & SATI3 & 20/09/07 & 91,54 & 27,37 & $457.572 .128,00$ & $418.872 .565,20$ & $125.229 .887,44$ \\
\hline Sul America & SULA11 & $04 / 10 / 07$ & 99,53 & 52,99 & $775.000 .000,00$ & $771.333 .949,97$ & 410.693.617,29 \\
\hline Bicbanco & BICB4 & $11 / 10 / 07$ & 87,16 & 23,67 & $821.526 .075,00$ & $716.013 .330,36$ & $194.445 .954,98$ \\
\hline Tenda & TEND3 & $11 / 10 / 07$ & 131,33 & 13,00 & $693.450 .000,00$ & $910.730 .999,98$ & $90.148 .500,00$ \\
\hline Trisul & TRIS3 & $11 / 10 / 07$ & 82,19 & 20,00 & $366.660 .250,00$ & $301.375 .019,30$ & $73.325 .618,53$ \\
\hline Seb & SEBB11 & $17 / 10 / 07$ & 72,42 & 22,42 & $413.000 .000,00$ & $299.112 .121,21$ & $92.612 .121,21$ \\
\hline Marisa & MARI3 & $19 / 10 / 07$ & 61,48 & 32,89 & $506.000 .000,00$ & $311.066 .370,92$ & $166.443 .343,66$ \\
\hline Agrenco & AGEN11 & $24 / 10 / 07$ & 43,75 & 1,06 & $666.000 .000,00$ & $291.375 .000,00$ & $7.044 .230,77$ \\
\hline Bovespa Holding & BOVH3 & $25 / 10 / 07$ & 124,16 & $39,01 *$ & $6.625 .520 .875,00$ & $8.226 .245 .694,09$ & 2.584.868.940,82 \\
\hline Amil & AMIL3 & $26 / 10 / 07$ & 94,61 & 72,39 & $1.400 .700 .000,00$ & 1.325.136.711,85 & 1.013.930.362,86 \\
\hline Br Brokers & BBRK3 & $26 / 10 / 07$ & 164,74 & 26,84 & $699.183 .850,00$ & 1.151.813.395,03 & $187.675 .665,00$ \\
\hline Helbor & HBOR3 & $26 / 10 / 07$ & 85,71 & 26,44 & 267.327.753,00 & 229.117.591,47 & $70.685 .214,39$ \\
\hline Laep & MILK11 & $30 / 10 / 07$ & 78,00 & 5,33 & $508.000 .000,00$ & $396.240 .000,00$ & $27.093 .333,33$ \\
\hline Panamericano & BPNM4 & $16 / 11 / 07$ & 101,64 & 27,98 & $777.024 .000,00$ & 789.784.766,08 & $217.414 .796,88$ \\
\hline $\mathrm{BM} \& \mathrm{~F}$ & BMEF3 & 29/11/07 & 92,24 & 29,32 & $5.983 .696 .920,00$ & $5.519 .646 .584,98$ & $1.754 .657 .954,41$ \\
\hline MPX Energia & MPXE3 & $13 / 12 / 07$ & 104,31 & 11,62 & 2.203.819.085,52 & 2.298.747.306,92 & 256.148.567,99 \\
\hline Tempo Part & TEMP3 & $17 / 12 / 07$ & 95,00 & 47,14 & $452.812 .500,00$ & $430.171 .875,00$ & $213.468 .750,00$ \\
\hline \multicolumn{4}{|c|}{$\begin{array}{l}\text { Fonte: CVM, Economática, Bovespa, Lopes Filho } \\
\left({ }^{*}\right) \text { No caso da Bovespa Holding, que não possuía } \\
\text { cotação na data de } 31.10 .08 \text {, foi utilizado o retorno } \\
\text { da ação da BM\&F }(29,32) \text {, empresa com a qual } \\
\text { integrou suas operações, corrigido pelo fator de } \\
1,330441 \text {, que corresponde à relação entre os } \\
\text { retornos na última data existente, } 19.08 .08 \text {. }\end{array}$} & TOTAL & 81.554.614.304,68 & 103.064.453.289,72 & $44.730 .615 .889,59$ \\
\hline
\end{tabular}

Da tabela anterior, podemos apresentar os seguintes comentários:

(i) conforme a coluna "Valor Original da Emissão", as emissões efetuadas nesse período, excluída a emissão da empresa TAM (em função da não obtenção de 
dados completos sobre a mesma), totalizaram, em valor nominal, $\mathrm{R} \$$ 81.554.614.304,68. Trata-se de um valor nominal, sem qualquer correção em função da variação de preços no período, mas será bastante útil para efeito de análises que faremos posteriormente;

(ii) Na coluna "Valor em 20.05.08”, temos o valor original da emissão (coluna anterior), corrigido pela variação nos preços observada em cada ação, informada na coluna “Cotação, em moeda original 100, ajustada por proventos - 20.05.08”. Ou seja, informa o valor, na data de 20.05.08, da emissão total, considerando a valorização ou desvalorização de cada ação respectiva.

(iii) Já a coluna "Valor em 31.10.08” repete o procedimento acima, apenas alterando a data de cálculo para 31.10.08.

A tabela anterior permite importantes comentários. Pela coluna mencionada no item (ii) retro, verificamos que o valor total das emissões de ações ali mencionadas alcançavam a soma de ...

Na tabela a seguir (Tabela 13), apresentamos as estatísticas descritivas dos retornos apresentados na tabela anterior (Tabela 12):

Tabela 13 - Retorno nominal dos IPOs - Estatísticas descritivas

\begin{tabular}{|l|r|r|r|r|r|}
\multicolumn{1}{c|}{} & \multicolumn{1}{c|}{$\begin{array}{c}\text { Cotação, em moeda } \\
\text { original 100, } \\
\text { ajustada por } \\
\text { proventos }\end{array}$} & \multicolumn{2}{c|}{ Valores em Reais } \\
\cline { 2 - 6 } & 20.05 .08 & 31.10 .08 & $\begin{array}{c}\text { Valor Original da } \\
\text { Emissão }\end{array}$ & $\begin{array}{c}\text { Valor em } \\
20.05 .08\end{array}$ & \multicolumn{2}{c|}{$\begin{array}{l}\text { Valor em } \\
\text { Média }\end{array}$} \\
\cline { 2 - 7 } & 129,25 & 55,68 & $799.555 .042,20$ & $1.010 .435 .816,57$ & $442.877 .385,05$ \\
\hline Maior & 615,50 & 308,09 & $6.625 .520 .875,00$ & $8.226 .245 .694,09$ & $4.323 .240 .795,38$ \\
\hline Menor & 29,44 & 1,06 & $16.000 .000,00$ & $42.134 .062,93$ & $7.044 .230,77$ \\
\hline Desvio-padrão & 91,32 & 52,60 & $930.054 .790,91$ & $1.261 .807 .057,93$ & $623.871 .618,14$ \\
\hline Nr. de observações & 102 & 101 & 102 & 102 & 101 \\
\hline
\end{tabular}

\subsection{Valor de Emissão e Valor Patrimonial}

Conforme apresentado no capítulo 2, existe muita discussão sobre o conteúdo informacional do Valor Patrimonial de uma ação. 
Tabela 14 - Ganho no valor patrimonial para sócios anteriores

\begin{tabular}{|c|c|c|c|c|c|c|c|}
\hline \multirow[t]{2}{*}{ Empresa } & \multicolumn{2}{|c|}{ Emissão } & \multicolumn{2}{|c|}{$\begin{array}{l}\text { Valor Patrimonial antes da } \\
\text { Emissão - R\$ }\end{array}$} & \multirow[t]{2}{*}{$\begin{array}{c}\text { VP após Oferta } \\
\text { R\$ }\end{array}$} & \multirow[t]{2}{*}{$\begin{array}{c}\text { Aumento do VP } \\
\text { para sócios } \\
\text { anteriores R\$ }\end{array}$} & \multirow{2}{*}{$\begin{array}{l}\text { Variação \% } \\
\text { no VP para } \\
\text { sócios } \\
\text { anteriores }\end{array}$} \\
\hline & Data & Valor & $\begin{array}{l}\text { Data do } \\
\text { Balanço }\end{array}$ & VP & & & \\
\hline Natura & $25 / 05 / 04$ & 36,50 & $31 / 03 / 04$ & 4,22 & 4,22 & - & $0,00 \%$ \\
\hline Gol & 23/06/04 & 26,57 & $31 / 03 / 04$ & 1,89 & 4,36 & 2,47 & $130,69 \%$ \\
\hline CPFL Energia & 28/09/04 & 17,22 & $30 / 06 / 04$ & 8,24 & 9,03 & 0,79 & $9,59 \%$ \\
\hline Grendene & 28/10/04 & nd & nd & nd & nd & nd & nd \\
\hline Dasa & $18 / 11 / 04$ & nd & nd & nd & nd & nd & nd \\
\hline Porto Seguro & $19 / 11 / 04$ & 18,75 & $30 / 09 / 04$ & 11,86 & 12,42 & 0,56 & $4,72 \%$ \\
\hline Renar & $25 / 02 / 05$ & 1,60 & $30 / 09 / 04$ & 0,98 & 1,10 & 0,12 & $12,24 \%$ \\
\hline $\begin{array}{l}\text { B2W Varejo - ex- } \\
\text { Submarino }\end{array}$ & $29 / 03 / 05$ & 21,62 & $31 / 12 / 04$ & 0,98 & 10,26 & 9,28 & $946,94 \%$ \\
\hline Localiza & $20 / 05 / 05$ & 11,50 & $31 / 03 / 05$ & 4,66 & 4,66 & - & $0,00 \%$ \\
\hline Energias BR & $12 / 07 / 05$ & 18,00 & $31 / 05 / 05$ & 22,72 & 19,90 & $(2,82)$ & $-12,41 \%$ \\
\hline OHL Brasil & $14 / 07 / 05$ & 18,00 & $31 / 03 / 05$ & 6,47 & 7,63 & 1,16 & $17,93 \%$ \\
\hline Nossa Caixa & $27 / 10 / 05$ & nd & nd & nd & nd & nd & nd \\
\hline Cosan & $17 / 11 / 05$ & 48,00 & $31 / 07 / 05$ & 11,96 & 20,83 & 8,87 & $74,16 \%$ \\
\hline Uol & $15 / 12 / 05$ & 18,00 & 30/09/05 & 1,19 & 3,40 & 2,21 & $185,71 \%$ \\
\hline Copasa & $07 / 02 / 06$ & 23,50 & $30 / 09 / 05$ & 26,78 & 25,87 & $(0,91)$ & $-3,40 \%$ \\
\hline Vivax & $07 / 02 / 06$ & nd & nd & nd & nd & nd & nd \\
\hline Gafisa & $16 / 02 / 06$ & 26,00 & $31 / 12 / 05$ & 7,41 & 10,12 & 2,71 & $36,57 \%$ \\
\hline Company & 01/03/06 & 16,60 & $31 / 12 / 05$ & 2,12 & 6,44 & 4,32 & $203,77 \%$ \\
\hline Totvs & 08/03/06 & 32,00 & $31 / 12 / 05$ & 4,28 & 12,70 & 8,42 & $196,73 \%$ \\
\hline Equatorial & $31 / 03 / 06$ & nd & nd & nd & nd & nd & nd \\
\hline Abnote & $26 / 04 / 06$ & nd & nd & nd & nd & nd & nd \\
\hline BrasilAgro & 28/04/06 & nd & nd & nd & nd & nd & nd \\
\hline CSU CardSystem & $28 / 04 / 06$ & nd & nd & nd & nd & nd & nd \\
\hline Lupatech & $12 / 05 / 06$ & 22,00 & $31 / 03 / 06$ & 2,13 & 5,04 & 2,91 & $136,62 \%$ \\
\hline GP Invest & $31 / 05 / 06$ & nd & nd & nd & nd & nd & nd \\
\hline Datasul & 01/06/06 & 18,00 & $31 / 03 / 06$ & 1,79 & 6,48 & 4,69 & $262,01 \%$ \\
\hline MMX Miner & $21 / 07 / 06$ & 815,00 & $31 / 03 / 06$ & 5,22 & 258,20 & 252,98 & $4846,36 \%$ \\
\hline Abyara & 26/07/06 & 25,00 & $31 / 05 / 06$ & 0,32 & 8,99 & 8,67 & $2709,38 \%$ \\
\hline Medial Saude & 21/09/06 & 21,50 & $30 / 06 / 06$ & 0,91 & 6,24 & 5,33 & $585,71 \%$ \\
\hline Klabinsegall & 06/10/06 & 15,00 & $30 / 06 / 06$ & 1,87 & 6,72 & 4,85 & $259,36 \%$ \\
\hline Santos BRP & $12 / 10 / 06$ & nd & nd & nd & nd & nd & nd \\
\hline M. Diasbranco & $17 / 10 / 06$ & 21,00 & $30 / 06 / 06$ & 6,00 & 6,00 & - & $0,00 \%$ \\
\hline Brascan Res & $20 / 10 / 06$ & 16,00 & $30 / 06 / 06$ & 1,17 & 5,17 & 4,00 & $341,88 \%$ \\
\hline Profarma & $25 / 10 / 06$ & 22,50 & 30/06/06 & 3,95 & 9,85 & 5,90 & $149,37 \%$ \\
\hline Terna Part & $26 / 10 / 06$ & nd & nd & nd & nd & nd & nd \\
\hline Ecodiesel & $21 / 11 / 06$ & nd & nd & nd & nd & nd & nd \\
\hline Odontoprev & $30 / 11 / 06$ & 28,00 & $30 / 09 / 06$ & 1,20 & 7,05 & 5,85 & $487,50 \%$ \\
\hline Positivo Inf & 08/12/06 & 23,50 & $30 / 09 / 06$ & 2,38 & 3,01 & 0,63 & $26,47 \%$ \\
\hline Lopes Brasil & $15 / 12 / 06$ & 20,00 & 30/09/06 & 0,09 & 0,09 & - & $0,00 \%$ \\
\hline Dufrybras & $19 / 12 / 06$ & nd & nd & nd & nd & nd & nd \\
\hline PDG Realt & $25 / 01 / 07$ & 14,00 & $30 / 09 / 06$ & 2,98 & 5,84 & 2,86 & $95,97 \%$ \\
\hline CC Des Imob & $30 / 01 / 07$ & 14,50 & 30/09/06 & 0,52 & 4,37 & 3,85 & $740,38 \%$ \\
\hline Rodobensimob & $30 / 01 / 07$ & 19,50 & $30 / 09 / 06$ & 2,10 & 9,30 & 7,20 & $342,86 \%$ \\
\hline
\end{tabular}




\begin{tabular}{|c|c|c|c|c|c|c|c|}
\hline Tecnisa & $31 / 01 / 07$ & 13,00 & $30 / 09 / 06$ & 1,47 & 4,85 & 3,38 & $229,93 \%$ \\
\hline Iguatemi & $06 / 02 / 07$ & 30,00 & 30/09/06 & 6,23 & 12,30 & 6,07 & $97,43 \%$ \\
\hline GVT Holding & $15 / 02 / 07$ & 18,00 & $31 / 12 / 06$ & 8,83 & 12,36 & 3,53 & $39,98 \%$ \\
\hline Anhanguera & $09 / 03 / 07$ & nd & nd & nd & nd & nd & nd \\
\hline JBS & 28/03/07 & 8,00 & $31 / 12 / 06$ & 0,26 & 1,63 & 1,37 & $526,92 \%$ \\
\hline Even & $30 / 03 / 07$ & 11,50 & $31 / 12 / 06$ & 1,35 & 3,99 & 2,64 & $195,56 \%$ \\
\hline Pine & $30 / 03 / 07$ & 19,00 & $31 / 12 / 06$ & 4,65 & 7,46 & 2,81 & $60,43 \%$ \\
\hline BR Malls Par & $04 / 04 / 07$ & 15,00 & $31 / 12 / 06$ & 5,17 & 7,82 & 2,65 & $51,26 \%$ \\
\hline Fer Heringer & $11 / 04 / 07$ & 17,00 & $31 / 12 / 06$ & 6,10 & 8,32 & 2,22 & $36,39 \%$ \\
\hline JHSF Part & $11 / 04 / 07$ & 8,00 & $31 / 12 / 06$ & 0,30 & 1,22 & 0,92 & $306,67 \%$ \\
\hline Metalfrio & $12 / 04 / 07$ & 19,00 & $31 / 12 / 06$ & 1,88 & 7,37 & 5,49 & $292,02 \%$ \\
\hline Bematech & $18 / 04 / 07$ & 15,00 & $31 / 12 / 06$ & 2,03 & 5,50 & 3,47 & $170,94 \%$ \\
\hline CR2 & $20 / 04 / 07$ & 20,00 & $31 / 12 / 06$ & 2,05 & 8,03 & 5,98 & $291,71 \%$ \\
\hline Agra Incorp & $25 / 04 / 07$ & 8,50 & $31 / 12 / 06$ & 1,39 & 5,08 & 3,69 & $265,47 \%$ \\
\hline Cremer & $27 / 04 / 07$ & 17,50 & $31 / 12 / 06$ & 5,25 & 9,30 & 4,05 & $77,14 \%$ \\
\hline Wilson Sons & $27 / 04 / 07$ & nd & nd & nd & nd & nd & nd \\
\hline Sofisa & $30 / 04 / 07$ & 12,00 & $31 / 12 / 06$ & 2,89 & 5,02 & 2,13 & $73,70 \%$ \\
\hline Tarpon & $30 / 05 / 07$ & nd & nd & nd & nd & nd & nd \\
\hline Inpar S/A & $05 / 06 / 07$ & 17,50 & $31 / 03 / 07$ & 0,65 & 7,02 & 6,37 & $980,00 \%$ \\
\hline Parana & $13 / 06 / 07$ & nd & nd & nd & nd & nd & nd \\
\hline SLC Agricola & $14 / 06 / 07$ & 14,00 & $31 / 03 / 07$ & 2,93 & 5,46 & 2,53 & $86,35 \%$ \\
\hline Log-In & $20 / 06 / 07$ & 14,25 & $31 / 03 / 07$ & 1,59 & 5,35 & 3,76 & $236,48 \%$ \\
\hline Eztec & $21 / 06 / 07$ & 11,00 & $31 / 03 / 07$ & 1,82 & 4,40 & 2,58 & $141,76 \%$ \\
\hline Cruzeiro Sul & $25 / 06 / 07$ & 15,50 & $31 / 03 / 07$ & 2,46 & 4,82 & 2,36 & $95,93 \%$ \\
\hline Daycoval & $28 / 06 / 07$ & 17,00 & $31 / 03 / 07$ & 2,97 & 6,28 & 3,31 & $111,45 \%$ \\
\hline Marfrig & 28/06/07 & 17,00 & $31 / 03 / 07$ & 3,71 & 5,91 & 2,20 & $59,30 \%$ \\
\hline Tegma & $02 / 07 / 07$ & 26,00 & $31 / 03 / 07$ & 1,53 & 4,89 & 3,36 & $219,61 \%$ \\
\hline Indusval & $11 / 07 / 07$ & 17,50 & $31 / 03 / 07$ & 5,22 & 8,61 & 3,39 & $64,94 \%$ \\
\hline Redecard & $12 / 07 / 07$ & 27,00 & $31 / 03 / 07$ & 0,10 & 0,70 & 0,60 & $600,00 \%$ \\
\hline Invest Tur & $13 / 07 / 07$ & $1.000,00$ & $31 / 08 / 07$ & $1.000,00$ & 932,48 & $(67,52)$ & $-6,75 \%$ \\
\hline Banco Patagonia & $19 / 07 / 07$ & nd & nd & nd & nd & nd & nd \\
\hline Minerva & 19/07/07 & 18,50 & $31 / 03 / 07$ & 3,63 & 7,11 & 3,48 & $95,87 \%$ \\
\hline Guarani & $20 / 07 / 07$ & 13,50 & $30 / 04 / 07$ & 5,06 & 7,39 & 2,33 & $46,05 \%$ \\
\hline Kroton & 20/07/07 & nd & nd & nd & nd & nd & $\mathrm{nd}$ \\
\hline MRV & $20 / 07 / 07$ & 26,00 & $31 / 03 / 07$ & 2,90 & 9,27 & 6,37 & $219,66 \%$ \\
\hline Triunfo Part & $20 / 07 / 07$ & 9,50 & $31 / 03 / 07$ & 1,97 & 3,71 & 1,74 & $88,32 \%$ \\
\hline Abc Brasil & $24 / 07 / 07$ & 13,50 & $31 / 03 / 07$ & 5,03 & 7,61 & 2,58 & $51,29 \%$ \\
\hline Multiplan & 26/07/07 & 25,00 & $31 / 03 / 07$ & 8,22 & 11,20 & 2,98 & $36,25 \%$ \\
\hline Providencia & 26/07/07 & 15,00 & $31 / 03 / 07$ & 0,08 & 5,33 & 5,25 & $6562,50 \%$ \\
\hline Springs & $26 / 07 / 07$ & 19,00 & $31 / 03 / 07$ & 26,47 & 24,49 & $(1,98)$ & $-7,48 \%$ \\
\hline Estacio & $27 / 07 / 07$ & nd & nd & nd & nd & nd & $\mathrm{nd}$ \\
\hline Generalshop & $27 / 07 / 07$ & 14,00 & $31 / 03 / 07$ & 3,76 & 7,45 & 3,69 & $98,14 \%$ \\
\hline Cosan Ltd & 16/08/07 & nd & nd & nd & nd & nd & nd \\
\hline Satipel & $20 / 09 / 07$ & nd & nd & nd & nd & nd & nd \\
\hline Sul America & $04 / 10 / 07$ & nd & nd & nd & nd & nd & nd \\
\hline Bicbanco & $11 / 10 / 07$ & 12,75 & $30 / 06 / 07$ & 4,27 & 5,53 & 1,26 & $29,51 \%$ \\
\hline
\end{tabular}




\begin{tabular}{|c|c|c|c|c|c|c|c|}
\hline Tenda & $11 / 10 / 07$ & 9,00 & $30 / 06 / 07$ & 0,59 & 4,12 & 3,53 & $598,31 \%$ \\
\hline Trisul & $11 / 10 / 07$ & 11,00 & $30 / 06 / 07$ & 2,48 & 5,42 & 2,94 & $118,55 \%$ \\
\hline Seb & $17 / 10 / 07$ & nd & nd & nd & nd & nd & nd \\
\hline Marisa & $19 / 10 / 07$ & 10,00 & $30 / 06 / 07$ & 0,35 & 2,64 & 2,29 & $654,29 \%$ \\
\hline Agrenco & $24 / 10 / 07$ & nd & nd & nd & nd & nd & nd \\
\hline Bovespa Holding & $25 / 10 / 07$ & 23,00 & $30 / 06 / 07$ & 2,06 & 2,06 & - & $0,00 \%$ \\
\hline Amil & $26 / 10 / 07$ & 14,00 & $30 / 06 / 07$ & 0,56 & 2,70 & 2,14 & $382,14 \%$ \\
\hline Br Brokers & $26 / 10 / 07$ & 950,00 & $30 / 06 / 07$ & 0,12 & 174,18 & 174,06 & $143850,41 \%$ \\
\hline Helbor & $26 / 10 / 07$ & 11,00 & $30 / 06 / 07$ & 3,47 & 6,36 & 2,89 & $83,29 \%$ \\
\hline Laep & $30 / 10 / 07$ & nd & nd & nd & nd & nd & nd \\
\hline Panamericano & $16 / 11 / 07$ & 10,00 & $30 / 09 / 07$ & 2,56 & 4,52 & 1,96 & $76,56 \%$ \\
\hline$B M \& F$ & 29/11/07 & 20,00 & 01/10/07 & 1,42 & 1,42 & - & $0,00 \%$ \\
\hline MPX Energia & $13 / 12 / 07$ & $1.006,63$ & $30 / 09 / 07$ & 0,38 & 272,48 & 272,10 & $71605,26 \%$ \\
\hline Tempo Part & $17 / 12 / 07$ & 7,00 & $30 / 09 / 07$ & 0,59 & 2,58 & 1,99 & $337,29 \%$ \\
\hline
\end{tabular}

Tabela 15 - Geração de Valor para os sócios anteriores

\begin{tabular}{|c|c|c|c|c|c|c|c|}
\hline \multirow[t]{2}{*}{ Empresa } & \multirow[t]{2}{*}{ Código } & \multicolumn{2}{|c|}{ Emissão } & \multicolumn{2}{|c|}{$\begin{array}{l}\text { Valor Patrimonial antes da } \\
\text { Emissão - R\$ }\end{array}$} & \multicolumn{2}{|c|}{$\begin{array}{c}\text { Geração de valor para sócios } \\
\text { anteriores }\end{array}$} \\
\hline & & Data & Valor & $\begin{array}{l}\text { Data do } \\
\text { Balanço }\end{array}$ & VP & Valor & $\%$ \\
\hline Natura & NATU3 & $25 / 05 / 04$ & 36,50 & $31 / 03 / 04$ & 4,22 & 32,28 & $764,9 \%$ \\
\hline Gol & GOLL4 & 23/06/04 & 26,57 & $31 / 03 / 04$ & 1,89 & 24,68 & $1305,8 \%$ \\
\hline CPFL Energia & CPFE3 & 28/09/04 & 17,22 & $30 / 06 / 04$ & 8,24 & 8,98 & $109,0 \%$ \\
\hline Grendene & GRND3 & $28 / 10 / 04$ & nd & nd & nd & nd & nd \\
\hline Dasa & DASA3 & $18 / 11 / 04$ & nd & nd & nd & nd & nd \\
\hline Porto Seguro & PSSA3 & $19 / 11 / 04$ & 18,75 & 30/09/04 & 11,86 & 6,89 & $58,1 \%$ \\
\hline Renar & RNAR3 & $25 / 02 / 05$ & 1,60 & $30 / 09 / 04$ & 0,98 & 0,62 & $63,3 \%$ \\
\hline B2W Varejo - ex-Submarino & SUBA3+BTOW3 & 29/03/05 & 21,62 & $31 / 12 / 04$ & 0,98 & 20,64 & $2106,1 \%$ \\
\hline Localiza & RENT3 & 20/05/05 & 11,50 & $31 / 03 / 05$ & 4,66 & 6,84 & $146,8 \%$ \\
\hline Energias BR & ENBR3 & $12 / 07 / 05$ & 18,00 & $31 / 05 / 05$ & 22,72 & $(4,72)$ & $-20,8 \%$ \\
\hline OHL Brasil & OHLB3 & $14 / 07 / 05$ & 18,00 & $31 / 03 / 05$ & 6,47 & 11,53 & $178,2 \%$ \\
\hline Nossa Caixa & BNCA3 & $27 / 10 / 05$ & nd & nd & nd & nd & nd \\
\hline Cosan & CSAN3 & $17 / 11 / 05$ & 48,00 & $31 / 07 / 05$ & 11,96 & 36,04 & $301,3 \%$ \\
\hline Uol & UOLL4 & $15 / 12 / 05$ & 18,00 & $30 / 09 / 05$ & 1,19 & 16,81 & $1412,6 \%$ \\
\hline Copasa & CSMG3 & 07/02/06 & 23,50 & $30 / 09 / 05$ & 26,78 & $(3,28)$ & $-12,2 \%$ \\
\hline Vivax & VVAX11 & $07 / 02 / 06$ & nd & nd & nd & nd & nd \\
\hline Gafisa & GFSA3 & $16 / 02 / 06$ & 26,00 & $31 / 12 / 05$ & 7,41 & 18,59 & $250,9 \%$ \\
\hline Company & CPNY3 & 01/03/06 & 16,60 & $31 / 12 / 05$ & 2,12 & 14,48 & $683,0 \%$ \\
\hline Totvs & TOTS3 & 08/03/06 & 32,00 & $31 / 12 / 05$ & 4,28 & 27,72 & $647,7 \%$ \\
\hline Equatorial & EQTL11+EQTL3 & $31 / 03 / 06$ & nd & nd & nd & nd & nd \\
\hline Abnote & ABNB3 & $26 / 04 / 06$ & nd & nd & nd & nd & nd \\
\hline BrasilAgro & AGRO3 & $28 / 04 / 06$ & nd & nd & nd & nd & nd \\
\hline CSU CardSystem & CARD3 & $28 / 04 / 06$ & nd & nd & nd & nd & nd \\
\hline Lupatech & LUPA3 & $12 / 05 / 06$ & 22,00 & $31 / 03 / 06$ & 2,13 & 19,87 & $932,9 \%$ \\
\hline GP Invest & GPIV11 & $31 / 05 / 06$ & nd & nd & nd & nd & nd \\
\hline Datasul & DSUL3 & 01/06/06 & 18,00 & $31 / 03 / 06$ & 1,79 & 16,21 & $905,6 \%$ \\
\hline MMX Miner & ММХMЗ & $21 / 07 / 06$ & 815,00 & $31 / 03 / 06$ & 5,22 & 809,78 & $15513,0 \%$ \\
\hline
\end{tabular}




\begin{tabular}{|c|c|c|c|c|c|c|c|}
\hline Abyara & ABYA3 & 26/07/06 & 25,00 & $31 / 05 / 06$ & 0,32 & 24,68 & $7712,5 \%$ \\
\hline Medial Saude & MEDI3 & $21 / 09 / 06$ & 21,50 & $30 / 06 / 06$ & 0,91 & 20,59 & $2262,6 \%$ \\
\hline Klabinsegall & KSSA3 & $06 / 10 / 06$ & 15,00 & $30 / 06 / 06$ & 1,87 & 13,13 & $702,1 \%$ \\
\hline Santos BRP & STBR11+STBP11 & $12 / 10 / 06$ & nd & nd & nd & nd & nd \\
\hline M. Diasbranco & MDIA3 & $17 / 10 / 06$ & 21,00 & 30/06/06 & 6,00 & 15,00 & $250,0 \%$ \\
\hline Brascan Res & BISA3 & 20/10/06 & 16,00 & 30/06/06 & 1,17 & 14,83 & $1267,5 \%$ \\
\hline Profarma & PFRM3 & $25 / 10 / 06$ & 22,50 & 30/06/06 & 3,95 & 18,55 & $469,6 \%$ \\
\hline Terna Part & TRNA11 & $26 / 10 / 06$ & $\mathrm{nd}$ & nd & nd & nd & nd \\
\hline Ecodiesel & ECOD3 & 21/11/06 & nd & nd & nd & nd & nd \\
\hline Odontoprev & ODPV3 & $30 / 11 / 06$ & 28,00 & 30/09/06 & 1,20 & 26,80 & $2233,3 \%$ \\
\hline Positivo Inf & POSI3 & 08/12/06 & 23,50 & 30/09/06 & 2,38 & 21,12 & $887,4 \%$ \\
\hline Lopes Brasil & LPSB3 & $15 / 12 / 06$ & 20,00 & 30/09/06 & 0,09 & 19,91 & $22122,2 \%$ \\
\hline Dufrybras & DUFB11 & $19 / 12 / 06$ & nd & nd & nd & nd & nd \\
\hline PDG Realt & PDGR3 & $25 / 01 / 07$ & 14,00 & 30/09/06 & 2,98 & 11,02 & $369,8 \%$ \\
\hline CC Des Imob & CCIM3 & $30 / 01 / 07$ & 14,50 & $30 / 09 / 06$ & 0,52 & 13,98 & $2688,5 \%$ \\
\hline Rodobensimob & RDNI3 & $30 / 01 / 07$ & 19,50 & 30/09/06 & 2,10 & 17,40 & $828,6 \%$ \\
\hline Tecnisa & TCSA3 & $31 / 01 / 07$ & 13,00 & $30 / 09 / 06$ & 1,47 & 11,53 & $784,4 \%$ \\
\hline Iguatemi & IGTA3 & $06 / 02 / 07$ & 30,00 & 30/09/06 & 6,23 & 23,77 & $381,5 \%$ \\
\hline GVT Holding & GVTT3 & $15 / 02 / 07$ & 18,00 & $31 / 12 / 06$ & 8,83 & 9,17 & $103,9 \%$ \\
\hline Anhanguera & AEDU11 & 09/03/07 & nd & nd & nd & nd & nd \\
\hline JBS & JBSS3 & $28 / 03 / 07$ & 8,00 & $31 / 12 / 06$ & 0,26 & 7,74 & $2976,9 \%$ \\
\hline Even & EVEN3 & $30 / 03 / 07$ & 11,50 & $31 / 12 / 06$ & 1,35 & 10,15 & $751,9 \%$ \\
\hline Pine & PINE4 & $30 / 03 / 07$ & 19,00 & $31 / 12 / 06$ & 4,65 & 14,35 & $308,6 \%$ \\
\hline BR Malls Par & BRML3 & $04 / 04 / 07$ & 15,00 & $31 / 12 / 06$ & 5,17 & 9,83 & $190,1 \%$ \\
\hline Fer Heringer & FHER3 & $11 / 04 / 07$ & 17,00 & $31 / 12 / 06$ & 6,10 & 10,90 & $178,7 \%$ \\
\hline JHSF Part & JHSF3 & $11 / 04 / 07$ & 8,00 & $31 / 12 / 06$ & 0,30 & 7,70 & $2566,7 \%$ \\
\hline Metalfrio & FRIO3 & $12 / 04 / 07$ & 19,00 & $31 / 12 / 06$ & 1,88 & 17,12 & $910,6 \%$ \\
\hline Bematech & BEMA3 & $18 / 04 / 07$ & 15,00 & $31 / 12 / 06$ & 2,03 & 12,97 & $638,9 \%$ \\
\hline CR2 & CRDE3 & $20 / 04 / 07$ & 20,00 & $31 / 12 / 06$ & 2,05 & 17,95 & $875,6 \%$ \\
\hline Agra Incorp & AGIN3 & $25 / 04 / 07$ & 8,50 & $31 / 12 / 06$ & 1,39 & 7,11 & $511,5 \%$ \\
\hline Cremer & CREM3 & $27 / 04 / 07$ & 17,50 & $31 / 12 / 06$ & 5,25 & 12,25 & $233,3 \%$ \\
\hline Wilson Sons & WSON11 & $27 / 04 / 07$ & $\mathrm{nd}$ & nd & nd & nd & nd \\
\hline Sofisa & SFSA4 & $30 / 04 / 07$ & 12,00 & $31 / 12 / 06$ & 2,89 & 9,11 & $315,2 \%$ \\
\hline Tarpon & TARP11 & $30 / 05 / 07$ & nd & nd & nd & nd & nd \\
\hline Inpar S/A & INPR3 & 05/06/07 & 17,50 & $31 / 03 / 07$ & 0,65 & 16,85 & $2592,3 \%$ \\
\hline Parana & PRBC4 & $13 / 06 / 07$ & nd & nd & nd & nd & nd \\
\hline SLC Agricola & SLCE3 & $14 / 06 / 07$ & 14,00 & $31 / 03 / 07$ & 2,93 & 11,07 & $377,8 \%$ \\
\hline Log-In & LOGN3 & $20 / 06 / 07$ & 14,25 & $31 / 03 / 07$ & 1,59 & 12,66 & $796,2 \%$ \\
\hline Eztec & EZTC3 & $21 / 06 / 07$ & 11,00 & $31 / 03 / 07$ & 1,82 & 9,18 & $504,4 \%$ \\
\hline Cruzeiro Sul & CZRS4 & $25 / 06 / 07$ & 15,50 & $31 / 03 / 07$ & 2,46 & 13,04 & $530,1 \%$ \\
\hline Daycoval & DAYC4 & $28 / 06 / 07$ & 17,00 & $31 / 03 / 07$ & 2,97 & 14,03 & $472,4 \%$ \\
\hline Marfrig & MRFG3 & $28 / 06 / 07$ & 17,00 & $31 / 03 / 07$ & 3,71 & 13,29 & $358,2 \%$ \\
\hline Tegma & TGMA3 & $02 / 07 / 07$ & 26,00 & $31 / 03 / 07$ & 1,53 & 24,47 & $1599,3 \%$ \\
\hline Indusval & IDVL4 & $11 / 07 / 07$ & 17,50 & $31 / 03 / 07$ & 5,22 & 12,28 & $235,2 \%$ \\
\hline Redecard & RDCD3 & $12 / 07 / 07$ & 27,00 & $31 / 03 / 07$ & 0,10 & 26,90 & $26900,0 \%$ \\
\hline Invest Tur & IVTT3 & $13 / 07 / 07$ & $1.000,00$ & $31 / 08 / 07$ & & - & $0,0 \%$ \\
\hline
\end{tabular}




\begin{tabular}{|c|c|c|c|c|c|c|c|}
\hline & & & & & $1.000,00$ & & \\
\hline Banco Patagonia & BPAT11 & $19 / 07 / 07$ & nd & nd & nd & nd & nd \\
\hline Minerva & BEEF3 & $19 / 07 / 07$ & 18,50 & $31 / 03 / 07$ & 3,63 & 14,87 & $409,6 \%$ \\
\hline Guarani & ACGU3 & $20 / 07 / 07$ & 13,50 & $30 / 04 / 07$ & 5,06 & 8,44 & $166,8 \%$ \\
\hline Kroton & KROT11 & $20 / 07 / 07$ & nd & nd & nd & nd & nd \\
\hline MRV & MRVE3 & $20 / 07 / 07$ & 26,00 & $31 / 03 / 07$ & 2,90 & 23,10 & $796,6 \%$ \\
\hline Triunfo Part & TPIS3 & $20 / 07 / 07$ & 9,50 & $31 / 03 / 07$ & 1,97 & 7,53 & $382,2 \%$ \\
\hline Abc Brasil & ABCB4 & $24 / 07 / 07$ & 13,50 & $31 / 03 / 07$ & 5,03 & 8,47 & $168,4 \%$ \\
\hline Multiplan & MULT3 & $26 / 07 / 07$ & 25,00 & $31 / 03 / 07$ & 8,22 & 16,78 & $204,1 \%$ \\
\hline Providencia & PRVI3 & $26 / 07 / 07$ & 15,00 & $31 / 03 / 07$ & 0,08 & 14,92 & $18650,0 \%$ \\
\hline Springs & SGPS3 & $26 / 07 / 07$ & 19,00 & $31 / 03 / 07$ & 26,47 & $(7,47)$ & $-28,2 \%$ \\
\hline Estacio & ESTC11+ESTC3 & $27 / 07 / 07$ & nd & nd & nd & nd & nd \\
\hline Generalshop & GSHP3 & $27 / 07 / 07$ & 14,00 & $31 / 03 / 07$ & 3,76 & 10,24 & $272,3 \%$ \\
\hline Cosan Ltd & CZLT11 & $16 / 08 / 07$ & nd & nd & nd & nd & nd \\
\hline Satipel & SATI3 & $20 / 09 / 07$ & nd & nd & nd & nd & nd \\
\hline Sul America & SULA11 & $04 / 10 / 07$ & nd & nd & nd & nd & nd \\
\hline Bicbanco & BICB4 & $11 / 10 / 07$ & 12,75 & $30 / 06 / 07$ & 4,27 & 8,48 & $198,6 \%$ \\
\hline Tenda & TEND3 & $11 / 10 / 07$ & 9,00 & $30 / 06 / 07$ & 0,59 & 8,41 & $1425,4 \%$ \\
\hline Trisul & TRIS3 & $11 / 10 / 07$ & 11,00 & $30 / 06 / 07$ & 2,48 & 8,52 & $343,5 \%$ \\
\hline Seb & SEBB11 & $17 / 10 / 07$ & nd & nd & nd & nd & nd \\
\hline Marisa & MARI3 & $19 / 10 / 07$ & 10,00 & $30 / 06 / 07$ & 0,35 & 9,65 & $2757,1 \%$ \\
\hline Agrenco & AGEN11 & $24 / 10 / 07$ & nd & nd & nd & nd & nd \\
\hline Bovespa Holding & BOVH3 & $25 / 10 / 07$ & 23,00 & $30 / 06 / 07$ & 2,06 & 20,94 & $1016,5 \%$ \\
\hline Amil & AMIL3 & $26 / 10 / 07$ & 14,00 & $30 / 06 / 07$ & 0,56 & 13,44 & $2400,0 \%$ \\
\hline Br Brokers & BBRK3 & $26 / 10 / 07$ & 950,00 & $30 / 06 / 07$ & 0,12 & 949,88 & $785024,0 \%$ \\
\hline Helbor & HBOR3 & $26 / 10 / 07$ & 11,00 & $30 / 06 / 07$ & 3,47 & 7,53 & $217,0 \%$ \\
\hline Laep & MILK11 & $30 / 10 / 07$ & nd & nd & nd & nd & nd \\
\hline Panamericano & BPNM4 & $16 / 11 / 07$ & 10,00 & $30 / 09 / 07$ & 2,56 & 7,44 & $290,6 \%$ \\
\hline $\mathrm{BM} \& \mathrm{~F}$ & BMEF3 & 29/11/07 & 20,00 & $01 / 10 / 07$ & 1,42 & 18,58 & $1308,5 \%$ \\
\hline MPX Energia & MPXE3 & $13 / 12 / 07$ & $1.006,63$ & $30 / 09 / 07$ & 0,38 & $1.006,25$ & $264802,6 \%$ \\
\hline Tempo Part & TEMP3 & $17 / 12 / 07$ & 7,00 & $30 / 09 / 07$ & 0,59 & 6,41 & $1086,4 \%$ \\
\hline
\end{tabular}

Fonte: CVM - Prospectos de emissão

"nd" indica que não foi possível obter a informação, por diferentes razões (não obtenção de prospecto, ou não detalhamento suficiente da informação).

Tabela 16 - Diluição para novos sócios

\begin{tabular}{|c|c|c|c|c|c|c|c|c|}
\hline \multirow[t]{2}{*}{ Empresa } & \multirow[t]{2}{*}{ Código } & \multicolumn{2}{|c|}{ Emissão } & \multicolumn{2}{|c|}{$\begin{array}{c}\text { Valor Patrimonial } \\
\text { antes da Emissão - R\$ }\end{array}$} & \multirow[t]{2}{*}{$\begin{array}{l}\text { VP após } \\
\text { Oferta R\$ }\end{array}$} & \multicolumn{2}{|c|}{$\begin{array}{l}\text { Diluição para novos } \\
\text { sócios }\end{array}$} \\
\hline & & Data & Valor & \begin{tabular}{|l|} 
Data do \\
Balanço
\end{tabular} & VP & & Valor & $\%$ \\
\hline Natura & NATU3 & $25 / 05 / 04$ & 36,50 & $31 / 03 / 04$ & 4,22 & 4,22 & 32,28 & $88,4 \%$ \\
\hline Gol & GOLL4 & $23 / 06 / 04$ & 26,57 & $31 / 03 / 04$ & 1,89 & 4,36 & 22,21 & $83,6 \%$ \\
\hline CPFL Energia & CPFE3 & $28 / 09 / 04$ & 17,22 & $30 / 06 / 04$ & 8,24 & 9,03 & 8,19 & $47,6 \%$ \\
\hline \begin{tabular}{|l} 
Grendene \\
\end{tabular} & GRND3 & $28 / 10 / 04$ & nd & nd & $\mathrm{nd}$ & $\mathrm{nd}$ & nd & $\mathrm{nd}$ \\
\hline Dasa & DASA3 & $18 / 11 / 04$ & $\mathrm{nd}$ & nd & nd & nd & $\mathrm{nd}$ & $\mathrm{nd}$ \\
\hline Porto Seguro & PSSA3 & $19 / 11 / 04$ & 18,75 & $30 / 09 / 04$ & 11,86 & 12,42 & 6,89 & $36,7 \%$ \\
\hline Renar & RNAR3 & $25 / 02 / 05$ & 1,60 & $30 / 09 / 04$ & 0,98 & 1,10 & 0,50 & $31,3 \%$ \\
\hline B2W Varejo - ex-Submarino & SUBA3+BTOW3 & $29 / 03 / 05$ & 21,62 & $31 / 12 / 04$ & 0,98 & 10,26 & 11,36 & $52,5 \%$ \\
\hline Localiza & RENT3 & $20 / 05 / 05$ & 11,50 & $31 / 03 / 05$ & 4,66 & 4,66 & 6,84 & $59,5 \%$ \\
\hline Energias BR & ENBR3 & $12 / 07 / 05$ & 18,00 & $31 / 05 / 05$ & 22,72 & 19,90 & $(1,90)$ & $-10,6 \%$ \\
\hline OHL Brasil & OHLB3 & $14 / 07 / 05$ & 18,00 & $31 / 03 / 05$ & 6,47 & 7,63 & 10,37 & $57,6 \%$ \\
\hline Nossa Caixa & BNCA3 & $27 / 10 / 05$ & $\mathrm{nd}$ & nd & nd & nd & $\mathrm{nd}$ & $\mathrm{nd}$ \\
\hline Cosan & CSAN3 & $17 / 11 / 05$ & 48,00 & $31 / 07 / 05$ & 11,96 & 20,83 & 27,17 & $56,6 \%$ \\
\hline Uol & UOLL4 & $15 / 12 / 05$ & 18,00 & $30 / 09 / 05$ & 1,19 & 3,40 & 14,60 & $81,1 \%$ \\
\hline
\end{tabular}




\begin{tabular}{|c|c|c|c|c|c|c|c|c|}
\hline Copasa & CSMG3 & $07 / 02 / 06$ & 23,50 & 30/09/05 & 26,78 & 25,87 & $(2,37)$ & $-10,1 \%$ \\
\hline Vivax & VVAX11 & 07/02/06 & $\mathrm{nd}$ & nd & nd & nd & nd & $\mathrm{nd}$ \\
\hline Gafisa & GFSA3 & 16/02/06 & 26,00 & $31 / 12 / 05$ & 7,41 & 10,12 & 15,88 & $61,1 \%$ \\
\hline Company & CPNY3 & $01 / 03 / 06$ & 16,60 & $31 / 12 / 05$ & 2,12 & 6,44 & 9,56 & $57,6 \%$ \\
\hline Totvs & TOTS3 & $08 / 03 / 06$ & 32,00 & $31 / 12 / 05$ & 4,28 & 12,70 & 19,30 & $60,3 \%$ \\
\hline Equatorial & EQTL11+EQTL3 & $31 / 03 / 06$ & $\mathrm{nd}$ & \begin{tabular}{|l|}
$\mathrm{nd}$ \\
\end{tabular} & $\mathrm{nd}$ & $\mathrm{nd}$ & $\mathrm{nd}$ & $\mathrm{nd}$ \\
\hline Abnote & ABNB3 & $26 / 04 / 06$ & $\mathrm{nd}$ & $\mathrm{nd}$ & nd & nd & nd & $\mathrm{nd}$ \\
\hline BrasilAgro & AGRO3 & 28/04/06 & nd & $\mathrm{nd}$ & $\mathrm{nd}$ & nd & nd & \begin{tabular}{c|c}
$\mathrm{nd}$ \\
\end{tabular} \\
\hline CSU CardSystem & CARD3 & 28/04/06 & nd & $\mathrm{nd}$ & nd & nd & nd & $\mathrm{nd}$ \\
\hline \begin{tabular}{|l|} 
Lupatech \\
\end{tabular} & LUPA3 & 12/05/06 & 22,00 & $31 / 03 / 06$ & 2,13 & 5,04 & 16,96 & $77,1 \%$ \\
\hline GP Invest & GPIV11 & $31 / 05 / 06$ & $\mathrm{nd}$ & $\mathrm{nd}$ & $\mathrm{nd}$ & $\mathrm{nd}$ & $\mathrm{nd}$ & $\mathrm{nd}$ \\
\hline Datasul & DSUL3 & 01/06/06 & 18,00 & $31 / 03 / 06$ & 1,79 & 6,48 & 11,52 & $64,0 \%$ \\
\hline MMX Miner & MMXM3 & $21 / 07 / 06$ & 815,00 & $31 / 03 / 06$ & 5,22 & 258,20 & 556,80 & $68,3 \%$ \\
\hline Abyara & ABYA3 & $26 / 07 / 06$ & 25,00 & $31 / 05 / 06$ & 0,32 & 8,99 & 16,01 & $64,0 \%$ \\
\hline Medial Saude & MEDI3 & 21/09/06 & 21,50 & $30 / 06 / 06$ & 0,91 & 6,24 & 15,26 & $71,0 \%$ \\
\hline Klabinsegall & KSSA3 & 06/10/06 & 15,00 & 30/06/06 & 1,87 & 6,72 & 8,28 & $55,2 \%$ \\
\hline Santos BRP & STBR11+STBP11 & $12 / 10 / 06$ & $\mathrm{nd}$ & $\mathrm{nd}$ & $\mathrm{nd}$ & $\mathrm{nd}$ & $\mathrm{nd}$ & $\mathrm{nd}$ \\
\hline M. Diasbranco & MDIA3 & 17/10/06 & 21,00 & 30/06/06 & 6,00 & 6,00 & 15,00 & $71,4 \%$ \\
\hline Brascan Res & BISA3 & 20/10/06 & 16,00 & 30/06/06 & 1,17 & 5,17 & 10,83 & $67,7 \%$ \\
\hline Profarma & PFRM3 & $25 / 10 / 06$ & 22,50 & 30/06/06 & 3,95 & 9,85 & 12,65 & $56,2 \%$ \\
\hline Terna Part & TRNA11 & $26 / 10 / 06$ & $\mathrm{nd}$ & \begin{tabular}{|r|}
$\mathrm{nd}$ \\
\end{tabular} & $\mathrm{nd}$ & $\mathrm{nd}$ & $\mathrm{nd}$ & $\mathrm{nd}$ \\
\hline Ecodiesel & ECOD3 & $21 / 11 / 06$ & nd & $\mathrm{nd}$ & nd & nd & nd & nd \\
\hline Odontoprev & ODPV3 & $30 / 11 / 06$ & 28,00 & 30/09/06 & 1,20 & 7,05 & 20,95 & $74,8 \%$ \\
\hline Positivo Inf & POSI3 & $08 / 12 / 06$ & 23,50 & 30/09/06 & 2,38 & 3,01 & 20,49 & $87,2 \%$ \\
\hline Lopes Brasil & LPSB3 & $15 / 12 / 06$ & 20,00 & 30/09/06 & 0,09 & 0,09 & 19,91 & $99,6 \%$ \\
\hline Dufrybras & DUFB11 & 19/12/06 & $\mathrm{nd}$ & nd & $\mathrm{nd}$ & $\mathrm{nd}$ & nd & $\mathrm{nd}$ \\
\hline PDG Realt & PDGR3 & 25/01/07 & 14,00 & 30/09/06 & 2,98 & 5,84 & 8,16 & $58,3 \%$ \\
\hline CC Des Imob & CCIM3 & $30 / 01 / 07$ & 14,50 & 30/09/06 & 0,52 & 4,37 & 10,13 & $69,9 \%$ \\
\hline Rodobensimob & RDNI3 & $30 / 01 / 07$ & 19,50 & $30 / 09 / 06$ & 2,10 & 9,30 & 10,20 & $52,3 \%$ \\
\hline Tecnisa & TCSA3 & $31 / 01 / 07$ & 13,00 & 30/09/06 & 1,47 & 4,85 & 8,15 & $62,7 \%$ \\
\hline Iguatemi & IGTA3 & $\begin{array}{l}06 / 02 / 07 \\
\end{array}$ & 30,00 & 30/09/06 & 6,23 & 12,30 & 17,70 & $59,0 \%$ \\
\hline GVT Holding & GVTT3 & $15 / 02 / 07$ & 18,00 & $31 / 12 / 06$ & 8,83 & 12,36 & 5,64 & $31,3 \%$ \\
\hline Anhanguera & AEDU11 & 09/03/07 & $\mathrm{nd}$ & nd & nd & $\mathrm{nd}$ & $\mathrm{nd}$ & $\mathrm{nd}$ \\
\hline JBS & JBSS3 & 28/03/07 & 8,00 & $31 / 12 / 06$ & 0,26 & 1,63 & 6,37 & $79,6 \%$ \\
\hline Even & EVEN3 & $30 / 03 / 07$ & 11,50 & 31/12/06 & 1,35 & 3,99 & 7,51 & $65,3 \%$ \\
\hline Pine & PINE4 & $30 / 03 / 07$ & 19,00 & $31 / 12 / 06$ & 4,65 & 7,46 & 11,54 & $60,7 \%$ \\
\hline BR Malls Par & BRML3 & $04 / 04 / 07$ & 15,00 & $31 / 12 / 06$ & 5,17 & 7,82 & 7,18 & 47,9\% \\
\hline Fer Heringer & FHER3 & $11 / 04 / 07$ & 17,00 & $31 / 12 / 06$ & 6,10 & 8,32 & 8,68 & $51,1 \%$ \\
\hline JHSF Part & JHSF3 & $11 / 04 / 07$ & 8,00 & $31 / 12 / 06$ & 0,30 & 1,22 & 6,78 & $84,8 \%$ \\
\hline Metalfrio & FRIO3 & $12 / 04 / 07$ & 19,00 & $31 / 12 / 06$ & 1,88 & 7,37 & 11,63 & $61,2 \%$ \\
\hline Bematech & BEMA3 & 18/04/07 & 15,00 & $31 / 12 / 06$ & 2,03 & 5,50 & 9,50 & $63,3 \%$ \\
\hline CR2 & CRDE3 & $20 / 04 / 07$ & 20,00 & $31 / 12 / 06$ & 2,05 & 8,03 & 11,97 & $59,9 \%$ \\
\hline Agra Incorp & AGIN3 & $25 / 04 / 07$ & 8,50 & $31 / 12 / 06$ & 1,39 & 5,08 & 3,42 & $40,2 \%$ \\
\hline Cremer & CREM3 & $27 / 04 / 07$ & 17,50 & $31 / 12 / 06$ & 5,25 & 9,30 & 8,20 & $46,9 \%$ \\
\hline Wilson Sons & WSON11 & 27/04/07 & $\mathrm{nd}$ & $\mathrm{nd}$ & $\mathrm{nd}$ & $\mathrm{nd}$ & $\mathrm{nd}$ & $\mathrm{nd}$ \\
\hline Sofisa & SFSA4 & $30 / 04 / 07$ & 12,00 & $31 / 12 / 06$ & 2,89 & 5,02 & 6,98 & $58,2 \%$ \\
\hline Tarpon & TARP11 & $30 / 05 / 07$ & $\mathrm{nd}$ & nd & $\mathrm{nd}$ & $\mathrm{nd}$ & $\mathrm{nd}$ & nd \\
\hline Inpar S/A & INPR3 & $05 / 06 / 07$ & 17,50 & $31 / 03 / 07$ & 0,65 & 7,02 & 10,48 & $59,9 \%$ \\
\hline Parana & PRBC4 & 13/06/07 & $\mathrm{nd}$ & $\mathrm{nd}$ & $\mathrm{nd}$ & $\mathrm{nd}$ & $\mathrm{nd}$ & $\mathrm{nd}$ \\
\hline SLC Agricola & SLCE3 & $14 / 06 / 07$ & 14,00 & 31/03/07 & 2,93 & 5,46 & 8,54 & $61,0 \%$ \\
\hline Log-In & LOGN3 & 20/06/07 & 14,25 & $31 / 03 / 07$ & 1,59 & 5,35 & 8,90 & $62,5 \%$ \\
\hline Eztec & EZTC3 & $21 / 06 / 07$ & 11,00 & $31 / 03 / 07$ & 1,82 & 4,40 & 6,60 & $60,0 \%$ \\
\hline Cruzeiro Sul & CZRS4 & $25 / 06 / 07$ & 15,50 & $31 / 03 / 07$ & 2,46 & 4,82 & 10,68 & $68,9 \%$ \\
\hline Daycoval & DAYC4 & $28 / 06 / 07$ & 17,00 & $31 / 03 / 07$ & 2,97 & 6,28 & 10,72 & $63,1 \%$ \\
\hline Marfrig & MRFG3 & 28/06/07 & 17,00 & $31 / 03 / 07$ & 3,71 & 5,91 & 11,09 & $65,2 \%$ \\
\hline Tegma & TGMA3 & 02/07/07 & 26,00 & $31 / 03 / 07$ & 1,53 & 4,89 & 21,11 & $81,2 \%$ \\
\hline Indusval & IDVL4 & $11 / 07 / 07$ & 17,50 & $31 / 03 / 07$ & 5,22 & 8,61 & 8,89 & $50,8 \%$ \\
\hline Redecard & RDCD3 & $12 / 07 / 07$ & 27,00 & $31 / 03 / 07$ & 0,10 & 0,70 & 26,30 & $97,4 \%$ \\
\hline Invest Tur & IVTT3 & $13 / 07 / 07$ & $1.000,00$ & $31 / 08 / 07$ & $1.000,00$ & 932,48 & 67,52 & $6,8 \%$ \\
\hline Banco Patagonia & BPAT11 & 19/07/07 & $\mathrm{nd}$ & nd & $\mathrm{nd}$ & $\mathrm{nd}$ & nd & $\mathrm{nd}$ \\
\hline Minerva & BEEF3 & 19/07/07 & 18,50 & $31 / 03 / 07$ & 3,63 & 7,11 & 11,39 & $61,6 \%$ \\
\hline Guarani & ACGU3 & $20 / 07 / 07$ & 13,50 & $30 / 04 / 07$ & 5,06 & 7,39 & 6,11 & $45,3 \%$ \\
\hline Kroton & KROT11 & 20/07/07 & $\mathrm{nd}$ & $\mathrm{nd}$ & $\mathrm{nd}$ & $\mathrm{nd}$ & $\mathrm{nd}$ & $\mathrm{nd}$ \\
\hline MRV & MRVE3 & 20/07/07 & 26,00 & $31 / 03 / 07$ & 2,90 & 9,27 & 16,73 & $64,3 \%$ \\
\hline Triunfo Part & TPIS3 & $20 / 07 / 07$ & 9,50 & $31 / 03 / 07$ & 1,97 & 3,71 & 5,79 & $60,9 \%$ \\
\hline Abc Brasil & ABCB4 & $24 / 07 / 07$ & 13,50 & $31 / 03 / 07$ & 5,03 & 7,61 & 5,89 & $43,6 \%$ \\
\hline Multiplan & MULT3 & $26 / 07 / 07$ & 25,00 & $31 / 03 / 07$ & 8,22 & 11,20 & 13,80 & $55,2 \%$ \\
\hline Providencia & PRVI3 & $26 / 07 / 07$ & 15,00 & $31 / 03 / 07$ & 0,08 & 5,33 & 9,67 & $64,5 \%$ \\
\hline Springs & SGPS3 & $26 / 07 / 07$ & 19,00 & $31 / 03 / 07$ & 26,47 & 24,49 & $(5,49)$ & $-28,9 \%$ \\
\hline Estacio & ESTC11+ESTC3 & $27 / 07 / 07$ & $\mathrm{nd}$ & $\mathrm{nd}$ & $\mathrm{nd}$ & nd & $\mathrm{nd}$ & $\mathrm{nd}$ \\
\hline Generalshop & GSHP3 & $27 / 07 / 07$ & 14,00 & $31 / 03 / 07$ & 3,76 & 7,45 & 6,55 & $46,8 \%$ \\
\hline
\end{tabular}




\begin{tabular}{|c|c|c|c|c|c|c|c|c|}
\hline Cosan Ltd & CZLT11 & $16 / 08 / 07$ & nd & nd & nd & nd & nd & nd \\
\hline Satipel & SATI3 & $20 / 09 / 07$ & nd & nd & nd & nd & nd & nd \\
\hline Sul America & SULA11 & $04 / 10 / 07$ & nd & nd & nd & nd & nd & nd \\
\hline Bicbanco & BICB4 & $11 / 10 / 07$ & 12,75 & $30 / 06 / 07$ & \begin{tabular}{l|l}
4,27 \\
\end{tabular} & 5,53 & 7,22 & $56,6 \%$ \\
\hline Tenda & TEND3 & $11 / 10 / 07$ & 9,00 & $30 / 06 / 07$ & 0,59 & 4,12 & 4,88 & $54,2 \%$ \\
\hline Trisul & TRIS3 & $11 / 10 / 07$ & 11,00 & $30 / 06 / 07$ & 2,48 & 5,42 & 5,58 & $50,7 \%$ \\
\hline Seb & SEBB11 & $17 / 10 / 07$ & nd & \begin{tabular}{r|}
$\mathrm{nd}$ \\
\end{tabular} & $\mathrm{nd}$ & nd & nd & nd \\
\hline Marisa & MARI3 & $19 / 10 / 07$ & 10,00 & $30 / 06 / 07$ & 0,35 & 2,64 & 7,36 & $73,6 \%$ \\
\hline \begin{tabular}{|l|} 
Agrenco \\
\end{tabular} & AGEN11 & $24 / 10 / 07$ & nd & $\begin{aligned} \mathrm{nd} \\
\end{aligned}$ & $\mathrm{nd}$ & nd & nd & nd \\
\hline Bovespa Holding & BOVH3 & $25 / 10 / 07$ & 23,00 & $30 / 06 / 07$ & 2,06 & 2,06 & 20,94 & $91,0 \%$ \\
\hline Amil & AMIL3 & $26 / 10 / 07$ & 14,00 & $30 / 06 / 07$ & 0,56 & 2,70 & 11,30 & $80,7 \%$ \\
\hline Br Brokers & BBRK3 & $26 / 10 / 07$ & 950,00 & $30 / 06 / 07$ & 0,12 & 174,18 & 775,82 & $81,7 \%$ \\
\hline Helbor & HBOR3 & $26 / 10 / 07$ & 11,00 & $30 / 06 / 07$ & 3,47 & 6,36 & 4,64 & $42,2 \%$ \\
\hline Laep & MILK11 & $30 / 10 / 07$ & $\mathrm{nd}$ & $\begin{aligned} \mathrm{nd} \\
\end{aligned}$ & $\mathrm{nd}$ & nd & nd & $\mathrm{nd}$ \\
\hline Panamericano & BPNM4 & $16 / 11 / 07$ & 10,00 & $30 / 09 / 07$ & 2,56 & 4,52 & 5,48 & $54,8 \%$ \\
\hline BM\&F & BMEF3 & $29 / 11 / 07$ & 20,00 & 01/10/07 & 1,42 & 1,42 & 18,58 & $92,9 \%$ \\
\hline MPX Energia & MPXE3 & $13 / 12 / 07$ & $1.006,63$ & $30 / 09 / 07$ & 0,38 & 272,48 & 734,15 & $72,9 \%$ \\
\hline Tempo Part & TEMP3 & $17 / 12 / 07$ & 7,00 & $30 / 09 / 07$ & 0,59 & 2,58 & 4,42 & $63,1 \%$ \\
\hline
\end{tabular}

Fonte: CVM - Prospectos de emissão

"nd" indica que não foi possível obter a informação, por diferentes razões (não obtenção de prospecto, ou não detalhamento suficiente da informação).

\begin{tabular}{|l|r|r|r|r|r|r|}
\cline { 2 - 7 } \multicolumn{1}{c|}{} & \multicolumn{7}{c|}{} & \multicolumn{1}{c|}{} \\
\hline Média & 65,92 & & 16,85 & 27,91 & 38,01 & 0,59 \\
\hline Maior & $1.006,63$ & & $1.000,00$ & 932,48 & 775,82 & 1,00 \\
\hline Menor & 1,60 & & 0,08 & 0,09 & $(5,49)$ & $(0,29)$ \\
\hline Desvio-padrão & 206,15 & & 112,89 & 113,16 & 132,71 & 0,22 \\
\hline Nr. de observações & 77 & & 77 & 77 & 77 & 77 \\
\hline
\end{tabular}




\title{
7 CONCLUSÕES FINAIS E CONSIDERAÇÕES
}

Maria da Conceição Tavares, quando da análise do período econômico compreendido entre os anos de 1966 e 1970, teceu as seguintes considerações:

\begin{abstract}
No período decorrido entre 1966 e a atualidade (final de 1970) foram tomando forma algumas das características pertencentes ao novo estilo de desenvolvimento capitalista. Seria difícil pensar em dar uma visão integrada do novo esquema, seja por tratar-se de um processo inacabado, seja pela escassez de pesquisas de apoio, ou ainda, por uma certa dificuldade de afastar-se dos padrões tradicionais de análise.” (p. 173). "Por esses motivos, limitar-nos-emos à analise de certos traços que caracterizam os processos de expansão, incorporação e difusão do progresso técnico e da reconcentração na economia [...].
\end{abstract}

Essa realidade, e principalmente a dificuldade apontada pela citada autora, também se aplica nas conclusões que possam ser feitas em relação ao ciclo de aberturas de capital do período 2004/2007 aqui estudado. O fato desse processo ainda estar ocorrendo, em conjunto com uma crise internacional de elevada magnitude, obriga o pesquisador a ser bastante criterioso em suas conclusões. O ritmo das mudanças econômicas é elevado, o que pode fazer com que afirmações conclusivas sejam rapidamente questionadas.

Em função dessa realidade, optou-se, no presente estudo, por uma abordagem exploratóriodescritiva, considerada a mais adequada dentro desse contexto.

Retomando o problema de pesquisa inicialmente traçado, a questão que se apresentava era verificar se o movimento de aberturas de capital via emissão de ações, iniciado em 2007, vinha trazendo benefícios reais à economia brasileira como um todo. Uma vez que esse processo, como toda relação econômica, envolve vendedores e compradores, a questão seria verificar se esses benefícios alcançavam os dois lados envolvidos, ou seja, as empresas e investidores que estavam vendendo essas ações, bem como os investidores compradores, pessoas físicas ou jurídicas, nacionais ou estrangeiras, que tenham investido nesses papéis, e consequentemente nessas empresas.

Na economia em geral, e no mundo das finanças em particular, os benefícios são determinados pelo retorno gerado. Em decorrência dessa realidade, os "benefícios reais à economia brasileira” foram analisados em função dos retornos das ações emitidas nesse período. 
No entanto, antes de realizar tal tarefa, este trabalho passou por etapas anteriores, a fim de cumprir os objetivos secundários traçados inicialmente.

A pesquisa bibliográfica foi subdividida em quatro tópicos. Inicialmente, foi discutida a importância do sistema financeiro, e particularmente do mercado de capitais, como fonte de financiamento de longo prazo às empresas. Essa importância justifica a constante busca pelas autoridades governamentais pela fixação de condições propícias para o crescimento e solidificação do mercado de capitais como um todo, principalmente do mercado de ações. Um mercado dinâmico permitiria que a economia não vivesse apenas ciclos esporádicos de abertura de capital pela emissão de ações, mas sim experimentasse uma constante disponibilidade de capitais em busca de novas emissões. Isso possibilitaria que as empresas, no momento de necessidade de capitais de longo prazo, tivessem diferentes alternativas de captação, permitindo uma alocação de recursos mais eficiente para a sociedade.

Posteriormente, repassamos o processo de abertura de capital, buscando descrever e conhecer, em linhas gerais, todas as diferentes etapas pelas quais a empresa precisa passar para negociar suas ações em bolsa de valores. Como vimos, uma empresa que queira contar com essa alternativa de financiamento precisa cumprir diferentes exigências, que visam proteger os investidores e o mercado em geral.

Em seguida, discutiu-se a questão do valor e o processo de determinação do mesmo, sob diferentes enfoques. Além de existirem diferentes metodologias para seu cálculo, a questão ainda é controversa, tendo em vista as variáveis consideradas em cada metodologia. Essas dificuldades são ainda mais marcantes para empresas que estão abrindo seu capital, onde o conjunto de informações disponíveis ainda é pequeno, tornando mais complexa a determinação do valor dessa nova ação.

Terminando essa etapa, foram repassados alguns estudos sobre IPOs, no Brasil e no exterior, particularmente aqueles estudos que serviram de base para a abordagem aqui construída. Esses estudos mostraram que existe uma ampla diferenciação nas abordagens sobre o tema. Um tema que se destaca nesses estudos é a questão do underpricing no primeiro dia, gerando diferentes discussões. Vários trabalhos indicam que a valorização expressiva verificada no primeiro dia de negociação das novas ações seriam indícios de sub-precificação, fazendo com 
que as empresas, e/ou os sócios vendedores (dependendo se a emissão é primária ou secundária), percam dinheiro. Esse fato é identificado pela expressão “dinheiro sobre a mesa” (money in the table)”. A comparação aqui realizada, comentada mais adiante, levanta questionamentos a esse fato, pois ao mesmo tempo em que deixam de receber o equivalente à valorização verificada no primeiro dia, a empresa, e/ou os sócios vendedores conseguem obter uma valorização bastante expressiva em seus papéis, considerando o valor patrimonial prévio de suas ações. Ao trocar a situação de baixíssima liquidez antes da emissão pela situação de liquidez após a oferta, conseguem valorizações expressivas em seus ativos, as quais dificilmente seriam possíveis se optassem por uma negociação privada desses ativos. Considerando-se ainda que a tomada de dívida, com base em sua situação patrimonial prévia, teria várias limitantes, principalmente no volume de recursos que poderiam ser alavancados, essa troca de uma situação de não liquidez para a posição de liquidez gera expressivos ganhos, muitas vezes superiores à valorização verificada no primeiro dia de negociação da ação, da qual abrem mão.

Essa realidade não é contemplada nos estudos sobre underpricing, razão pela qual acreditamos que o presente estudo, ao levantar e apontar tal realidade, poderá contribuir para futuros trabalhos sobre o tema.

A etapa seguinte consistiu na comparação do atual ciclo de emissões (2004/2007) com os ciclos anteriores de emissões verificados no Brasil, especificamente o ciclo ocorrido no período 1968/71 e o ciclo verificado nos primeiros anos da república no Brasil, no período de 1889/91, num período de crise econômica denominada Encilhamento. Apesar de ocorrerem em períodos históricos e econômicos completamente distintos do atual, verificamos que todos apresentam as mesmas características gerais, sendo as principais o (i) forte crescimento do volume de negócios no mercado de ações, a (ii) expressiva valorização do mercado de ações em tais períodos, o (iii) forte crescimento no volume e número de empresas abrindo seu capital, o (iv) crescente número de investidores participando do mercado de ações, (v) elevada especulação financeira, com certa dose de euforia e, posteriormente, (vi) quedas abruptas nos índices de ação, que resulta em fortes perdas aos investidores e forte diminuição no mercado de emissões primárias, até a ocorrência de um novo ciclo. 
Assim, no capítulo 4, efetuamos um breve estudo sobre os ciclos do período 1968/71 e do período do Encilhamento, traçando suas características gerais e suas conseqüências para o mercado de capitais brasileiro.

No capitulo seguinte, efetuamos uma análise qualitativa do ciclo 2004/2007, identificando seus antecedentes e as condições que permitiram sua ocorrência: as condições macroeconômicas do país, a conjuntura internacional de crescimento mundial, a elevada liquidez internacional, as mudanças nos marcos legais e no ambiente de negócios do país, as práticas de governança corporativa e os diferentes níveis de mercado criados pela Bovespa, a atuação dos intermediários (bancos de investimento, corretoras e escritórios de advocacia) e de novos agentes (fundos de Private Equity e Venture Capital), dentre outros fatores.

Como vimos, o forte volume verificado no ano de 2007 não vem se repetindo neste ano de 2008, quando foram verificadas apenas quatro emissões de ações, com forte redução dos volumes transacionados. Tal realidade, pela ótica do presente estudo, decorreu de duas realidades, uma intrínseca ao mercado de ações (endógena) e outro externa (exógena). A primeira decorreria de alguns problemas verificados no mercado de IPOs no Brasil, particularmente a forte desvalorização sofrida por algumas ações, em decorrência de problemas societários em alguns casos e, principalmente, por uma hipótese que levantamos no presente estudo: uma precificação (valuation) equivocada efetuada pelo mercado no momento da emissão, que resultaria nas fortes desvalorizações posteriores. Como demonstrado, mesmo até a data de 20.05.08, pico histórico do Ibovespa (73.516 pontos), grande parte das novas ações vinham apresentando retornos inferiores ao índice do mercado, além de apresentarem fortes desvalorizações até tal data.

Por fim, no capítulo 6, discutimos essas novas emissões com base nos retornos observados, utilizando os conceitos de underpricing no curto prazo e overpricing no longo prazo, previstos na literatura e estudos sobre IPOs. Essa realidade também se observa no mercado brasileiro, sendo que o underpricing, no nosso caso, atinge níveis inferiores aos verificados nos mercados externos. Em relação ao overpricing, verificamos que, na visão dos acionistas compradores dessas ações, o retorno, no conjunto, vem sendo negativo, redundando na perda de riqueza para os mesmos. Na última etapa, analisamos os valores patrimoniais prévios às emissões, comparando-os com os preços de emissão, verificando uma forte geração de riqueza para os acionistas vendedores e elevada diluição societária para os novos acionistas. 


\section{REFERÊNCIAS}

ASSAF NETO, Alexandre. Mercado Financeiro. $3^{\text {a }}$ ed.. São Paulo: Atlas, 2000.

BRUNI, Adriano Leal. As Decisões de Investimentos. São Paulo: Atlas, 2003.

CASTRO, Antonio Barros de; LESSA, Carlos Francisco. Introdução à Economia: Uma Abordagem Estruturalista. 26 Ed.. Rio de Janeiro: Forense-Universitária, 1984.

COMISSÃO DE VALORES MOBILIÁRIOS. Instrução 361 de 05.03.2002. . Instrução 400 de 29.12.2003. . Instrução 436 de 05.07.2006.

COPELAND, T.; KOLLER, T.; MURRIN, J. Valuation - Measuring and Managing the Value of Companies. Second Edition. McKinsey \& Company, Inc., 1995.

DAMODARAN, Aswath. Avaliação de Investimentos: Ferramentas e Técnicas para a Determinação do Valo de Qualquer Ativo. Rio de Janeiro: Qualitymark Ed., 1997.

DAMODARAN, Aswath. A Face Oculta da Avaliação. São Paulo: Makron Books, 2002.

FACHIN, Odília. Fundamentos de Metodologia. 4. ed. - São Paulo: Saraiva, 2005.

GIL, Antonio Carlos. Técnicas de pesquisa em economia e elaboração de monografias. $3^{\text {a }}$ edição. São Paulo: Atlas, 2000. . Como elaborar projetos de pesquisa. 4a edição. São Paulo: Atlas, 2002.

GREMAUD, A. P.; SAES, F.A.M.; TONETO JUNIOR, R. Formação Econômica do Brasil. São Paulo: Atlas, 1997.

IUDÍCIBUS, S. Teoria da Contabilidade. $7^{\mathrm{a}}$ ed. São Paulo: Atlas, 2004. ; LOPES, Alexsandro B. Teoria Avançada da Contabilidade. São Paulo: Atlas, 2004. 
KERLINGER, Fred N. Metodologia da Pesquisa em Ciências Sociais. São Paulo: EPU, 1980.

LAGO, Luiz Aranha Corrêa do. A Retomada do Crescimento e as Distorções do "Milagre”: 1967-1973”. In: Abreu, Marcelo de Paiva (org.). “A Ordem do Progresso: Cem Anos de Política Econômica Republicana, 1889-1989”. Rio de Janeiro: Elsevier, 1990.

LAKATOS, Eva Maria; MARCONI, Marina de Andrade. Metodologia científica. 4. ed. - 3. reimpr. - São Paulo: Atlas, 2006.

LEAL, Ricardo P. Câmara. Por que há Retornos Anormais nas Aberturas de Capital? Revista de Administração da USP, v. 25, no 4, p.107-112, out./dez. 1991. In: LEAL, Ricardo P. C. (Org.). Finanças Corporativas. São Paulo: Atlas, 2001.

Três Desafios para as Aberturas de Capital. In: LEAL, Ricardo P. C. (Org.). Finanças Corporativas. São Paulo: Atlas, 2001.

LOPES, Alexsandro B. A informação contábil e o mercado de capitais. São Paulo: Pioneira Thomson Learning, 2002.

; MARTINS, Eliseu. Teoria da Contabilidade - Uma Nova Abordagem. São Paulo: Atlas, 2005.

MARCONI, Marina de A.; LAKATOS, Eva M. Técnicas de Pesquisa. 4a edição. São Paulo: Atlas, 1999.

MARTINS, Eliseu. Avaliação de Empresas: da Mensuração Contábil à Econômica - artigo obtido na internet.

Martins, Gilberto de Andrade. Guia para Elaboração de Monografias e trabalhos de conclusão de curso. São Paulo: Atrás, 2000.

PEREIRA, Luiz C. Bresser. Economia Brasileira: Uma Introdução Crítica; $3^{a}$ edição. São Paulo: Ed. 34, 1998.

PÓVOA, Alexandre. Valuation - Como Precificar Ações. São Paulo: Globo, 2004. 
PRADO JÚNIOR, Caio. História Econômica do Brasil. 13ª edição. São Paulo: Editora Brasiliense, 1970.

RODRIGUES, Hélio. Um Estudo do Sistema Financeiro Nacional: 1964-1978. Araraquara: FCL / Laboratório Editorial / UNESP; São Paulo: Cultura Acadêmica Editora, 2002.

TAVARES, Maria da Conceição. Natureza e Contradição do Desenvolvimento Financeiro Recente. In Da Substituição de Importações ao Capitalismo Financeiro - Ensaios sobre a Economia Brasileira. $3^{\text {a }}$ edição. Rio de janeiro: Zahar Editores, 1974. 